
NUCLEAR PARA REATORES DE PESQUISA

MIGUEL LUIZ MIOTTO NEGRO

Tese apresentada como parte dos requisitos para obtenção do Grau de Doutor em Ciências na Área de Tecnologia Nuclear - Reatores

Orientador:

Prof. Dr. Delvonei Alves de Andrade

Coorientador:

Prof. Dr. Michelangelo Durazzo 
INSTITUTO DE PESQUISAS ENERGÉTICAS E NUCLEARES

Autarquia associada à Universidade de São Paulo

\section{DESENVOLVIMENTO DE UM MODELO PARA DIMENSIONAMENTO DA CAPACIDADE PRODUTIVA DE FÁBRICAS DE COMBUSTÍVEL NUCLEAR PARA REATORES DE PESQUISA}

MIGUEL LUIZ MIOTTO NEGRO

Tese apresentada como parte dos requisitos para obtenção do Grau de Doutor em Ciências na Área de Tecnologia Nuclear - Reatores

Orientador:

Prof. Dr. Delvonei Alves de Andrade

Coorientador:

Prof. Dr. Michelangelo Durazzo

Versão Corrigida

Versão Original disponível no IPEN

São Paulo 


\section{DEDICATÓRIA}

Ao meu companheiro Berti, com amor, admiração e gratidão por sua compreensão, paciência, apoio e presença ao longo da elaboração deste trabalho.

A meus pais, com amor, por sempre estarem ao meu lado, desejarem o meu bem e apoiarem o meu progresso.

A Débora Miotto Negro e Doraci Coli, in memoriam. 


\section{AGRADECIMENTOS}

Ao Dr. Delvonei Alves de Andrade pelo acolhimento, orientação e apoio.

Ao Dr. Michelangelo Durazzo pelas informações práticas e objetivas.

Ao. Dr. Marcelo Linardi pela motivação em cursar a pós-graduação do Instituto de Pesquisas Energéticas e Nucleares.

À Dra. Ana Cecília de Souza Lima que nos anos de convivência muito me ensinou, contribuindo para meu crescimento científico e intelectual.

Ao Dr. Marco Aurélio de Mesquita que foi a fonte dos conhecimentos da área de produção, essenciais para este trabalho.

Aos técnicos da fábrica de combustível nuclear do Instituto de Pesquisas Energéticas e Nucleares, por compartilharem seus conhecimentos e experiência.

Ao Instituto de Pesquisas Energéticas e Nucleares, por colocar à disposição sua fábrica de combustível nuclear e por possibilitar e incentivar o crescimento profissional de seus servidores.

Ao Conselho Nacional de Desenvolvimento Científico e Tecnológico (CNPq), pelo auxílio financeiro para o desenvolvimento de parte deste trabalho por meio do processo número 310274/2012-5. 


\section{Resumo}

A demanda por combustível nuclear para reatores de pesquisa está aumentando em nível mundial, enquanto várias de suas fábricas têm pequeno volume de produção. Este trabalho estabeleceu um modelo conceitual com duas estratégias para o aumento da capacidade produtiva dessas fábricas. Foram abordadas as fábricas que produzem elementos combustíveis tipo placa carregados com LEU U $\mathrm{U}_{3} \mathrm{Si}_{2}-\mathrm{Al}$, tipicamente usados em reatores nucleares de pesquisa. A primeira estratégia baseia-se na literatura da área de administração da produção e é uma prática frequente nas fábricas em geral. A segunda estratégia aproveita a possibilidade de desmembrar setores produtivos, comum em instalações de produção de combustível nuclear. Ambas as estratégias geraram diferentes cenários de produção, os quais devem ser seguros em relação à criticalidade. Foram coletados dados de uma fábrica real de combustível nuclear para reatores de pesquisa. As duas estratégias foram aplicadas a esses dados com a finalidade de testar o modelo proposto, o que configurou um estudo de caso. A aplicação das estratégias aos dados coletados deu-se por meio de simulação de eventos discretos em computador. Foram criados diversos modelos de simulação para abranger todos os cenários gerados, de forma que o teste indicou um aumento da capacidade produtiva de até $207 \%$ sem necessidade de aquisição de novos equipamentos. Os resultados comprovam que o modelo atingiu plenamente o objetivo proposto. Como principal conclusão pode-se apontar a eficácia do modelo proposto, fato que foi validado pelos dados da fábrica.

Palavras-chave: Fabricação de combustível de siliceto de urânio; Hidrólise de hexafluoreto de urânio; Reatores nucleares de pesquisa; Gestão da capacidade de produção 


\begin{abstract}
Although many nuclear fuel factories have small production volumes, the demand for nuclear fuel for research reactors is increasing worldwide. This work established a conceptual model with two strategies to increase the production capacity of these factories. We addressed factories that produce plate-type fuel elements loaded with LEU U3Si2-Al, which are typically used in nuclear research reactors. The first strategy is based on production management literature and is a regular practice in general manufacturing plants. The second strategy takes advantage of the fact that productive sectors can be separated in nuclear fuel production facilities. Both strategies have generated different production scenarios that are assumed to be safe in relation to nuclear criticality. We collected data from a real plant that produces nuclear fuel for research reactors and applied the model to that data, aiming to test the proposed model by setting up a case study. Through the use of computer software, we applied the two strategies to this data by means of discrete events simulation and created several simulation models in order to cover all generated scenarios. Our tests indicated an increase of up to $207 \%$ in productive capacity without the need of acquiring new equipment, thus showing that the model has fully achieved its proposed objective. One of the main conclusions that we point out is the model's effectiveness, which was validated by the factory data.
\end{abstract}

Keywords: Fabrication of uranium silicide fuel; hydrolysis of uranium hexafluoride; nuclear research reactors; production capacity management 


\section{LISTA DE FIGURAS}

Figura 1 - Elemento combustível tipo placa típico ............................................

Figura 2 - Esquema da fábrica de combustível nuclear do IPEN .........................28

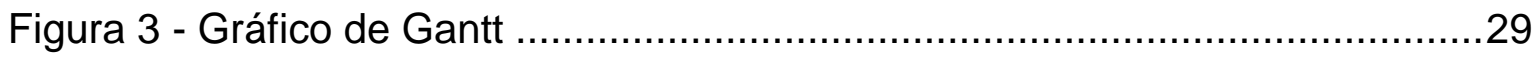

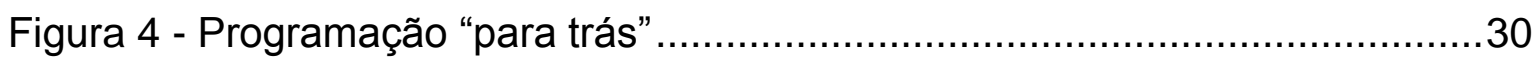

Figura 5 - Dinâmica de geração e simulação dos cenários....................................41

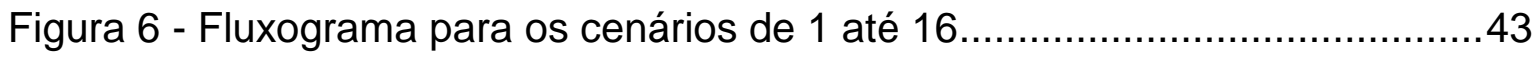

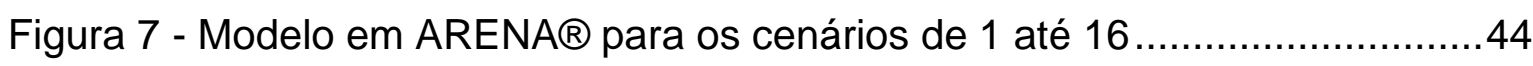

Figura 8 - Dimensionamento da capacidade pelo pico da demanda......................54

Figura 9 - Dimensionamento pelo pico com demanda constante..........................55

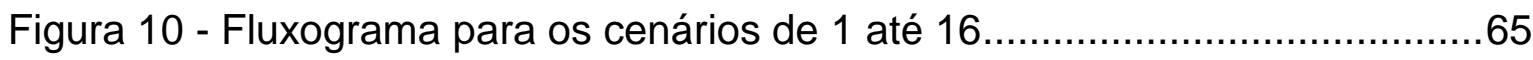

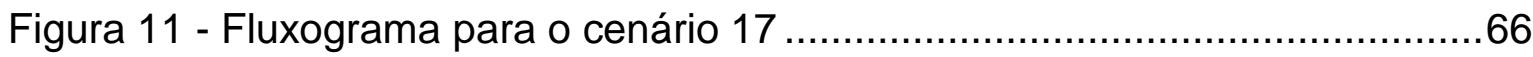

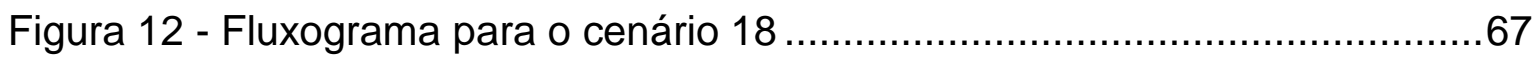

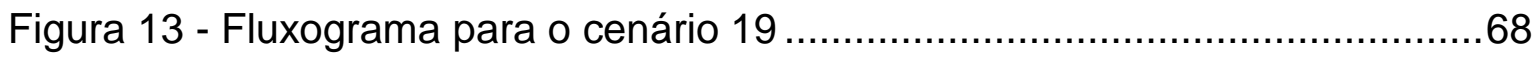

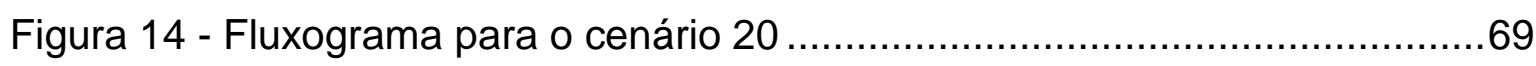

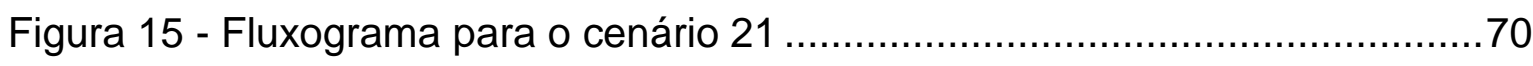

Figura 16 - Fluxograma para o cenário 22 ................................................... 71

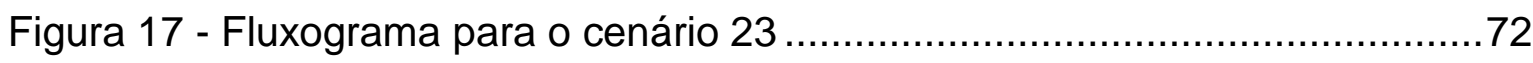

Figura 18 - Modelo em ARENA® para os cenários de 1 até $16 \ldots \ldots \ldots \ldots \ldots \ldots \ldots \ldots \ldots . . . . . . .75$

Figura 19 - Modelo em ARENA® para o cenário 17 ...........................................76

Figura 20 - Modelo em ARENA® para o cenário 18 ...........................................77

Figura 21 - Modelo em ARENA ${ }^{\circledR}$ para o cenário 19 ..........................................78

Figura 22 - Modelo em ARENA® para o cenário 20 ………………….............79

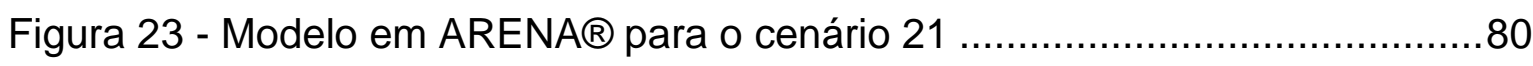

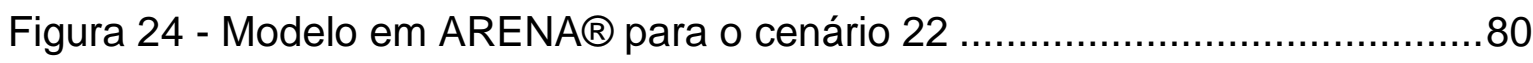

Figura 25 - Modelo em ARENA® para o cenário 23 .......................................... 81 


\section{LISTA DE TABELAS}

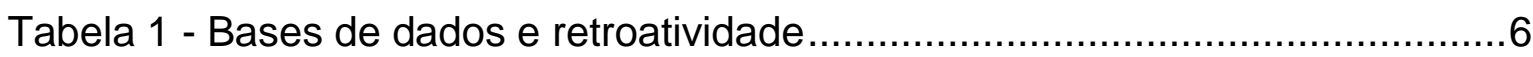

Tabela 2 - Lead times dos centros de trabalho ................................................28

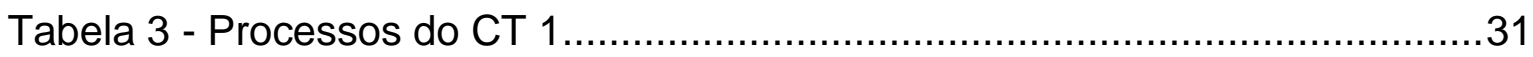

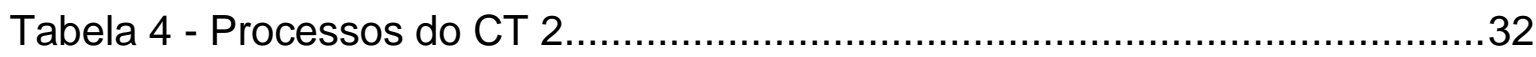

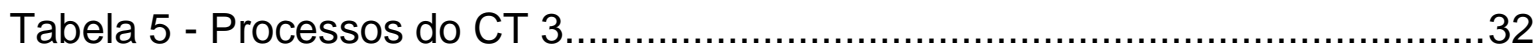

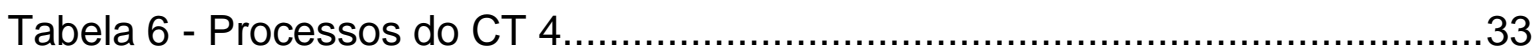

Tabela 7 - Hipóteses adotadas para todos os cenários ………………...............40

Tabela 8 - Lead times segundo a estratégia tradicional ........................................46

Tabela 9 - Dados dos cenários pela estratégia da divisão ....................................48

Tabela 10 - Resultados pela estratágia tradicional .............................................51

Tabela 11 - Resultados pela estratégia da divisão................................................52

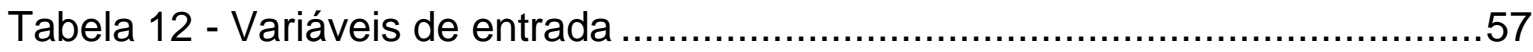

Tabela 13 - Resultados do modelo para minimização do custo de produção ........60

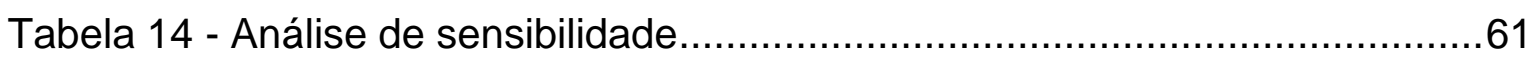

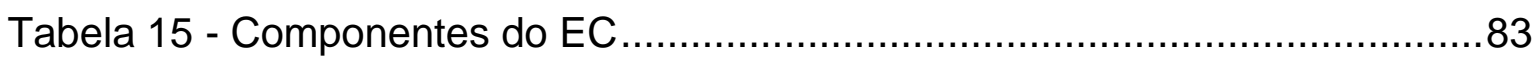

Tabela 16 - Sequência de cálculo de custo de alumínio .......................................83

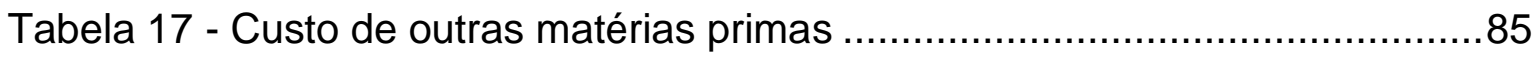

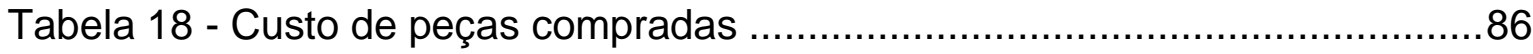

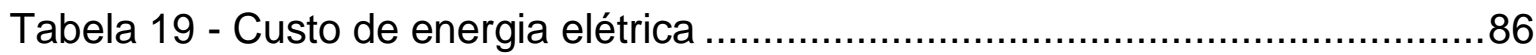

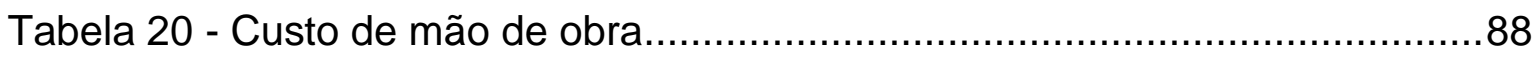

Tabela 21 - Estimativa de custo de um EC tipo placa típico .................................8 


\section{LISTA DE ABREVIATURAS E SIGLAS}

CAPES Coordenadoria de Aperfeiçoamento de Pessoal de Nível Superior

CNEN Comissão Nacional de Energia Nuclear

CT

Centro de trabalho

DES

Discrete Event Simulation - Simulação de Eventos Discretos

EC

Elemento combustível

GTRI

Global Threat Reduction Initiative - Iniciativa de Redução da Ameaça Global

HEU Higly Enriched Uranium - Urânio altamente enriquecido

IAEA International Atomic Energy Agency - Agência Internacional de Energia Atômica

IEA-R1 Instituto de Energia Atômica - Reator 1

IPEN Instituto de Pesquisas Energéticas e Nucleares

LEU Low Enriched Uranium - Urânio de baixo enriquecimento

LEU U ${ }_{3} \mathrm{Si}_{2}-\mathrm{Al}$ Siliceto de urânio de baixo enriquecimento e disperso em matriz de alumínio

LEU UF6 $\quad$ Hexafluoreto de urârio de baixo enriquecimento

PC Placa combustível

PCP Planejamento e Controle da Produção

Reduced Enrichment for Research and Test Reactors -

RERTR Redução de Enriquecimento para Reatores de Pesquisa e de Testes 


\section{LISTA DE SÍMBOLOS E FÓRMULAS}

\begin{tabular}{|c|c|}
\hline Al & Alumínio \\
\hline C & Tempo de ciclo \\
\hline $\mathrm{CP}$ & Capacidade produtiva \\
\hline $\mathrm{CP}_{\mathrm{t}}$ & Capacidade produtiva no mês $t$ \\
\hline D & Demanda anual \\
\hline $\mathrm{d}_{\mathrm{t}}$ & Demanda no mês $t$ \\
\hline $\mathrm{HNO}_{3}$ & Ácido nítrico \\
\hline $\mathrm{IB}_{1}$ & Estoque ao princípio do primeiro mês \\
\hline $\mathrm{IB} \mathrm{B}_{\mathrm{t}}$ & Estoque ao princípio do mês $t$ \\
\hline IC & Custo para manutenção de estoque \\
\hline $\mathrm{IC}_{\mathrm{t}}$ & Custo de estoque no mês $t$ \\
\hline $\mathrm{IE}_{\mathrm{t}}$ & Estoque ao final do mês $t$ \\
\hline $\operatorname{Imax}$ & Estoque máximo no mês $t$ \\
\hline $\operatorname{Imin}_{\mathrm{t}}$ & Estoque mínimo no mês $t$ \\
\hline$f(x)$ & Função objetivo \\
\hline L & Lead time - tempo de atravessamento \\
\hline Mg & Magnésio \\
\hline $\mathrm{N}$ & Nitrogênio \\
\hline $\mathrm{R}$ & Taxa de juros ao mês \\
\hline $\mathrm{Si}$ & Silício \\
\hline $\mathrm{SnCl}$ & Cloreto estanoso \\
\hline $\mathrm{T}$ & Horizonte de tempo de planejamento de produção \\
\hline $\mathrm{U}_{3} \mathrm{Si}_{2}$ & Siliceto de urânio \\
\hline $\mathrm{UF}_{4}$ & Tetrafluoreto de urânio \\
\hline $\mathrm{UF}_{6}$ & Hexafluoreto de urânio \\
\hline$x_{t}$ & Quantidade de EC a ser produzida no mês $t$ \\
\hline W & Custo de produção de um EC \\
\hline
\end{tabular}




\section{SUMÁRIO}

1 INTRODUÇÃO

2 OBJETIVO, ORIGINALIDADE E CONTRIBUIÇÃO .........................................

3 REVISÃO BIBLIOGRÁFICA

3.1 ENGENHARIA DO COMBUSTÍVEL NUCLEAR …....................................

3.1.1 Especificação do combustível nuclear ..................................................

3.1.2 Elemento combustível tipo placa típico ……......................................... 8

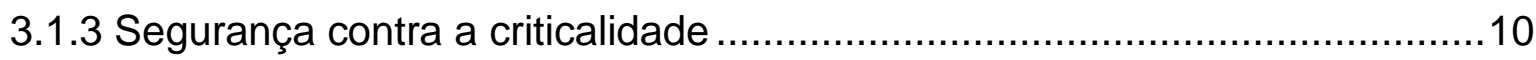

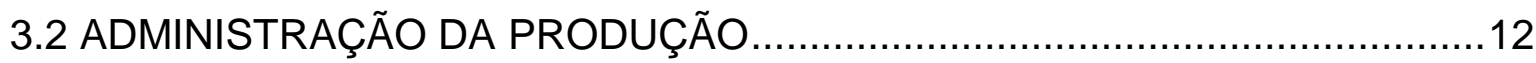

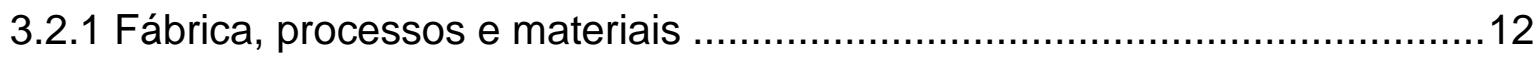

3.2.1.1 Definir as estratégias da organização e da produção ..............................13

3.2.1.2 Analisar a demanda, o produto, os materiais e os processos ...................14

3.2.1.3 Identificar gargalos e verificar a necessidade de mudanças dos processos

3.2.1.4 Estudar possível novo arranjo físico …………..............................16

3.2.1.5 Implementar as mudanças e verificar sua eficácia....................................17

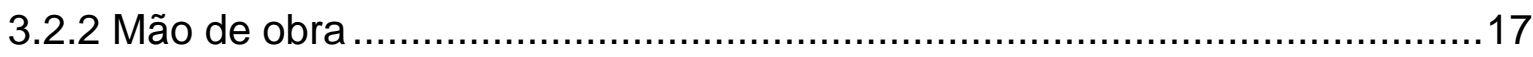

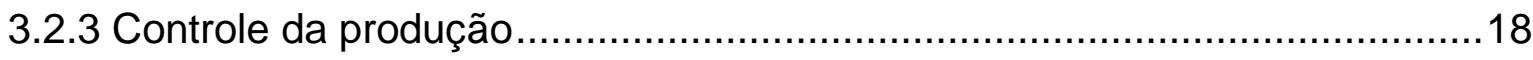

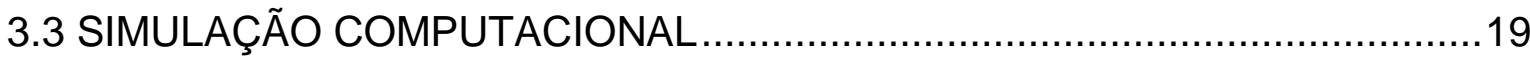

4 METODOLOGIA

4.1 PROPOSIÇÃO DE UM MODELO PARA A EXPANSÃO DA CAPACIDADE ..23

4.2 TESTE E AVALIAÇÃO DO MODELO PROPOSTO .....................................23

4.2.1 Aplicação do modelo proposto à fábrica de combustível nuclear do IPEN ..24

4.2.1.1 Passo 1: Definir as estratégias da organização e da produção ................24

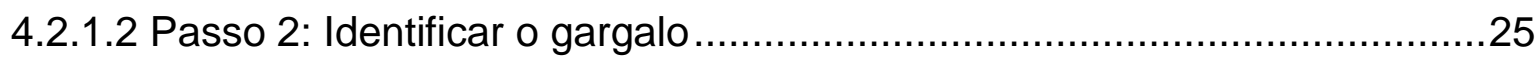

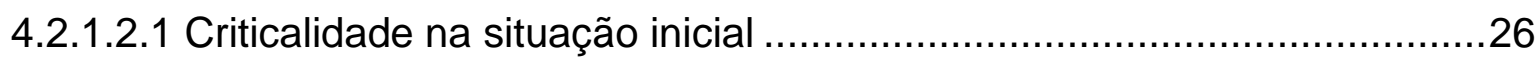

4.2.1.2.2 Mapeamento de processos e coleta de dados .....................................27

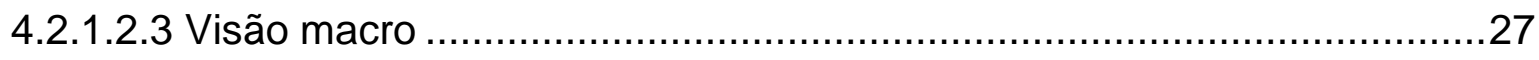

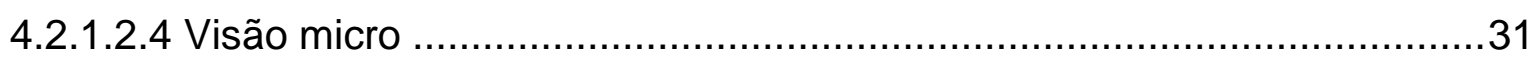

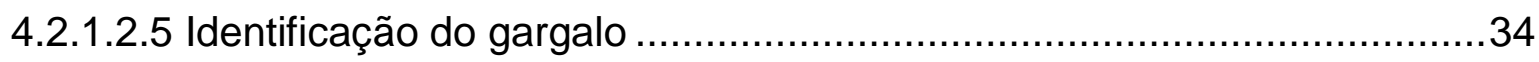

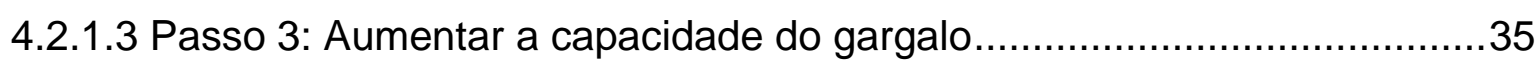




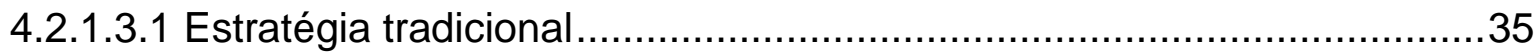

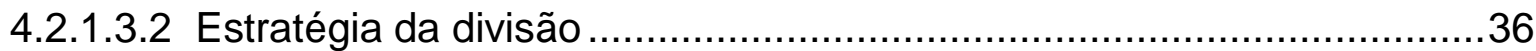

4.2.1.4 Passo 4: Se necessário, alterar o arranjo físico ………………..............37

4.2.1.5 Passo 5: Verificar o risco de criticalidade na nova configuração................38

4.2.1.6 Passo 6: Verificar se a demanda está atendida ......................................38

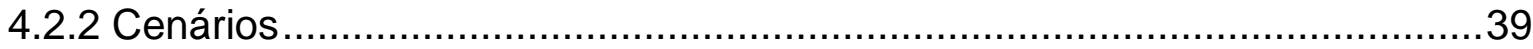

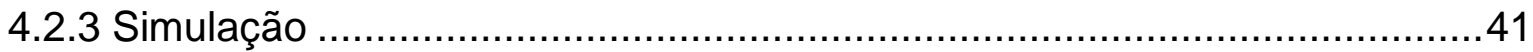

4.2.3.1 Construção do modelo de simulação ……………...............................42

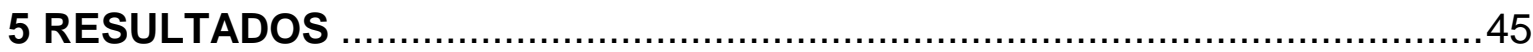

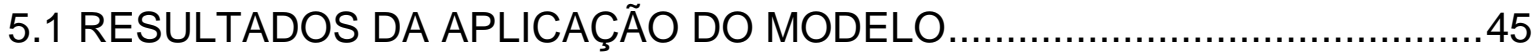

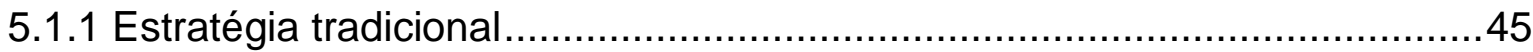

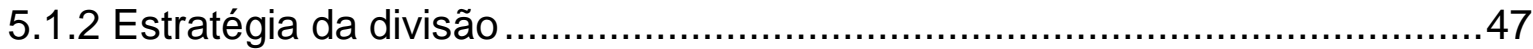

5.1.3 Passos 4, 5 e 6 do guia para modelagem de simulação ……………….......49

5.2 RESULTADOS DA SIMULAÇÃO EM COMPUTADOR .................................4

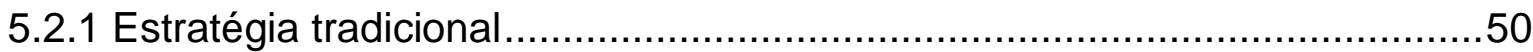

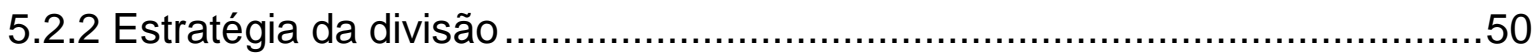

6 OUTROS ASPECTOS DO GERENCIAMENTO DA CAPACIDADE

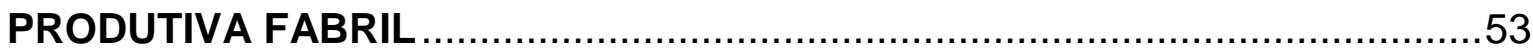

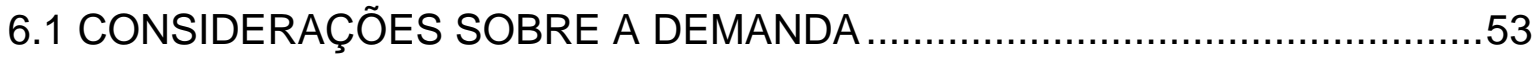

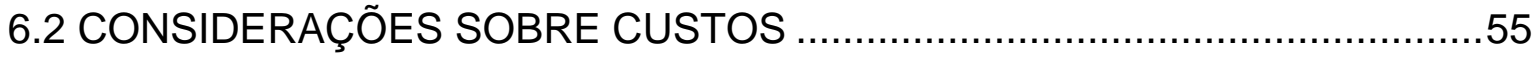

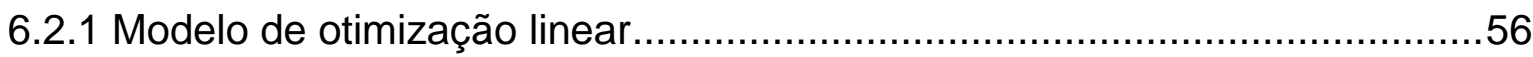

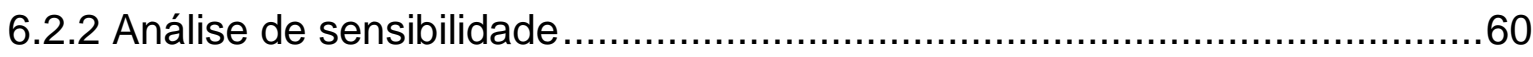

7. CONCLUSÕES

8. APÊNDICE A - FLUXOGRAMAS E MODELOS DE SIMULAÇÃO ….............64

9. APÊNDICE B - ESTIMATIVA DE CUSTO DE UM EC …............................

10 ÍNDICE

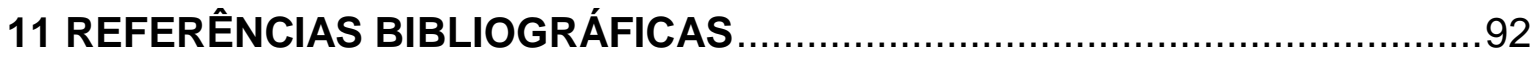




\section{INTRODUÇÃO}

O conhecimento sobre tecnologia nuclear remonta ao ano de 1938, quando os cientistas Otto Hahn, Lise Meitner e Fritz Strassman caracterizaram a fissão do átomo de urânio [1]. Assim, os 79 anos de história da tecnologia nuclear tornam-na uma área relativamente recente dentro da ciência. Apesar disso, poucos anos após a Segunda Guerra Mundial já havia diversos reatores nucleares de pesquisa com altos fluxos de nêutrons, os quais permitiram o rápido avanço do conhecimento nesta nova área da ciência [1].

Já nos primórdios desse conhecimento, constatou-se a necessidade de um ambiente adequado à manutenção da reação de fissão em cadeia e de forma controlada. Esse ambiente ficou conhecido como reator nuclear a fissão, ou simplesmente reator nuclear. Duas das principais características de todos reatores onde ocorre a fissão de urânio são o fluxo de nêutrons e a produção de calor, as quais estão intrinsicamente ligadas. A evolução dessa tecnologia indicou basicamente dois tipos de reatores nucleares. No primeiro deles há mais interesse no fluxo de nêutrons que no calor produzido. No segundo tipo, o uso do calor predomina sobre o fluxo de nêutrons [2]. Por outro lado, dado que todos os reatores nucleares produzem calor, essa característica tornou-se uma forma frequente de referir-se a um reator nuclear. Assim a potência térmica do reator converteu-se em um parâmetro de identificação desses equipamentos.

Percebeu-se que diferentes dispositivos podiam ser aquecidos pelos reatores onde há predomínio do calor. Um desses dispositivos seria um gerador de vapor e assim surgiram as primeiras usinas de geração de energia elétrica de fonte nuclear. Por esse motivo, esses reatores foram denominados reatores de potência [2]. A potência térmica típica dos reatores de usinas nucleares varia de $3.000 \mathrm{a}$ 6.000 MW [3]. Como exemplo cita-se a usina de Angra 2, na qual a capacidade de geração de energia elétrica é de $1.350 \mathrm{MW}$ e a potência térmica de seu reator nuclear é de $3.771 \mathrm{MW}$ [4].

Por outro lado, no início da era nuclear, usava-se o fluxo de nêutrons quase que exclusivamente para a pesquisa nessa área. Por isso os reatores com alto fluxo de nêutrons foram chamados de reatores de pesquisa [2]. Os primeiros 
reatores nucleares de pesquisa tinham potências térmicas de 1 até $100 \mathrm{~W}$, isto é, muito inferiores àquelas dos reatores de potência. Até a década de 1960 foram construídos diversos reatores de pesquisa em vários países e sua potência térmica típica era de até $2 \mathrm{MW}$. Ainda hoje estão em operação alguns reatores de pesquisa com potências dessa ordem. Um deles está localizado em São Paulo. Trata-se do reator IPEN/MB-01, que entrou em operação em 1988 e cuja potência máxima é de 100 W. É um reator genuinamente brasileiro, concebido pelo Instituto de Pesquisas Energéticas e Nucleares (IPEN) em conjunto com a Marinha do Brasil [5].

Em contrapartida, a partir da década de 1950 surgiu um novo ramo dentro do desenvolvimento da tecnologia nuclear, que foi a medicina nuclear $[6,7]$. Descobriu-se que a radiação pode ser benéfica no tratamento e diagnóstico de algumas enfermidades. Alguns dos tipos da radiação em questão são produzidos em reatores de pesquisa. Por outro lado, viu-se que alguns componentes de medicamentos tinham sua eficácia aumentada, quando eram irradiados por um feixe de nêutrons. Assim, nasceram os radiofármacos, que são medicamentos irradiados por nêutrons ou cujos componentes foram irradiados por nêutrons. $O$ fluxo de nêutrons presente nos reatores de pesquisa foi, e ainda é, a principal fonte de nêutrons para a produção de radiofármacos. A demanda da medicina nuclear por rádiofármacos tem crescido continuamente e a taxas elevadas [8,9], impondo uma utilização dos reatores nucleares de pesquisa muito maior que a prevista originalmente. No caso do Brasil, o IPEN foi a instituição pioneira na produção de radioisótopos e radiofármacos, iniciando-a em 1959 com seu reator de pesquisa "Instituto de Energia Atômica - Reator 1 (IEA-R1)". Atualmente o IPEN produz 97\% dos radioisótopos usados no Brasil por meio desse mesmo reator e também de seus cíclotrons [10].

A partir da década de 1990 surgiu outro ramo dentro do desenvolvimento da tecnologia nuclear, que foi a indústria eletrônica. Descobriu-se que a irradiação de silício por nêutrons aumenta a condutividade elétrica desse elemento [11-13]. Por outro lado, o silício é um elemento fundamental na fabricação de processadores e circuitos integrados. Assim, quanto maior sua condutividade elétrica, maior a capacidade de processamento dos componentes citados. Além disso, o aumento considerável do uso de computadores e telefones celulares explica o grande interesse da indústria eletrônica no uso dos reatores nucleares de pesquisa $[8,9]$. 
De outra parte, a pesquisa e o ensino de tecnologia nuclear também têm crescido [8,9]. Esse crescimento causa um aumento do uso dos reatores nucleares de pesquisa, pois estes são responsáveis por parte considerável da geração e da transmissão de conhecimento sobre tecnologia nuclear.

Entretanto, a medicina nuclear, a indústria eletrônica e a pesquisa nuclear provocaram não apenas aumento do uso dos reatores nucleares de pesquisa, mas também aumento de sua potência térmica. Nas últimas décadas, diversos desses reatores tiveram sua capacidade aumentada, isto é, passaram de uma potência média de $2 \mathrm{MW}$ para 5 ou $6 \mathrm{MW}$, a exemplo do IEA-R1 [5]. Entretanto, fluxos de nêutrons consideravelmente mais elevados só são conseguidos com elevação da potência de projeto do reator. Por isso, os reatores de pesquisa construídos nas últimas décadas têm potência térmica mínima da ordem de $20 \mathrm{MW}$, chegando até aos $100 \mathrm{MW}[14,15]$. O crescimento do uso e da potência de reatores nucleares de pesquisa nas últimas décadas, por sua vez, acarretou - e ainda acarreta - crescimento da demanda pelo combustível usado para acioná-los $[8,9,16-21]$.

A necessidade de combustível nuclear para reatores de pesquisa tem sido suprida por empresas que o produzem e vendem a terceiros. Entretanto, há instalações de produção desse tipo de combustível que ainda o fazem como no início da era nuclear. São instalações que suprem reatores com potências entre 2 e 10 MW. Essa capacidade produtiva é insuficiente para atender à demanda de reatores com potências da ordem de 20 a 50 MW. Por isso, o aumento da produção impõe a ampliação da capacidade produtiva de algumas instalações de fabricação desse combustível. Naturalmente, a ampliação de capacidade deve ser feita mantendo-se a segurança dos processos produtivos e a qualidade do produto final. Esses fatos conduzem à formulação da seguinte questão de pesquisa: Como aumentar a capacidade produtiva de fábricas de combustível nuclear para reatores de pesquisa com segurança e qualidade?

A resposta à questão de pesquisa exige a aplicação de conhecimentos da área de administração da produção na fabricação de combustível nuclear para reatores de pesquisa. Dentro da área de administração da produção, deve-se focar o dimensionamento da capacidade produtiva de manufaturas, o qual geralmente é feito na fase de projeto da fábrica [22]. Os conceitos desse tipo de projeto também 
se aplicam às modificações de fábricas existentes, como é o caso de várias das atuais instalações de fabricação de combustível nuclear.

Em contrapartida, para responder adequadamente à questão de pesquisa, são necessárias algumas delimitações de escopo quanto ao combustível nuclear. A primeira delas refere-se ao tipo de combustível, pois há vários tipos de combustível nuclear para reatores de pesquisa [23]. Neste trabalho foi selecionado o combustível a base de siliceto de urânio $\left(\mathrm{U}_{3} \mathrm{Si}_{2}\right)$, devido ao seu largo emprego em reatores de pesquisa, à sua boa capacidade de carga de urânio e excelente desempenho [21].

Outra delimitação de escopo refere-se à rota de produção de $\mathrm{U}_{3} \mathrm{Si}_{2}$, pois esse combustível pode ser obtido por processos diversos [24]. Neste trabalho foi escolhida a rota que inclui a hidrólise do hexafluoreto de urânio (UFG), pelos seguintes motivos:

- relativa simplicidade;

- produção de quantidades pequenas dos produtos intermediários, fato que contribui para a segurança, conforme exposto em seções subsequentes;

- a elevação da demanda provavelmente também afetará fábricas que usam essa rota de produção;

- os dados disponíveis para este trabalho provém de uma instalação que usa essa rota.

Sob outra perspectiva, há poucas instalações que usam a rota da hidrólise de $U_{6}$. Assim explica-se a ausência de literatura para guiar o aumento de capacidade, conforme citado mais adiante. Essa falta de literatura específica também justifica a escolha da rota citada.

A última delimitação de escopo refere-se ao vetor responsável pela disponibilização do combustível nuclear no reator de pesquisa. Neste estudo foi considerado o elemento combustível (EC) tipo placa típico, pois esse é o tipo de EC mais comumente usado em reatores nucleares de pesquisa [25-29]. Nas seções subsequentes estão expostos detalhes do tipo de EC selecionado para este trabalho. 


\section{OBJETIVO, ORIGINALIDADE E CONTRIBUIÇÃO}

O objetivo deste trabalho consiste na proposição e teste de um modelo conceitual para expansão da capacidade produtiva de fábricas de EC tipo placa típico para reatores nucleares de pesquisa, que usem $\bigcup_{3} \mathrm{Si}_{2}$ e cuja rota de produção inclua a hidrólise de UF6.

A questão de pesquisa mencionada anteriormente e suas delimitações de escopo levaram à definição do objetivo deste trabalho.

A originalidade deste estudo deve-se a uma lacuna de publicações científicas sobre este tema. Essa lacuna foi comprovada por meio de buscas em diferentes bases de dados de publicações científicas em novembro de 2015, outubro de 2016 e abril de 2017. Cada base de dados tem sua própria data inicial, isto é, a data a partir da qual houve registro de publicações científicas relacionadas ao tema deste trabalho naquela base de dados. O período correspondente às respostas das bases de dados para as buscas efetuadas neste trabalho estendese desde o ano inicial de registro de cada base de dados até novembro de 2015, outubro de 2016 e abril de 2017 respectivamente. Na Tabela 1 estão expostas as bases de dados consultadas e seus correspondentes anos de início de registro de publicações científicas relacionadas ao tema deste estudo.

As buscas foram feitas com expressões na língua inglesa, visando maior retorno de respostas das bases de dados. As expressões citadas foram alocadas nos campos "título" e "tópico ou assunto" nos respectivos mecanismos de busca. Seguem-se algumas das expressões usadas para as buscas citadas.

- methods of capacity increasing for production of nuclear fuel using the hydrolysis of $U F_{6}$ for research reactors - métodos de aumento de capacidade para produção de combustível nuclear usando a hidrólise de $U_{6}$ para reatores de pesquisa;

- methods of capacity increasing for production of nuclear fuel for research reactors - métodos de aumento de capacidade para produção de combustível nuclear para reatores de pesquisa;

- capacity planning of nuclear fuel for research reactors - planejamento de capacidade de combustível nuclear para reatores de pesquisa; 
- production increase of nuclear fuel for research reactors - aumento de produção de combustível nuclear para reatores de pesquisa;

- production of nuclear fuel for research reactors - produção de combustível nuclear para reatores de pesquisa.

Tabela 1 - Bases de dados e retroatividade

\begin{tabular}{lc}
\hline \multicolumn{1}{c}{ Base de dados } & Ano inicial \\
\hline Web of Science - Teia de Ciência & 1900 \\
Google Acadêmico & 1940 \\
SCOPUS - Base de dados da editora Elsevier & 1956 \\
Science Direct - Ciência Direto & 1947 \\
Agência Internacional de Energia Atômica & 1957 \\
Sistema Integrado de Bibliotecas da Universidade de São Paulo & 1947 \\
Portal de Periódicos da Coordenadoria de Aperfeiçoamento de & 1972 \\
Pessoal de Nível Superior (CAPES) & 1960 \\
American Nuclear Society - Sociedade Nuclear Americana & 1996 \\
Associação Brasileira de Engenharia de Produção & 1968 \\
Universidade Federal de São Carlos & 1969 \\
Sociedade Brasileira de Pesquisa Operacional &
\end{tabular}

Fonte: autor da tese.

Várias das bases de dados utilizadas retornam respostas, mas nenhuma delas coincide com o tema deste trabalho. A maioria das respostas relaciona-se com partes do tema, como, por exemplo, a parte química detalhada da hidrólise de $\mathrm{UF}_{6}$ ou a otimização de recarga de combustível em um reator de potência. Até o fechamento deste caderno, abril de 2017, não se encontraram publicações semelhantes ao modelo proposto neste projeto de pesquisa. Além disso, algumas das bases de dados não retornaram resposta alguma.

Quanto à contribuição, este trabalho colabora com a base científica por meio do aporte de conhecimentos da área de administração da produção para a fabricação de EC tipo placa contendo $\mathrm{U}_{3} \mathrm{Si}_{2}$ para reatores nucleares de pesquisa. 


\section{REVISÃO BIBLIOGRÁFICA}

\subsection{ENGENHARIA DO COMBUSTÍVEL NUCLEAR}

\subsubsection{Especificação do combustível nuclear}

Nesta seção são detalhadas as características e nomenclatura do combustível nuclear adotado para este trabalho, que é o siliceto de urânio, ou $\mathrm{U}_{3} \mathrm{Si}_{2}$, conforme já mencionado. Inicia-se pela questão do enriquecimento.

Em 1978 os Estados Unidos estabeleceram o Programa de Redução de Enriquecimento para Reatores de Pesquisa e de Testes - Reduced Enrichment for Research and Test Reactors (RERTR) -, atualmente incorporado ao programa denominado Iniciativa de Redução da Ameaça Global - Global Threat Reduction Initiative (GTRI) [30,31]. Ambos os programas visavam e ainda visam a não proliferação de armas nucleares por meio da redução do nível de enriquecimento de urânio nos combustíveis usados em instalações nucleares civis [32]. Esses programas atingiram diretamente os reatores nucleares de pesquisa, pois, até o fim da década de 1970, esses reatores usavam urânio altamente enriquecido - higly enriched uranium (HEU). A partir do início dos anos 80 , as instituições responsáveis por reatores nucleares de pesquisa desenvolveram tecnologias que permitiram o funcionamento de seus reatores em conformidade com os programas RERTR e GTRI. Atualmente, o nível de enriquecimento de urânio presente no combustível da maior parte dos reatores nucleares de pesquisa em todo o mundo corresponde à concentração de $19,75 \pm 0,25 \%$ em massa do isótopo ${ }^{235} \mathrm{U}$ [23]. Esse valor é conhecido como urânio de baixo enriquecimento - low enriched uranium (LEU). Com base nesses fatos, selecionou-se LEU para a concentração de urânio no combustível considerado neste trabalho. Além disso, adotou-se que a densidade de urânio no combustível é de $3,2 \mathrm{~g} / \mathrm{cm}^{3}$, por ser a mais comum em reatores nucleares de pesquisa [33-35].

Quanto à rota de produção do combustível considerada, foi mencionada a escolha daquela que passa pela hidrólise de $\mathrm{UF}_{6}$. Foi dado destaque a essa reação química, pois os dados disponíveis para este trabalho vieram de uma fábrica 
que usa essa rota de produção. Entretanto, a totalidade do processo produtivo de $\mathrm{U}_{3} \mathrm{Si}_{2}$ inclui outras duas reações químicas [21]. Por esse motivo faz-se uma breve explanação dessas reações.

A conversão de $\mathrm{UF}_{6}$ em tetrafluoreto de urânio $\left(\mathrm{UF}_{4}\right)$ requer duas reações químicas. A primeira delas é a hidrólise de $U_{F}$, representada na equação (1). Na segunda reação forma-se $U_{4}$, conforme a equação (2). A terceira reação é a redução de $\mathrm{UF}_{4}$ a urânio metálico, representada na equação (3). Finalmente obtém-se a liga intermetálica $\mathrm{U}_{3} \mathrm{Si}_{2}$ por processos metalúrgicos, descritos em detalhe na literatura $[21,24]$.

$$
\begin{aligned}
\mathrm{UF}_{6}+2 \mathrm{H}_{2} \mathrm{O} & \rightarrow \mathrm{UO}_{2} \mathrm{~F}_{2}+4 \mathrm{HF} \\
\mathrm{UO}_{2} \mathrm{~F}_{2}+\mathrm{SnCl}_{2}+4 \mathrm{HF} & \rightarrow \mathrm{UF}_{4}+\mathrm{SnCl}_{2} \mathrm{~F}_{2}+2 \mathrm{H}_{2} \mathrm{O} \\
\mathrm{UF}_{4}+2 \mathrm{Mg} & \rightarrow \mathrm{U}+2 \mathrm{MgF}_{2}
\end{aligned}
$$

$\mathrm{Na}$ maioria dos processos produtivos de combustível para reatores nucleares de pesquisa, o $\mathrm{U}_{3} \mathrm{Si}_{2}$ é moído e seu pó é misturado a pó de alumínio (Al). Essa mistura de pós é prensada e envolvida por placas de alumínio e o conjunto resultante é laminado a quente e a frio. Esses processos são exclusivamente metalúrgicos, isto é, não há reação química entre $\mathrm{U}_{3} \mathrm{Si}_{2}$ e $\mathrm{Al}$. Dessa forma, dispõese uma quantidade considerável de alumínio nas proximidades das moléculas de $\mathrm{U}_{3} \mathrm{Si}_{2}$. Nessa situação diz-se que o $\mathrm{U}_{3} \mathrm{Si}_{2}$ está disperso em matriz de Al. Assim, chega-se à nomenclatura do combustível selecionado para este trabalho: trata-se de siliceto de urânio de baixo enriquecimento e disperso em matriz de alumínio, geralmente denominado $\mathrm{LEU} \mathrm{U}_{3} \mathrm{Si}_{2}-\mathrm{Al}[23,27,36,37]$.

\subsubsection{Elemento combustível tipo placa típico}

Neste trabalho considera-se que o produto final de uma fábrica de combustível nuclear é um elemento combustível tipo placa típico. A função desse produto é disponibilizar combustível nuclear aos reatores de pesquisa. As principais características de um EC tipo placa típico são [21,23,27,36,38]:

- O EC contém cerca de 20 placas planas em seu interior; 
- Essas placas estão carregadas com LEU U3Siz-Al e por isso são chamadas de placas combustíveis (PC);

- Há espaço entre as PC para a circulação de água para refrigeração e para a moderação de nêutrons;

- As PC são geralmente feitas de alumínio, assim como as demais partes estruturais do EC.

Na Figura 1 expõe-se um desenho esquemático de um EC tipo placa típico, comumente usado em reatores nucleares de pesquisa [39].

Figura 1 - Elemento combustível tipo placa típico

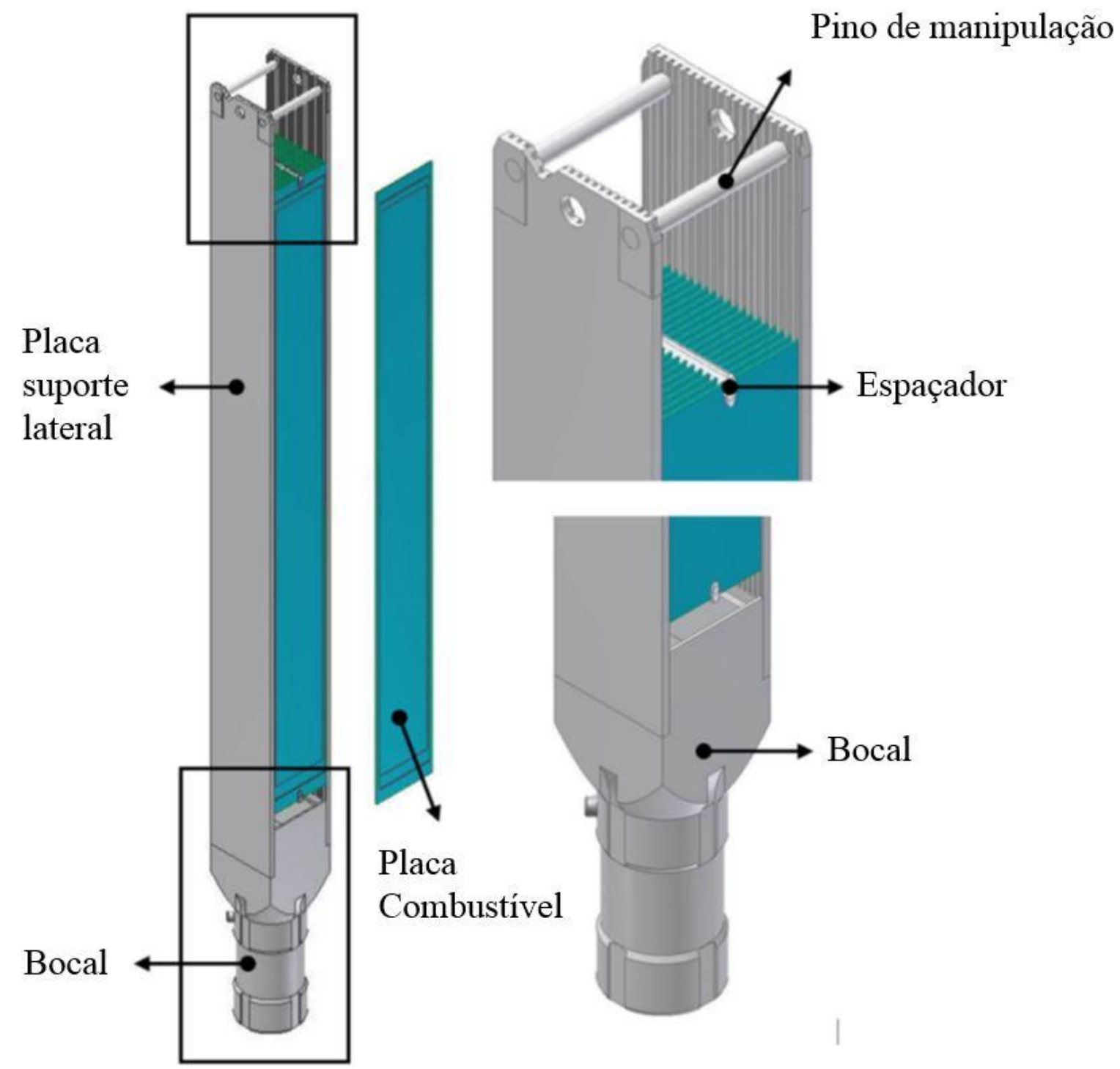

Fonte: [39] 


\subsubsection{Segurança contra a criticalidade}

Criticalidade é o termo que se refere ao balanço de nêutrons em um sistema nuclear. Esse conceito abrange as seguintes três situações [40].

- Sistema sub-crítico: a taxa de perda de nêutrons do sistema é maior que a taxa de produção de nêutrons, fato que impossibilita a auto-sustentação da reação nuclear;

- Sistema crítico: a taxa de perda de nêutrons do sistema é igual à taxa de produção de nêutrons. Nesta situação a reação nuclear se auto-sustenta;

- Sistema super-crítico: a taxa de perda de nêutrons do sistema é menor que a taxa de produção de nêutrons, situação que gera o aumento exponencial da reação nuclear.

Vê-se que qualquer situação diferente da sub-crítica leva à reação nuclear em cadeia e por isso precisa ser controlada [41]. A área de segurança de criticalidade nuclear busca a prevenção de acidentes radioativos provenientes de uma reação nuclear auto-sustentada e não controlada. Para atingir seus objetivos, essa área busca limitar o acúmulo de combustível nuclear visando manter o sistema na condição sub-crítica. Por isso, a maioria de suas recomendações dirigem-se a pequenas massas de combustível, diâmetros limitados de vasos, razoável distância entre os equipamentos e controle sobre os processos químicos e físicos [41-43] . Nesse sentido, a rota de produção adotada neste trabalho é apropriada, pois gera pequenas quantidades de produtos intermediários, como mencionado anteriormente.

As exigências quanto à segurança contra a criticalidade de qualquer instalação nuclear estão expressas em normas da Agência Internacional de Energia Atômica - International Atomic Energy Agency (IAEA) e da Comissão Nacional de Energia Nuclear (CNEN) [44,45]. Uma instalação de fabricação de EC para reatores nucleares de pesquisa inclui uma multiplicidade de estações de trabalhos e de áreas de armazenamento de material físsil em curto e em longo prazos. Algumas das recomendações da área de segurança contra a criticalidade para fábricas desse tipo estão apresentadas a seguir [42]:

- Todas e cada uma das estações de trabalho precisam ser dimensionadas para operar em situação sub-crítica; 
- Todas e cada uma das áreas de armazenamento, suas disposições, seus distanciamentos e os tipos de embalagens nelas usados devem ser projetados e dimensionados de forma que todas as áreas de armazenamento sejam sub-críticas;

- O material estocado e em trânsito deve ser considerado quanto à sua formulação e estado físico, pois gases, sólidos e líquidos requerem tratamentos distintos e específicos para manterem-se sub-críticos;

- O percurso de material físsil por toda a fábrica deve ser feito com manipulação específica, visando manter esse transporte sub-crítico, principalmente no caso de condições imprevistas;

- Cuidados especiais devem ser tomados com embalagens e processos produtivos, para evitar vazamento de líquidos, precipitação, escape de gases, dissolução de sólidos, falhas de instrumentos e acidentes durante a transferência entre contenedores;

- Todas as operações precisam ser efetuadas por pessoal bem treinado.

Nessa lista fica claro que as recomendações da área de segurança contra criticalidade são opostas ao aumento de capacidade produtiva. Ou seja, é necessário promover a harmonização entre o aumento de produção e a segurança contra criticalidade. Entretanto, tal harmonização é uma atividade de extensão e complexidade consideráveis e geralmente é feita por equipes de profissionais $[40,41,43]$.

Neste trabalho foi proposto um modelo para aumento da capacidade produtiva de fábricas de combustível nuclear, como exposto mais adiante. Esse modelo inclui alterações da configuração de produção sub-crítica, algumas das quais acrescentam transporte de produtos intermediários físseis. Assim, antes da implementação prática de qualquer das configurações de produção geradas neste trabalho, é necessário realizar um estudo criterioso e detalhado da segurança contra a criticalidade oferecida por essa configuração. Caso esse estudo indique que uma determinada configuração de produção resultará em um sistema crítico ou super-crítico, essa configuração deve ser desconsiderada e deve-se buscar outra forma de aumentar a produção.

Desse modo, foi adotada a seguinte hipótese sobre segurança contra criticalidade nuclear neste trabalho: toda e qualquer configuração de produção 
gerada neste estudo é sub-crítica. Caso essa hipótese não tivesse sido adotada, não teria sido possível considerar diversas das configurações de produção que constam de seções subsequentes.

\subsection{ADMINISTRAÇÃO DA PRODUÇÃO}

Esta área do conhecimento lida com o projeto, análise e melhoria de sistemas de produção [46-49] e encontra-se na interface entre as ciências naturais e as ciências sociais [50]. Portanto, toda e qualquer instalação produtiva, de qualquer setor da economia, é fortemente influenciada pelas ações de seus administradores. Em outras palavras, as decisões da gerência influenciam partes essenciais de todos os sistemas produtivos. Tais decisões podem ser traduzidas em dados, os quais, por sua vez, são necessários a este trabalho. Os dados provenientes de ações gerencias usados neste trabalho estão expostos na seção de metodologia.

No setor industrial, os sistemas produtivos são compostos basicamente pelos seguintes cinco elementos: fábrica, processos, materiais, mão de obra e planejamento e controle $[46,47,51]$. Esses elementos foram considerados neste trabalho e estão detalhados a seguir.

\subsubsection{Fábrica, processos e materiais}

Os processos e materiais necessários à produção do EC tipo placa típico foram abordados na seção de engenharia nuclear. Quanto à fábrica, focou-se o processo de projetá-la, pois um dos elementos de seu projeto é o dimensionamento de sua capacidade produtiva. Assim, foi revisada inicialmente a literatura sobre administração de capacidade de fábricas em geral. Esse conteúdo é amplamente abordado na literatura sobre gerenciamento de operações [51-58].

$\mathrm{Na}$ literatura mencionada foram encontrados vários conceitos e métodos para projetar, modelar e analisar o crescimento da capacidade produtiva de fábricas em geral. Tais métodos tem vários pontos em comum. Foi estabelecida uma correlação entre esses pontos e essa correlação foi designada neste trabalho como 
modelo genérico. Assim, o modelo genérico para ampliação da capacidade produtiva de fábricas em geral adotado neste trabalho é o seguinte:

Modelo genérico [46,47,49,59-62]

1. Definir as estratégias da organização e da produção;

2. Analisar a demanda, o produto, os materiais e os processos;

3. Identificar o(s) gargalo(s);

4. Verificar a necessidade de mudanças dos processos;

5. Estudar possível novo arranjo físico;

6. Implementar as mudanças definidas nos passos anteriores;

7. Verificar e quantificar a eficácia das mudanças.

O detalhamento dos sete passos que compõem o modelo acima está descrito nas próximas seções.

\subsubsection{Definir as estratégias da organização e da produção}

Estabelecer a estratégia da organização é uma tarefa da alta gerência e afeta a todas as áreas da instituição [52-55,57,63,64]. A estratégia da organização inclui decisões a respeito de qual mercado atender, em qual região geográfica e para qual faixa de renda, entre outras. Essas decisões impactam diretamente a produção, seja qual for o ramo de atividade da organização $[54,55,63]$. No contexto fabril, a produção é parte essencial de toda e qualquer manufatura e também deve determinar sua própria estratégia. Naturalmente, a estratégia da produção precisa estar alinhada à estratégia organizacional.

A estratégia da produção depende de informações e decisões a respeito da demanda a ser atendida, dos produtos a serem produzidos e da capacidade produtiva, entre outros $[56,58,65]$. Dessa forma, o dimensionamento da capacidade produtiva é um dos pontos de referência para a elaboração da estratégia da produção.

O planejamento da capacidade produtiva depende de decisões provenientes tanto da estratégia organizacional como da estratégia da produção. Para esse gerenciamento devem ser considerados, principalmente, fatores como previsões de demanda, velocidade de resposta e confiabilidade do fornecimento. 
Vários desses dados não estavam disponíveis para a execução deste estudo. Entretanto, dois deles puderam ser feitos, como segue.

I. Muitos autores afirmam que a capacidade deve ser projetada para curto, médio e longo prazos $[22,63,64,66]$. Combustível nuclear para reatores de pesquisa é um produto que não muda significativamente em curto e médio prazo e sabe-se que seu mercado está em crescimento. Esses fatos permitiram delimitar o escopo deste trabalho ao planejamento da capacidade apenas em longo prazo.

II. Um parâmetro relevante para o dimensionamento da capacidade produtiva é a medida dessa capacidade[46,65]. É necessário estabelecer um sistema de mensuração da capacidade, o qual varia conforme a organização e também pode variar dentro de uma mesma organização. Por exemplo: pode-se medir a capacidade pelos insumos consumidos e também pelo volume de produção $[47,48,54]$. Para este trabalho foi definido como indicador de medida de capacidade o volume de produção anual em número de EC. Esse parâmetro foi escolhido, pois o EC tipo placa típico é o produto cuja demanda está em elevação e é o produto final das fábricas de combustível nuclear, às quais dirige-se este trabalho.

3.2.1.2 Analisar a demanda, o produto, os materiais e os processos

O conhecimento detalhado dos quatro elementos desta subseção é fundamental na administração de produção em qualquer área [22,52-55]. Esses quatro elementos estão intimamente relacionados, de forma que qualquer alteração em um deles afeta os demais.

Variações da demanda impõem aumentar ou diminuir estoques, bem como acelerar ou retardar o ritmo de produção. Pode haver demanda por um produto agora e por outro produto similar, mas não igual, no momento seguinte. Uma alteração da demanda deste tipo altera o produto, os materiais, os processos produtivos e o ritmo de produção $[46,58,65]$.

É preciso ter em mente o produto final com clareza. Ou seja, é necessário saber todos os detalhes técnicos e funcionais sobre o produto final que 
será enviado ao mercado. Esse conhecimento orienta a produção e aumenta as chances de sucesso da organização $[47,55,56]$.

Quanto aos materiais, faz-se necessário saber em detalhes quais matérias primas serão usadas diretamente pela organização, quais produtos intermediários serão produzidos e quais partes e subsistemas serão comprados de terceiros [51-53].

Processos são os procedimentos executados com as matérias primas, produtos intermediários e partes compradas com a finalidade de obter-se o produto final. Os processos precisam ser conhecidos com profundidade, definidos em detalhes e conhecidos por todos os envolvidos com a produção. Recomenda-se que sejam escritos e que sua descrição seja exposta a todo o pessoal do chão de fábrica $[49,67]$.

3.2.1.3 Identificar gargalos e verificar a necessidade de mudanças dos processos

Muitos autores denominam como gargalo o processo que tem o custo mais alto ou o maior tempo de execução entre todos os demais processos de uma cadeia produtiva $[22,58,63,64,68]$. Assim, o gargalo é o processo que mais influencia negativamente o desempenho da produção de uma fábrica qualquer. Por este motivo seu estudo é fundamental para a busca da expansão da capacidade produtiva.

O gargalo é um dos principais temas da Teoria das Restrições $[59,69,70]$, a qual prevê sua abordagem por dois ângulos. O primeiro deles é o conhecimento do gargalo em si, buscando identificar sua natureza, suas características e seu funcionamento. O segundo ângulo é a análise das relações do gargalo com os demais processos do fluxo produtivo.

Segundo a abordagem por processos [46], a identificação do gargalo pode se beneficiar de duas formas de considerar a produção de uma fábrica. Essas duas formas são geralmente denominadas como visão micro ou específica e visão macro ou geral. A visão micro considera cada processo individualmente e a visão macro considera conjuntos de processos, que podem ser agrupados em células de manufatura, centros de trabalho (CT), ou apenas segundo afinidade [51-53,71]. $\mathrm{Na}$ busca pela identificação do gargalo pode-se alternar da visão micro para a macro 
e vice-versa. Essa alternância deve ocorrer levando-se em conta as características da fábrica, dos processos, dos produtos intermediários e do produto final $[47,58]$.

Grande parte da literatura aponta que uma maneira de expandir a capacidade produtiva é expandir a capacidade do gargalo $[59,68,69]$. planejamento da expansão do gargalo deve ser feito considerando os seguintes elementos:

- como essa expansão afetará os processos executados após o gargalo;

- equilíbrio do novo fluxo de produção;

- eventual necessidade de mudança de arranjo físico;

- aspectos particulares da fábrica.

A expansão da capacidade do gargalo acarreta alterações importantes na natureza e no desempenho desse processo. Essas alterações determinam um novo fluxo de materiais e de produtos intermediários nos processos próximos ao gargalo. Esse novo fluxo é maior que o anterior, fato que demanda seu balanceamento. Esse balanceamento é conseguido por meio de mudanças em outros processos [54,56,72], podendo afetar toda a fábrica e não apenas os processos das proximidades do gargalo. Essas mudanças visam a adequação dos processos, para que cada um deles seja capaz de acomodar as alterações geradas pela expansão da capacidade do gargalo.

\subsubsection{Estudar possível novo arranjo físico}

É essencial um arranjo físico lógico para que o fluxo de materiais seja eficiente em toda a fábrica $[58,63,64,68]$. O novo fluxo de materiais e de produtos intermediários citado na seção anterior pode surgir em toda a fábrica ou em apenas parte dela e precisa ser balanceado. Esse balanceamento é conseguido por meio do estudo da natureza e características do novo fluxo e de suas relações com o arranjo físico atual [22,53-55]. Essa análise pode indicar a necessidade de mudanças no arranjo físico atual, para equilibrar o novo e aumentado fluxo de produção. No caso específico de fábricas de combustível nuclear, as eventuais mudanças do arranjo físico devem ser feitas dentro das normas de segurança contra a criticalidade. 
3.2.1.5 Implementar as mudanças e verificar sua eficácia

Todas as atividades citadas anteriormente são de projeto. Neste ponto passa-se da teoria à prática, por meio da introdução das definições feitas nos passos anteriores na fábrica real. Além disso, o desempenho de todos os processos e do eventual novo arranjo físico precisam ser cuidadosamente medidos de preferência diretamente no chão de fábrica $[22,63]$.

\subsubsection{Mão de obra}

A mão de obra é um fator de produção considerado primordial por várias abordagens econômicas [73-75]. Essa importância naturalmente também ocorre quando se pretende ampliar a capacidade produtiva de uma fábrica. Da mesma forma como a mão de obra é fundamental para o sucesso de qualquer empresa, também pode ser o principal fator de seu fracasso, caso não seja adequadamente administrada [76]. No caso específico deste trabalho, a administração da mão de obra tem três aspectos principais: qualificação, segurança e quantidade.

Um dos aspectos da qualificação da mão de obra no contexto deste trabalho é sua capacitação. Ou seja, é necessário capacitar a mão de obra para a configuração de produção específica que porventura venha a ser implantada em uma fábrica real de EC tipo placa contendo $\mathrm{LEU} \mathrm{U}_{3} \mathrm{Si}_{2}$-Al. Essa capacitação poderá ocorrer por meio de treinamento para aquisição de conhecimento dos processos, das relações entre os processos, dos requisitos para transporte de produtos intermediários e dos procedimentos de segurança $[46,47]$. $O$ treinamento em segurança deve abranger informações sobre a radiotividade dos produtos intermediários e sobre os riscos de acidentes químicos, físicos e de criticalidade [29,35,45,79]. Todo o conteúdo da capacitação precisa ser previamente preparado, adaptando-o às características particulares da configuração de produção implementada.

Quanto à segurança dos trabalhadores de instalações nucleares, um dos principais itens é a limitação da dose de radiação $[40,44]$. Essa limitação impõe o monitoramento com dosímetros para medir a dose de radiação recebida por esses trabalhadores e impõe também limites de tempo durante os quais o trabalhador 
pode exercer suas atividades. De acordo com a dose recebida, o trabalhador precisa ser afastado de suas funções temporariamente ou definitivamente $[29,40,44]$. No caso de expansão da capacidade produtiva de uma fábrica de combustível nuclear, analogamente ao treinamento citado no parágrafo anterior, os trabalhadores precisam submeter-se aos controles da área de proteção radiológica. Esses controles são definidos segundo a configuração de produção que porventura venha a ser implementada na prática.

No tocante às definições sobre quantidade de mão de obra, estas dependem do fluxo de produção, do número de turnos de trabalho, do arranjo físico e das limitações impostas pelas áreas de segurança contra a criticalidade e de proteção radiológica $[57,64,68]$.

Outro problema relacionado à mão de obra é seu custo. Segue uma lista de alguns dos componentes de custo de mão de obra em uma fábrica de combustível nuclear que experimenta crescimento em sua capacidade produtiva:

- novas contratações;

- necessidade de horas extras;

- treinamentos diversos;

- adequação da ergonomia aos novos fluxos de materiais;

- diferentes práticas de segurança.

Pelo exposto anteriormente, percebe-se que a mão de obra requer um tratamento extenso e complexo. Esses fatos impossibilitaram sua inclusão neste estudo. Por isso, foi adotada a seguinte hipótese: haverá mão de obra suficiente e qualificada para executar todas as configurações de produção geradas ao longo deste trabalho.

\subsubsection{Controle da produção}

A importância da área de Planejamento e Controle da Produção (PCP) pode ser demonstrada por seus objetivos, resumidos a seguir $[46,47,54,63,80]$ :

- Economizar matéria prima;

- Buscar processos produtivos econômicos e seguros;

- Usar eficazmente a fábrica para maximizar a produtividade; 
- Aumentar a eficiência pela coordenação de processos;

- Assegurar a entrega de produtos;

- Alocar o trabalhador correto ao trabalho correto e com remuneração correta;

- Minimizar a rotatividade de trabalhadores;

- Reduzir desperdícios.

O projeto de um sistema de PCP é uma atividade extensa, que vai além do limite deste trabalho. Entretanto, alguns conceitos dessa área foram considerados neste trabalho e enriqueceram suas conclusões. Esse conteúdo está exposto no capítulo 6 .

Com relação à qualidade, deve-se ter em mente que ela precisa ser mantida ou melhorada ao mesmo tempo em que ocorre o aumento de capacidade produtiva, objeto deste trabalho. Isto é, quando aumenta-se a escala de produção, é necessário garantir que [58,65,81]:

- As matérias primas tenham qualidade suficiente;

- Os processos sejam conhecidos e bem executados;

- Haja testes de qualidade durante o processo e não apenas no final;

- Os defeitos sejam corrigidos o quanto antes.

$\mathrm{Na}$ lista acima estão apresentados alguns dos muitos problemas de qualidade que precisam ser levados em conta à medida em que se avança na escala de produção. Dessa maneira, vê-se que a área da qualidade requer um tratamento extenso e complexo. Assim, adota-se a seguinte hipótese: não há problemas de qualidade em matérias primas, nem em produtos intermediários e nem em produtos finais em todos os cenários gerados neste trabalho. Sem a consideração dessa hipótese, não seria possível desenvolver o modelo de expansão proposto mais adiante.

\subsection{SIMULAÇÃO COMPUTACIONAL}

A modelagem matemática de sistemas de manufatura traz muitos benefícios [65,71,72]. Alguns desses benefícios estão listados a seguir.

- Consideração das interações entre partes de um sistema;

- Geração de alternativas para melhoria de desempenho; 
- Geração de informações sobre o balanceamento entre capacidade e demanda;

- Possibilidade de estudo de cenários de mudanças;

- Análise do sistema antes da implementação de mudanças na prática.

Os benefícios listados motivaram a inclusão de simulação neste trabalho. Os modelos de simulação de sistemas complexos são uma aproximação ao sistema real, pois contém abstrações e simplificações da realidade $[61,83,85]$. Além disso, um modelo de simulação deve ser desenvolvido para um determinado conjunto de objetivos. De fato, um modelo válido para um objetivo pode não o ser para outro.

Há várias maneiras matemáticas para modelar sistemas de produção fabril $[92,93]$. Possíveis roteiros para essa modelagem são encontrados na literatura [82,84,86,89-91]. Com base nesses roteiros, foi adaptado e elaborado um guia passo-a-passo para a construção do modelo de simulação usado neste trabalho. Este guia é apresentado na sequência.

Guia para modelagem de simulação

1. Análise do problema e coleta de informações;

2. Coleta de dados;

3. Construção do modelo de simulação;

4. Verificação e validação do modelo;

5. Projeto e execução de experimentos de simulação;

6. Análise dos resultados.

Um tipo comum de simulação em computador é a simulação contínua, a qual acompanha continuamente a dinâmica do sistema ao longo do tempo. Esse tipo de simulação é baseada em atividades, o tempo é dividido em períodos e o estado do sistema é atualizado de acordo com as atividades que ocorrem em cada período.

A Simulação de Eventos Discretos, Discrete Event Simulation (DES) modela a operação de um sistema como uma sequência discreta de eventos no tempo. Cada evento ocorre em um determinado instante no tempo e marca uma mudança de estado no sistema. Assume-se que não há alteração no sistema entre eventos consecutivos. Dessa forma, a simulação passa diretamente no tempo de um evento para outro. Dado que DES não precisa simular a cada período de tempo, 
ela geralmente é executada muito mais rápido do que a simulação contínua correspondente.

Atualmente DES é empregada com sucesso em diferentes áreas da produção de diferentes fábricas, tais como processamento em lotes, processamento contínuo, planejamento da capacidade e sequenciamento de operações (job floor scheduling) [80,94-96]. Esses fatos levaram à escolha de DES para a simulação computacional realizada neste trabalho.

Simulação DES pode ser realizada com diferentes softwares, tais como Simul8, ProModel e AutoMod [97]. Neste trabalho foi usado o software ARENA ${ }^{\circledR}$ da empresa Rockwell Automation [98], pelos seguintes motivos:

- ARENA ${ }^{\circledR}$ é o primeiro da lista das 10 melhores e mais usadas ferramentas de simulação na atualidade [97,99];

- a versão acadêmica do $\operatorname{ARENA}^{\circledR}$ está disponível para alunos da Universidade de São Paulo por meio de seu acordo com a Rockwell Automation sobre licenças de uso desse software. 


\section{METODOLOGIA}

Conforme citado anteriormente, a contribuição deste trabalho se dá pela aplicação de conceitos de administração da produção à expansão de fábricas de EC tipo placa típicos carregados com LEU U USi2-Al. Essa aplicação de conceitos constitui a hipótese que deverá ser testada. Em outras palavras, pretende-se verificar se essa aplicação responde à questão de pesquisa mencionada anteriormente. Portanto, a metodologia geral deste trabalho é a dedutiva, ou seja, aquela que testa a teoria que embasa um estudo [50,100,101]. Entretanto, dentro da metodologia geral há outras duas, como segue.

Conforme mencionado anteriormente, a administração da produção é uma área de conhecimento situada na interface entre as ciências naturais e as sociais $[67,102,103]$. Assim, surge a necessidade de usar tanto a metodologia das ciências naturais, como a das ciências sociais. A metodologia típica das ciências naturais é a quantitativa e a das sociais, a qualitativa. Por isso, neste trabalho estão presentes tanto a metodologia quantitativa, como a qualitativa $[50,102,103]$.

Para a parte de engenharia nuclear será usada a metodologia de levantamento de dados quantitativos e qualitativos, típica das ciências naturais [100]. No tocante à administração da produção, há duas partes como segue [72]:

- o teste do modelo proposto mais adiante enquadra-se na metodologia de estudo de caso e

- a geração dos cenários e a construção de seus respectivos modelos de simulação correspondem à modelagem quantitativa.

A realização deste trabalho se deu pelos seguintes dois grupos de atividades:

1. Proposição de um modelo para expansão da capacidade produtiva de fábricas de EC tipo placa típicos carregados com LEU U ${ }_{3} \mathrm{Si}_{2}-\mathrm{Al}$ e

2. Teste e avaliação do modelo proposto. 


\subsection{PROPOSIÇÃO DE UM MODELO PARA A EXPANSÃO DA CAPACIDADE}

O modelo para expansão da capacidade produtiva de fábricas de EC tipo placa típicos carregados com $\mathrm{LEU} \mathrm{U}_{3} \mathrm{Si}_{2}$-Al apresentado a seguir foi estabelecido por meio de

- adaptações do modelo genérico da seção 3.2.1 e

- considerações provenientes da parte prática deste trabalho, exposta na seção 4.2.

Modelo proposto

1. Definir as estratégias da organização e da produção;

2. Identificar o gargalo;

3. Aumentar a capacidade do gargalo;

4. Se necessário, alterar o arranjo físico;

5. Verificar o risco de criticalidade na nova configuração;

6. Verificar se a demanda está atendida.

O passo 2 do modelo genérico da seção 3.2.1 trata da análise de demanda, produto, materiais e processos. Nota-se que esse passo do modelo genérico não faz parte do modelo proposto. Os motivos para essa exclusão são:

- a demanda tem tratamento próprio no passo 6 do modelo proposto e

- produto, materiais e processos são conhecidos e estão apresentados nas seções de engenharia nuclear e de teste do modelo.

Também se percebe que os passos 6 e 7 do modelo genérico da seção 3.2.1 foram excluídos do modelo proposto, dado que este é um trabalho conceitual. O detalhamento dos passos do modelo proposto consta das seções subsequentes.

\subsection{TESTE E AVALIAÇÃO DO MODELO PROPOSTO}

Uma das partes do teste e da avaliação do modelo proposto foi a simulação por eventos discretos (DES). Como em qualquer simulação em computador, DES precisa de dados. Os dados foram obtidos da fábrica de 
combustível nuclear pertencente ao Instituto de Pesquisas Energéticas e Nucleares, IPEN, que integra a Comissão Nacional de Energia Nuclear, CNEN, e está localizado em São Paulo, SP. Essa fábrica produz EC tipo placa para um reator nuclear de pesquisa, o qual também pertence ao IPEN. A fábrica de combustível nuclear do IPEN produz LEU U ${ }_{3} \mathrm{Si}_{2}$-Al por meio da hidrólise de $\mathrm{UF}_{6}$ e usa esse combustível em seus EC.

O teste seguiu os conceitos da metodologia de estudo de caso citada anteriormente. Para realizar esse teste, o modelo foi aplicado à fábrica de combustível nuclear do IPEN, usando os dados dessa fábrica. A avaliação foi feita mediante a comparação dos resultados da simulação DES detalhada mais adiante.

\subsubsection{Aplicação do modelo proposto à fábrica de combustível nuclear do IPEN}

A época da coleta de dados para este trabalho corresponde ao período de março a novembro de 2014 e foi chamada de situação inicial. A coleta de dados foi feita por meio de consulta à literatura disponível internamente ao IPEN e também presencialmente na fábrica, conforme detalhado em seções subsequentes. Cada passo da aplicação do modelo proposto teve tratamento específico, conforme exposto a seguir.

\subsubsection{Passo 1: Definir as estratégias da organização e da produção}

Conforme mencionado anteriormente, as definições das estratégias da organização e da produção são tarefas da alta gerência. Com relação à fábrica de combustível nuclear do IPEN, foram obtidas informações sobre essas decisões durante a coleta de dados para este trabalho. Essas informações constituem as estratégias da organização e da produção usadas e estão listadas a seguir.

- A instituição produz e consome seu próprio combustível nuclear;

- A instituição não fornece esse combustível a terceiros;

- O único combustível produzido é LEU U $\mathrm{Si}_{2}-\mathrm{Al}$;

- O único produto final é um EC tipo placa típico contendo LEU U $\mathrm{Si}_{2}-\mathrm{Al}$;

- A rota de produção inclui a hidrólise de UF6. 
As estratégias mencionadas são típicas de fábricas de combustível nuclear para reatores de pesquisa [39,45,104]. Ou seja, as características da fábrica do IPEN são comuns a outras fábricas de combustível nuclear para reatores de pesquisa. Esse fato indica que a realização de um estudo de caso sobre a fábrica do IPEN está apropriada aos objetivos do presente trabalho, conforme exposto na revisão bibliográfica, item 3.2.1.1.

As estratégias da organização e da produção fazem parte das condições de contorno, ou seja, considera-se que não serão alteradas no contexto deste trabalho. Assim, essas estratégias correspondem ao cumprimento do passo 1 do modelo proposto.

\subsubsection{Passo 2: Identificar o gargalo}

Uma das condições básicas para a identificação do gargalo é o conhecimento detalhado dos processos. Por esse motivo, este trabalho iniciou-se com o estudo dos processos produtivos da fábrica de combustível nuclear do IPEN. Conforme mencionado, esse estudo foi feito por meio de consulta à documentação disponível internamente ao IPEN e também à literatura científica. A esta consulta, acrescentou-se a referida coleta de dados, a qual foi feita presencialmente por aproximadamente oito meses em todas as áreas e departamentos daquela fábrica. Seguem-se os registros gerados pela coleta de dados:

- todos os processos de fabricação;

- sequenciamento dos processos;

- tempo de execução de cada processo;

- arranjo físico;

- fluxos de materiais, produtos intermediários, pessoas e informações;

- características técnicas dos equipamentos e ferramentas de trabalho;

- procedimentos de trabalho;

- número e formação dos trabalhadores;

- medidas de segurança.

Os dados obtidos, gerados com os registros, têm um volume considerável, motivo pelo qual estão organizados e apresentados nas seções seguintes. 


\subsection{Criticalidade na situação inicial}

O projeto da fábrica de combustível nuclear do IPEN e também o projeto dos processos dessa fábrica datam da década de 1970 e foram fortemente influenciados por medidas de segurança contra criticalidade nuclear. Algumas delas estão descritas a seguir.

O hexafluoreto de urânio de baixo enriquecimento (LEU UF6) é a matéria prima essencial para a fabricação de LEU $\mathrm{U}_{3} \mathrm{Si}_{2}-\mathrm{Al}$. Assim, a própria matéria prima da fábrica já contém material físsil capaz de causar acidentes de criticalidade. Por isso o lote de produção foi definido em $3,0 \mathrm{~kg} \mathrm{UF} 6$, valor consideravelmente inferior à sua massa crítica [21].

Por outro lado, o lote de produção é transformado química e fisicamente em todos os processos da fábrica de combustível nuclear do IPEN. Ou seja, todos os processos lidam com material capaz de causar acidente de criticalidade. Por isso a segurança contra a criticalidade também impõe controle estrito sobre a quantidade equivalente de urânio que transita pela fábrica em seus diversos processos. Como consequência, os processos da fábrica de combustível nuclear do IPEN foram projetados em função do lote de 3,0 kg de UF6. Ou seja, nenhum processo da fábrica de combustível nuclear do IPEN processa mais que a quantidade de urânio equivalente a $3,0 \mathrm{~kg}$ de $\mathrm{UF}_{6}$.

Além disso, a fábrica de combustível nuclear do IPEN é dividida em centros de trabalho (CT), cada um deles responsável pela execução de diversos processos. O modo de operação dessa fábrica impõe que um lote de produção precisa acabar de ser processado por um certo CT e ser enviado ao próximo CT, antes de que outro lote possa ser admitido nesse CT. Dessa forma garante-se a presença de apenas um lote de produção por vez em cada CT. Desse modo, não ocorre a presença de dois lotes de produção ao mesmo tempo no mesmo CT, fato que poderia levar à criticalidade. Esse modo de operação também foi determinado para cumprir com a segurança contra a criticalidade nuclear e é denominado como processamento em lotes, batch processing.

As características de segurança contra a criticalidade da fábrica de combustível nuclear do IPEN levaram à definição de duas partes importantes deste trabalho: 
- o lote de produção considerado é o mesmo da realidade, ou seja, 3,0 kg de $\mathrm{UF}_{6}$;

- o foco é dado ao transcurso desse lote por todos os processos produtivos da fábrica de combustível nuclear do IPEN.

\subsection{Mapeamento de processos e coleta de dados}

Foram usadas as visões macro e micro para aumentar a compreensão dos processos existentes na fábrica de combustível nuclear do IPEN. As duas abordagens foram importantes também para levar em conta os reflexos da segurança contra a criticalidade no modo de operação da fábrica e em seus processos. Por isso o mapeamento de processos e a coleta de dados contém grande quantidade de informações, que ficam mais claramente expostas em seções separadas. É o que se faz a seguir.

\subsection{Visão macro}

Na situação inicial, a fábrica de combustível nuclear do IPEN estava dividida em quatro centros de trabalho (CT), cada um deles responsável pela execução de diversos processos. Entretanto, na visão macro, encara-se cada CT como uma única unidade de processamento, sem considerar seus processos individuais. Na Figura 2 está esquematizada a visão macro da fábrica de combustível nuclear do IPEN em sua situação inicial.

$\mathrm{Na}$ Figura 2 vê-se que a fábrica em questão era constituída por três edifícios, sendo que dois deles abrigavam os CT 1 e 2 respectivamente e o terceiro edifício abrigava os CT 3 e 4 . As linhas tracejadas indicam produtos intermediários e acabados e as linhas coloridas indicam diferentes matérias primas sendo entregues em diferentes CT. A distância entre os edifícios era de aproximadamente 200 metros.

O tempo que um lote de produção necessita para "atravessar" uma estação de trabalho, ou seja, ser transformado por uma certa estação de trabalho, é chamado tempo de atravessamento, mais conhecido como lead time (L). Os lead times dos quatro CT da fábrica de combustível nuclear do IPEN na situação inicial estão expostos na Tabela 2. 
Figura 2 - Esquema da fábrica de combustível nuclear do IPEN

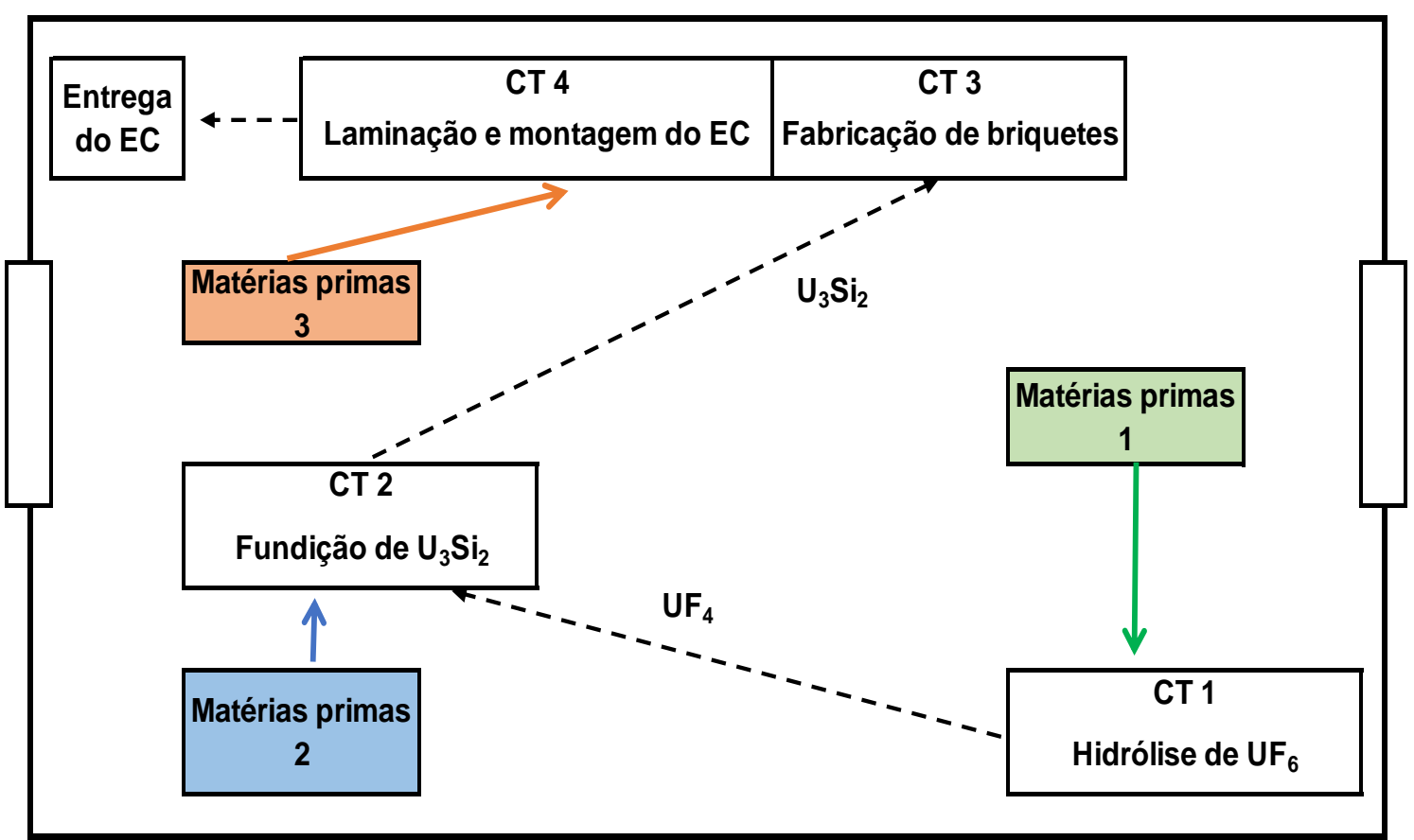

Tabela 2 - Lead times dos centros de trabalho

\begin{tabular}{lrrrrr}
\hline Centro de trabalho $-\mathrm{CT}$ & 1 & 2 & 3 & 4 & Total \\
Lead time $(\mathrm{L})$ em dias & 5,63 & 2,59 & 2,13 & 7,06 & 17,41 \\
\hline
\end{tabular}

Fonte: autor da tese

O CT com maior lead time na Tabela 2 é o CT 4. Esse fato caracteriza esse CT como o gargalo da situação inicial e será retomado mais adiante. Os dados da Tabela 2 permitem obter o ritmo de produção da fábrica em sua situação inicial. Para tanto, esquematiza-se o processamento dos quatro primeiros lotes de produção por meio do gráfico de Gantt da Figura 3. Nessa figura, a cor azul representa o primeiro lote de produção, a amarela, o segundo, a lilás, o terceiro e a verde, o quarto lote. As seguintes hipóteses foram adotadas para o levantamento do gráfico de Gantt da Figura 3:

a. No eixo horizontal consta o tempo de produção em dias úteis;

b. No eixo vertical estão representados os quatro CT da fábrica de combustível nuclear do IPEN; 
c. Há mão de obra capacitada e suficiente para manter a produção em todos os CT no ritmo indicado na Figura 3.

Figura 3 - Gráfico de Gantt

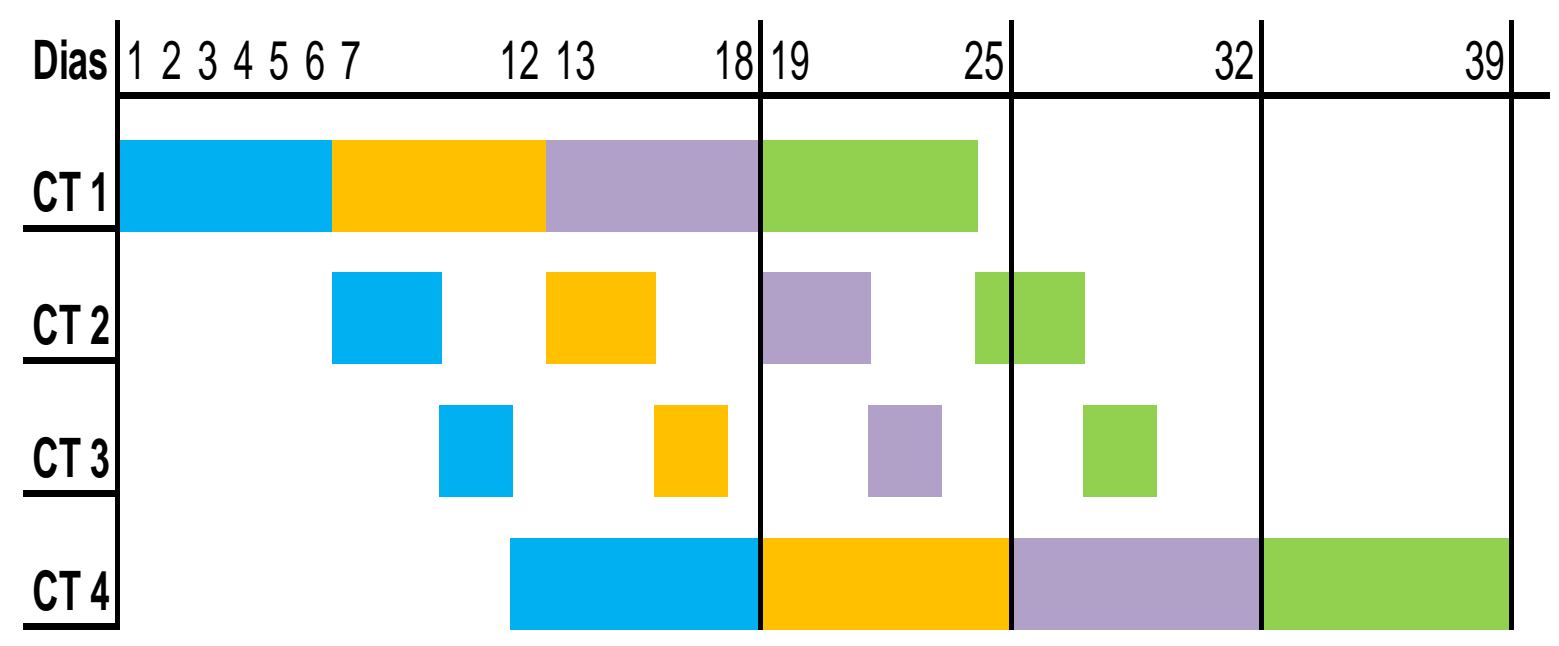

Fonte: autor da tese

Lote 1 - Azul, Lote 2 - Amarelo, Lote 3 - Lilás, Lote 4 - Verde

Pelo gráfico da Figura 3 conclui-se que o gargalo é o CT 4, devido à fila de produtos intermediários que se forma antes desse CT. Ou seja, os demais CT realizam suas tarefas em menos tempo que o CT 4, fato esperado com os dados da Tabela 2. Dessa forma, a velocidade máxima de toda a produção é limitada pelo lead time do CT 4.

A forma de programar a produção correspondente à Figura 3 é chamada de programação para a frente $[61,93,105]$. Uma característica dessa forma de programação é a possível geração de filas. Isto se dá neste caso, pois formam-se filas de produtos intermediários antes do CT 4 . Essa fila de produtos intermediários aumenta o risco de criticalidade, motivo pelo qual deve ser evitada. Uma forma de evitar tais filas é a chamada programação de produção para trás, ilustrada no Gráfico de Gantt da Figura 4.

Na Figura 4 observa-se que não há filas de produtos intermediários. Esse tipo de programação da produção dá-se da seguinte forma: programa-se o primeiro lote até o gargalo e subordina-se a programação dos demais lotes à programação do gargalo $[61,93,105]$. Uma consequência da programação para trás é que mais matéria prima fica no almoxarifado em seu estado inicial. Esse fator é 
importante em uma fábrica de combustível nuclear, pois contribui para a segurança contra a criticalidade.

Figura 4 - Programação "para trás"

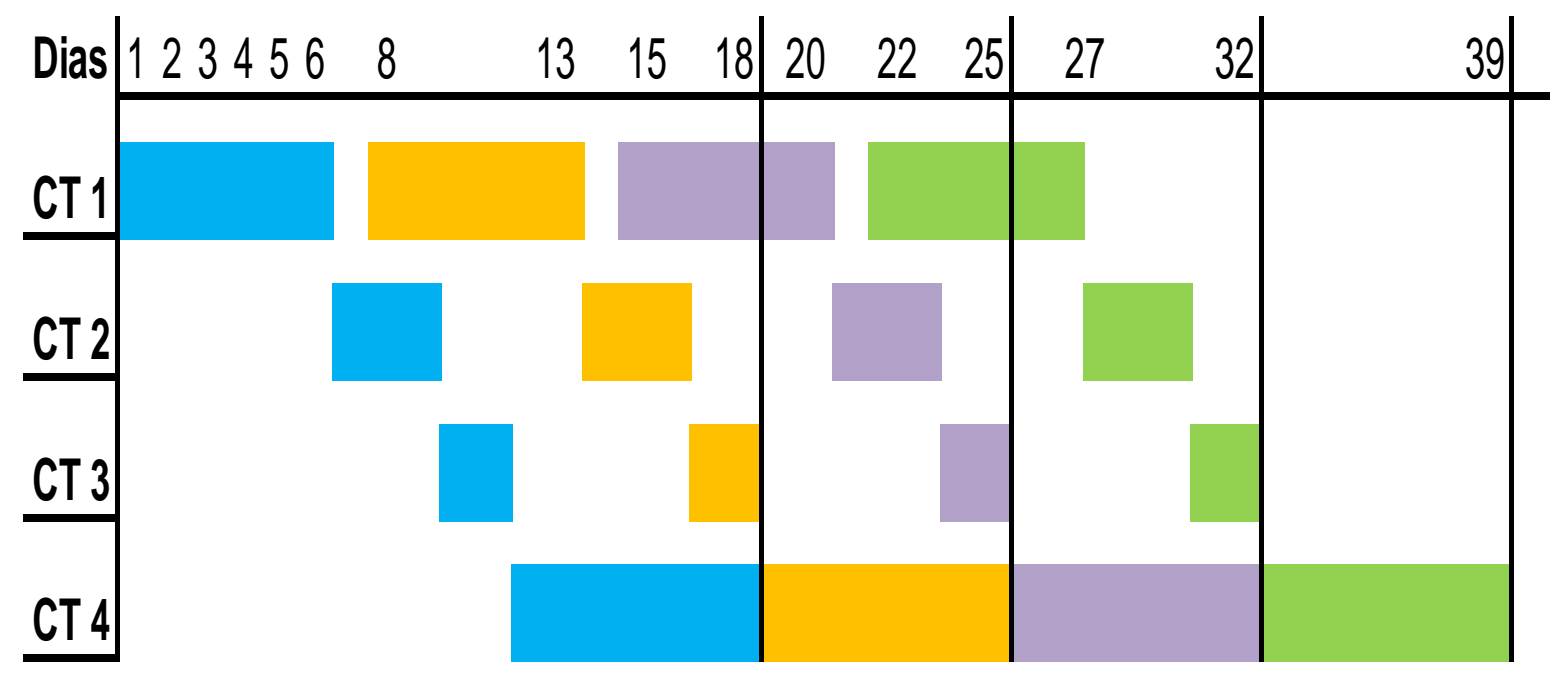

Fonte: autor da tese

Lote 1 - Azul, Lote 2 - Amarelo, Lote 3 - Lilás, Lote 4 - Verde

Nas Figuras 3 e 4 vê-se que o primeiro EC é acabado no $18^{\circ}$ dia de produção, o segundo, no 25 e e assim sucessivamente. Dessa forma, é produzido um EC a cada sete dias úteis. Esse tempo é geralmente denominado tempo de ciclo, (C) $[55,59,69]$. Portanto o tempo de ciclo total dessa fábrica na situação inicial era de 7 dias úteis.

Cabe assinalar que o lote de produção continha matéria-prima suficiente para produzir 24 PC. No entanto, o EC continha apenas 18 PC. Portanto, ao final do processamento de um lote real, eram produzidos um EC e 6 PC. Essas 6 PC sobressalentes eram usadas como estoque de segurança para o processo produtivo.

Os gráficos das Figuras 3 e 4 também permitem estimar a produção anual. Para tanto, eles foram estendidos pelo período total de um ano, otendo-se 28 EC produzidos. Esse resultado se deve ao fato de que a produção só entra em regime contínuo após o 18ํㅡㄹa útil do ano. 


\subsection{Visão micro}

Nesta visão, considera-se cada processo individualmente. Como citado, em cada CT são executados diversos processos produtivos. Nas Tabelas 3, 4, 5 e 6 estão apresentados alguns dados coletados na situação inicial, correspondendo aos respectivos processos. Nessas tabelas estão expostas as atividades executadas em cada CT, os tempos de cada processo e a numeração em ordem ascendente de execução, ou seja, seu sequenciamento.

Tabela 3 - Processos do CT 1

\begin{tabular}{llr}
\hline Nr. & Processos & Lead time \\
\hline 1 & Recebimento do cilindro contendo UF & \\
2 & Preparação para a transferência de UF 6 & 0,80 \\
3 & Transferência de UF6 do cilindro para a ampola & 2,45 \\
4 & Preparação para a hidrólise do UF6 na ampola $_{6}$ & 3,66 \\
5 & Hidrólise do UF6 contido na ampola & 2,54 \\
6 & Preparação para a precipitação do UF 4 & 3,74 \\
7 & Precipitação do UF 4 & 1,70 \\
8 & Lavagem e filtragem do UF 4 & 4,28 \\
9 & Secagem do UF4 & 1,83 \\
10 & Desidratação do UF & 17,50 \\
& Lead time total em horas & 6,50 \\
& Lead time total em dias & 45,00 \\
\hline
\end{tabular}

Fonte: autor da tese

Os dados das Tabelas 3 a 6 refletem o fluxo real de materiais e produtos intermediários pelo chão da fábrica, pois foram coletados e medidos presencialmente durante sua execução em seus respectivos centros de trabalho, com seus respectivos equipamentos, operadores e procedimentos.

É importante ressaltar que o sequenciamento de processos apresentado nas Tabelas 3, 4, 5 e 6 corresponde ao Caminho Crítico da produção do EC em questão. Isto é, cada operação dessas tabelas depende da operação anterior para ser executada, conforme consta também na literatura $[21,46,106,107]$. Este fato é relevante para possíveis alterações de arranjo físico que se façam necessárias em 
alguns cenários de produção gerados neste trabalho. Por esse motivo, assume-se a hipótese de que o sequenciamento de processos das Tabelas 3 a 6 não será alterado, seja qual for a mudança sugerida pelos cenários expostos mais adiante.

Tabela 4 - Processos do CT 2

\begin{tabular}{|c|c|c|}
\hline $\mathrm{Nr}$. & Processos & horas) \\
\hline 11 & Montagem do cadinho com a mistura UF-Mg & 2,35 \\
\hline 12 & Redução do UF4 a urânio metálico & 7,28 \\
\hline 13 & Desmontagem do cadinho e medição da densidade hidrostática & 0,84 \\
\hline 14 & Decapagem do urânio metálico & 0,56 \\
\hline 15 & Montagem do cadinho com urânio metálico e silício & 1,18 \\
\hline 16 & Fusão e refino da liga intermetálica $\mathrm{U}_{3} \mathrm{Si}_{2}$ & 8,20 \\
\hline \multirow[t]{3}{*}{17} & Medição da densidade hidrostática do tarugo de $\mathrm{U}_{3} \mathrm{Si}_{2}$ & 0,34 \\
\hline & Lead time total em horas & 20,75 \\
\hline & Lead time total em dias & 2,59 \\
\hline
\end{tabular}

Fonte: autor da tese

Tabela 5 - Processos do CT 3

\begin{tabular}{llr}
\hline Nr. & Processos & Lead time \\
\hline 18 & Moagem e classificação do pó de $\mathrm{U}_{3} \mathrm{Si}_{2}$ & 1,87 \\
19 & Homogeneização do pó de $\mathrm{U}_{3} \mathrm{Si}_{2}$ com pó de Al & 6,28 \\
20 & Prensagem da mistura $\mathrm{U}_{3} \mathrm{Si}_{2}$ e Al & 2,40 \\
21 & Controle dimensional dos briquetes & 2,76 \\
22 & Desgaseificação dos briquetes & 3,69 \\
& Lead time total em horas & 17,00 \\
& Lead time total em dias & 2,13 \\
\hline
\end{tabular}

Fonte: autor da tese

As unidades de tempo usadas nas Tabelas 3 a 6 são horas de trabalho e dias úteis, com oito horas de trabalho em cada dia. Na Tabela 3 estão apresentados dados coletados no CT 1. A hidrólise de UF 6 é feita nesse setor, fato que o torna particularmente vulnerável à criticalidade, devido à água usada nesse processo. Este fato requer cuidados especiais, caso seja necessário mudar o 
arranjo físico desse setor. O produto final do CT 1 é UF 4 na forma de pó, que é um dos produtos intermediários da fábrica de combustível nuclear do IPEN, pois é enviado ao CT 2 para o prosseguimento de seu processamento.

$\mathrm{Na}$ Tabela 4 estão apresentados dados coletados no CT 2. O produto final desse CT é o tarugo da liga intermetálica de $\mathrm{U}_{3} \mathrm{Si}_{2}$. Esse é outro produto intermediário na situação inicial, pois é enviado ao CT 3 para o prosseguimento de seu processamento. Na Tabela 5 estão apresentados dados coletados no CT 3 , cujo produto final é o briquete de $\mathrm{U}_{3} \mathrm{Si}_{2}-\mathrm{Al}$.

Tabela 6 - Processos do CT 4

\begin{tabular}{llr}
\hline Nr. & Processos & Lead time \\
\hline 23 & Recebimento das $)$ \\
24 & Preparação das placas de revestimento e de moldura & 1,67 \\
25 & Decapagem dos revestimentos e das molduras & 3,28 \\
26 & Montagem do conjunto & 4,55 \\
27 & Soldagem do conjunto & 1,12 \\
28 & Laminação a quente e recozimento & 1,50 \\
29 & Inspeção para blister & 8,83 \\
30 & Laminação a frio & 0,54 \\
31 & Pré-corte & 1,08 \\
32 & Quatro processos em PC & 3,43 \\
33 & Corte final & 8,37 \\
34 & Caldeamento & 2,86 \\
35 & Controle dimensional e segunda radiografia de PC & 2,21 \\
36 & Teste de esfregaço & 3,89 \\
37 & Decapagem das placas e componentes do EC & 1,67 \\
38 & Montagem do EC & 6,33 \\
39 & Controle de qualidade & 6,82 \\
40 & Fixação do bocal & 3,37 \\
41 & Fixação do pino de manipulação & 1,06 \\
42 & Controle dimensional do EC & 0,86 \\
43 & Limpeza e embalagem do EC & 0,96 \\
44 & Entrega do EC & 1,12 \\
& Lead time total em horas & 0,48 \\
& Lead time total em dias & 56,50 \\
\hline & & 7,06 \\
\hline
\end{tabular}

Fonte: autor da tese 
Na Tabela 6 estão apresentados dados coletados no CT 4. O produto final desse CT é o EC acabado, que é o produto final da fábrica, como mencionado. No CT 4 são recebidos diversos materiais e produtos intermediários, como se segue:

- Briquetes de LEU U $\mathrm{Si}_{2}-\mathrm{Al}$ do CT 3;

- Placas de alumínio de fornecedores externos;

- Componentes estruturais do EC também de fornecedores externos.

O "conjunto" mencionado na Tabela 6 é composto pela junção de um briquete de $\mathrm{U}_{3} \mathrm{Si}_{2}-\mathrm{Al}$, uma moldura em alumínio e duas placas de revestimento, também em alumínio. Ainda na Tabela 6 , o processo número 32 é chamado de "quatro processos em PC" pois abrange os processos de primeira radiografia das PC, inspeção para identificação de blisters nas PC, marcação das PC e identificação das PC. Cada um desses quatro processos ocorre imediatamente após a conclusão do anterior e todos eles são realizados na mesma estação de trabalho. Essas características indicam ser pouco provável que esses quatro processos venham a ser executados separadamente, mesmo com mudanças no arranjo físico da fábrica. Por esses motivos, esses quatro processos foram agrupados em apenas um, conforme exposto na Tabela 6.

Finalmente, cabe ressaltar que os processos 23, 24 e 25 da Tabela 6 são os únicos que não pertencem ao Caminho Crítico de Produção em toda a fábrica. Esses processos são executados simultaneamente aos processos do CT 3. Assim, seus tempos não foram considerados na simulação, ou seja, o lead time do CT 4 apresentado na Tabela 6 não inclui os tempos desses três processos.

\subsection{Identificação do gargalo}

Os dados coletados, organizados e apresentados nas seções anteriores são suficientes para identificar o gargalo, tarefa que foi executada por meio de duas estratégias diferentes e expostas mais adiante. Esses fatos asseguram 0 cumprimento do passo 2 do modelo proposto.

Por outro lado, para cada uma das duas estratégias para identificação do gargalo foi desenvolvida uma maneira diferente para aumentar a sua capacidade, que é o próximo passo do modelo proposto. As duas estratégias 
citadas são mais facilmente compreendidas, se apresentadas em conjunto com suas respectivas maneiras de aumentar a capacidade do gargalo. É o que se faz nas próximas seções.

\subsubsection{Passo 3: Aumentar a capacidade do gargalo}

Uma técnica frequente para identificar o gargalo é buscar o processo de maior tempo de execução e de maior custo dentre todos os processos de uma cadeia produtiva $[59,63,68,69]$. Por essa técnica, o gargalo da fábrica de combustível nuclear do IPEN em sua situação inicial é o processo de maior tempo de execução entre todos os processos de toda a fábrica, descritos nas Tabela 3 até 6. Esse tempo corresponde ao processo número 9 do CT 1, secagem de $\mathrm{UF}_{4}$, mencionado na Tabela 3. Porém, esse gargalo demonstra-se inadequado, conforme exposto a seguir.

De acordo com a visão macro exposta na Tabela 2, o lead time do CT 1 é menor que o lead time do CT 4. Ou seja, o CT 1 é menos crítico que o CT 4. Assim, a definição do gargalo como qualquer processo do CT 1 e sua respectiva ampliação acarretam as seguintes consequências:

- Custo para aquisição de equipamento para o aumento da capacidade desse gargalo;

- Aumento da fila de produtos intermediários na entrada do CT 4;

- Não há aumento da produção anual da fábrica.

Pelo exposto acima, nota-se que é inadequado identificar o gargalo como qualquer processo do CT 1 na situação inicial da fábrica de combustível nuclear do IPEN. Ainda de acordo com a visão macro exposta na Tabela 2, o gargalo é o CT 4, pois é o CT com o maior lead time naquela tabela. Este fato motivou a busca por outras estratégias para identificação do gargalo e para ampliação de sua capacidade, conforme consta das seções a seguir.

\subsection{Estratégia tradicional}

Esta estratégia aproxima-se das técnicas encontradas na literatura e por isso foi nomeada como tradicional. Nesta estratégia agrega-se a visão macro à 
visão micro e preconizam-se dois passos para a identificação do gargalo, como se segue:

A. Buscar o CT com o maior tempo de processamento, isto é, identificar o gargalo pela visão macro, e

B. Buscar o processo com maior tempo de processamento dentro do CT definido no passo $A$, conforme a visão micro.

De acordo com esta estratégia, deve-se identificar o gargalo dentro do CT 4. Esse é o processo 28, Laminação a quente e recozimento, da Tabela 6. Assim, cumpre-se o passo 2 do modelo proposto pela estratégia tradicional.

Quanto ao aumento da capacidade do gargalo, admite-se que a metodologia tradicional duplique essa capacidade. Esse aumento de capacidade geralmente é feito por meio da aquisição de novos equipamentos $[64,69]$. Os detalhes sobre como essa capacidade é expandida não são abordados, porque vão além do escopo deste trabalho. Considera-se que dobrar a capacidade do gargalo tenha dois efeitos:

- O processo do gargalo passa a ser executado em metade do tempo, e

- O tempo de processamento total é diminuído.

Assim, a estratégia tradicional é uma maneira de realizar também o passo 3 do modelo proposto

\subsection{Estratégia da divisão}

Os resultados da estratégia tradicional mostraram-se insatisfatórios perante a realidade da fábrica de combustível nuclear do IPEN, observada durante a coleta de dados. Esses fatos motivaram a elaboração de uma outra estratégia, que foi chamada estratégia da divisão. Esse nome lhe foi dado, pois esta determina que o aumento da capacidade do gargalo se dê pela divisão de um CT.

A estratégia da divisão baseia-se na visão macro, isto é, a definição do gargalo é feita pela busca do CT com maior lead time em uma dada configuração de produção. Para a situação inicial da fábrica, a estratégia da divisão identifica o gargalo como o CT com maior valor de lead time na Tabela 2, ou seja, o CT 4. Dessa forma está cumprido o passo 2 do modelo proposto pela estratégia da divisão. 
Esta estratégia prevê que a capacidade do gargalo seja aumentada por meio da divisão do CT identificado como gargalo. A divisão de um CT é possível porque em cada CT são realizados vários processos produtivos, os quais podem ser executados separadamente. Seguem os critérios adotados para a divisão dos CT pela estratégia da divisão:

- Buscar o equilíbrio entre as somas dos lead times dos CT resultantes;

- Manter agrupados processos que usem os mesmos equipamentos e

- Manter o sequenciamento dos processos.

O equilíbrio entre os lead times totais dos novos CT corresponde ao fator de aumento da capacidade do CT original, definido como gargalo. Assim, quanto melhor esse equilíbrio, maior será o aumento da capacidade do gargalo segundo esta estratégia.

Assume-se a hipótese que os CT resultantes da divisão sejam seguros contra a criticalidade, conforme mencionado na seção 3.1.3. Dessa forma pode ser processado um lote de produção em um dos novos CT ao mesmo tempo em que outro lote pode ser processo no outro CT resultante da divisão do CT original.

É importante ressaltar que na estratégia da divisão não há alteração de processos individuais. Por isso, a soma dos lead times dos novos CT é igual ao lead time do CT que os originou. Da mesma forma, o lead time total da fábrica é sempre o mesmo. No caso da fábrica de combustível nuclear do IPEN o lead time total é de 17,41 dias úteis, conforme consta na Tabela 2. Assim, a estratégia da divisão é outra maneira de cumprir também o passo 3 do modelo proposto.

\subsubsection{Passo 4: Se necessário, alterar o arranjo físico}

O aumento da capacidade do gargalo determinado na seção anterior pode impor mudanças no fluxo de materiais pela fábrica e em seu arranjo físico. Para tanto, é necessário conhecer em detalhes o aumento de capacidade proposto. Alguns desses detalhes referem-se ao tipo de aumento de capacidade efetuado. Isto é, a capacidade do gargalo foi conseguida por meio de:

- novo equipamento ou

- aumento de capacidade do equipamento anterior ou

- mudança no processo ou 
- aumento de turnos de trabalho ou

- horas extras ou

- uma combinação desses fatores.

Todos esses detalhes precisam ser conhecidos na implementação prática do modelo proposto. Além disso, também precisa ser conhecida com profundidade a relação entre cada fator relacionado ao aumento de capacidade, bem como seus impactos no fluxo de materiais intermediários e matérias primas. Por sua vez, esses impactos determinarão se será ou não necessário alterar o arranjo físico.

As atividades descritas no parágrafo anterior são bastante extensas, fato que levou à adoção da seguinte hipótese neste trabalho: considera-se que todas as configurações de produção geradas têm fluxos de materiais equilibrados e arranjos físicos adequados. Assim, assume-se cumprido o passo 4 do modelo proposto.

\subsubsection{Passo 5: Verificar o risco de criticalidade na nova configuração}

A situação inicial da fábrica de combustível nuclear do IPEN é sub-critica e provê segurança contra a criticalidade por meio de vários fatores citados anteriormente. Entretanto, essa segurança pode ser perdida devido às mudanças nos fluxos de materiais e no eventual novo arranjo físico, ocorridos após o aumento de capacidade. Por isso, essas mudanças necessitam ser estudadas pela equipe de segurança nuclear, antes de serem implementadas na prática, para garantir que o sistema continue sub-crítico, conforme previsto pelas normas [44,45]. Pode-se tomar como parâmetro a distância de 2 metros entre novos cenros de trabalho. Essa distância é segura contra a criticalidade, conforme consta de relatórios técnicos do Centro de Engenharia Nuclear do IPEN [108]. Assim, assume-se que toda e qualquer configuração de produção gerada neste estudo será sub-crítica [79]. Assim, cumpre-se o passo 5 do modelo proposto.

\subsubsection{Passo 6: Verificar se a demanda está atendida}

A idéia que embasa o passo 6 é a seguinte: A ampliação da capacidade do gargalo acarreta o aumento da capacidade de toda a fábrica, levando a um nível 
de produção mais elevado. Se esse novo nível atender à demanda, a ampliação de capacidade produtiva já terá sido suficiente. Caso contrário, é necesário aumentar a capacidade novamente. Isto é feito repetindo-se a aplicação do modelo proposto, voltando ao passo 2. Não se retomou o modelo pelo passo 1 porque não são consideradas quaisquer alterações no passo 1 , como mencionado anteriomente.

Por outro lado, não foi estabelecido um limite para a demanda, pois deseja-se testar a eficácia do modelo proposto em diferentes esquemas de produção. Desta forma, a demanda pode ser tão alta quanto a produção prevista, para fins deste trabalho. Assim, está satisfeito o passo 6 do modelo proposto.

\subsubsection{Cenários}

A metodologia empregada nesta seção é conhecida como modelagem quantitativa [50]. Neste trabalho denominou-se cenário a uma determinada configuração de produção. A configuração de produção da fábrica de combustível nuclear do IPEN em sua situação inicial, descrita nas seções anteriores, foi chamada de cenário 1. O aumento da capacidade do gargalo, o novo fluxo de materiais dele decorrente, o eventual novo arranjo físico e o novo nível de produção caracterizam uma nova configuração de produção, ou seja, um novo cenário. Neste trabalho considera-se que a principal alteração entre um cenário e seu subsequente seja o aumento da capacidade do gargalo. A numeração dos cenários é ascendente. Assim, cenários de números elevados correspondem às configurações de produção com capacidade produtiva maior que cenários de números mais baixos. Na Tabela 7 estão apresentadas as hipóteses válidas para todos os cenários.

Foi necessário adotar as hipóteses de 2, 3 e 4 da Tabela 7 por falta de dados referentes à qualidade e à mão de obra. As hipóteses 1, 5 e 6 foram adotadas como condições de contorno adicionais às estratégias da organização e da produção, apresentadas anteriormente.

Os procedimentos adotados para cada cenário foram:

1. parte-se de um cenário do qual são conhecidos o gargalo e a produção anual;

2. aumenta-se a capacidade do gargalo; 
3. o aumento de capacidade configura o próximo cenário;

4. aplica-se a simulação DES com o gargalo ampliado;

5. toma-se o valor da produção anual retornado pela DES;

6. retorna-se ao passo 1 com os dados gerados nos passos 3 e 5 .

Tabela 7 - Hipóteses adotadas para todos os cenários

\begin{tabular}{cl}
\hline Nr. & \multicolumn{1}{c}{ Hipótese } \\
\hline 1 & O fornecimento de UF6 é continuo e suficiente; \\
2 & A qualidade do UF 6 é suficiente para acionar todos os processos; \\
3 & Não há perdas devido à qualidade em toda a fábrica; \\
4 & $\begin{array}{l}\text { A mão de obra é suficiente e está treinada para executar todos os } \\
\text { processos; }\end{array}$ \\
5 & $\begin{array}{l}\text { O tempo de produção é de } 210 \text { dias úteis ao ano, ou seja, } \\
6\end{array}$ \\
\hline
\end{tabular}

Fonte: autor da tese

Os procedimentos de 1 a 6 foram repetidos conforme exposto mais adiante. Na Figura 5 ilustra-se a dinâmica das repetições desses procedimentos. Os procedimentos de 1 a 6 foram repetidos 15 vezes para a estratégia tradicional e 7 vezes para a estratégia da divisão. Em outras palavras, foram gerados 15 cenários para a estratégia tradicional e 7 para a estratégia da divisão. Ambas as estratégias partem do cenário 1 . Assim, tem-se:

a) Cenários da estratégia tradicional

Conforme mencionado, esta estratégia reduz pela metade o tempo de processo do gargalo. Esse novo tempo é então atribuído ao gargalo, fato que gera o próximo cenário. Dessa forma, o cenário 2 inclui a ampliação do gargalo do cenário 1 , o cenário 3 inclui a ampliação do gargalo do cenário 2 e assim sucessivamente. A repetição da aplicação desta estratégia foi interrompida no cenário 16, pois seu aumento produção de um cenário para o próximo é menor que o da estratégia da divisão, conforme exposto na seção de resultados. Dessa forma os números dos cenários da estratégia tradicional vão de 2 até 16 . 
Figura 5 - Dinâmica de geração e simulação dos cenários

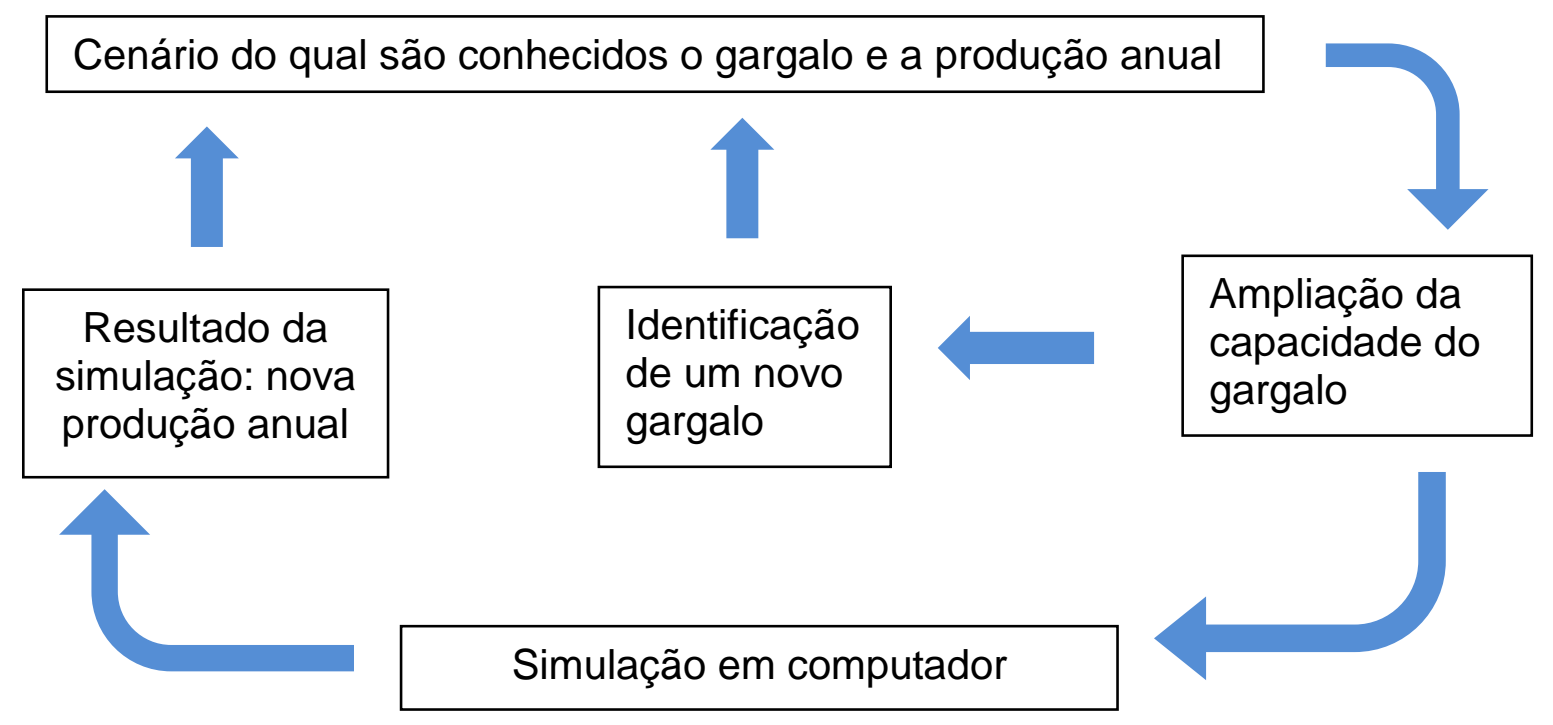

Fonte: autor da tese

b) Cenários da estratégia da divisão

Conforme mencionado, esta estratégia divide o CT considerado como gargalo. A divisão desse CT aumenta sua capacidade, fato que gera o próximo cenário. Foi mantida a numeração ascendente dos cenários para facilitar sua identificação. Dessa forma, o cenário 17 incorpora a ampliação da capacidade do gargalo do cenário 1 , conforme previsto pela estratégia da divisão. O cenário 18 inclui a ampliação do gargalo do cenário 17 e assim sucessivamente. A repetição da aplicação da estratégia da divisão foi interrompida no cenário 23, pois a melhor maneira de ampliar a capacidade do gargalo desse cenário é fazê-lo em um processo isolado. Mas alterar um único processo diverge da estratégia da divisão, fato que motivou sua conclusão. Dessa forma os números dos cenários da estratégia da divisão vão de 17 até 23.

\subsubsection{Simulação}

Na seção 3.3 está apresentado o guia para modelagem de simulação usado neste trabalho. A elaboração dos passos 1 e 2 desse guia foi feita $e$ 
apresentada nas seções anteriores. O passo 3 desse guia está exposto na seção a seguir.

\subsubsection{Construção do modelo de simulação}

Os fluxogramas são representações visuais das etapas de um processo ou sistema e os explicam com bastante clareza por meio de símbolos e texto $[83,85,109]$. Por isso, eles permitem entender rapidamente a essência dos fluxos de processos e sistemas e servem de base para a programação de algoritmos em computador. Desse modo, é interessante dispor-se de fluxogramas dos cenários, antes de iniciar a simulação. As definições da maneira de elaborar fluxogramas e de seus elementos constituintes encontram-se na literatura $[83,85]$. Como exemplo, apresenta-se a Figura 6, onde consta o fluxograma para os cenários de 1 até 16.

O fluxograma da Figura 6 baseia-se na visão macro da fábrica de combustível nuclear do IPEN em sua situação inicial. Os blocos de espera à direita do fluxograma indicam a realidade observada durante a coleta de dados. Ou seja, um lote de produção não entra em um CT qualquer, caso esse CT esteja processando o lote de produção anterior, devido à segurança contra a criticalidade. O fluxograma da Figura 6 corresponde ao cenário 1 e serviu de base para a elaboração do modelo de simulação desse mesmo cenário em ARENA $^{\circledR}$, o qual está exposto na Figura 7.

Analogamente ao cenário 1, os fluxogramas correspondentes ao demais cenários formaram a base sobre a qual foram construídos os respectivos modelos de simulação em $A R E N A^{\circledR}$. A construção dos fluxogramas para os cenários posteriores ao cenário 1 sofreu variações conforme a estratégia de identificação do gargalo e de aumento de sua capacidade. Essas variações estão tratadas no Capítulo 5, bem como os passos 4, 5 e 6 do guia para modelagem de simulação.

Cabe ressaltar que tratam-se de modelos para sistemas híbridos, isto é, sistemas que resultam da combinação de um software com um sistema contínuo. Neste caso o software é o ARENA ${ }^{\circledR}$ e o sistema contínuo a ser modelado é a fábrica de combustível nuclear do IPEN. 
Figura 6 - Fluxograma para os cenários de 1 até 16

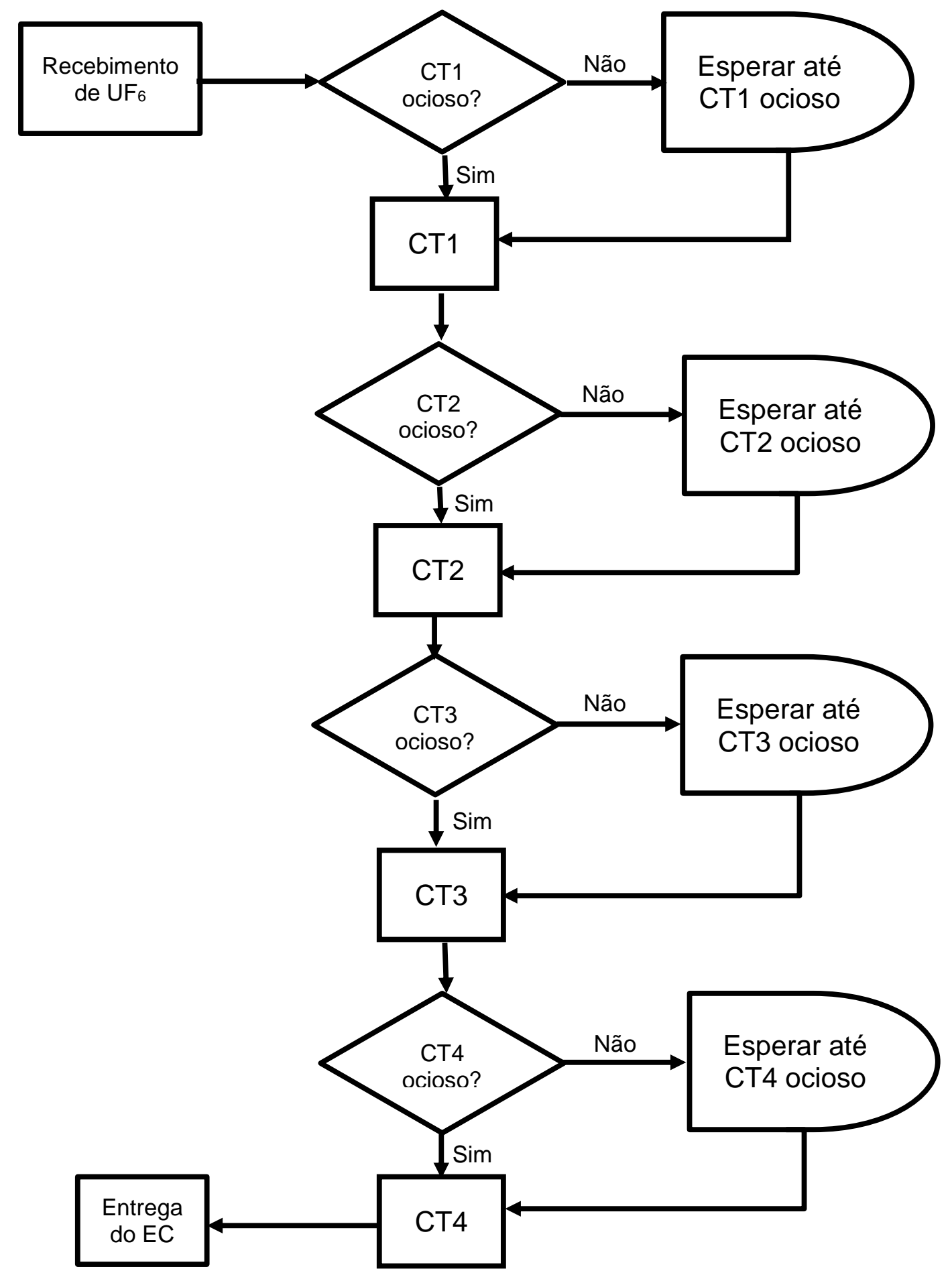

Fonte: autor da tese 
Na Figura 7 está apresentado o modelo em ARENA ${ }^{\circledR}$ correspondente ao fluxograma da Figura 6. Esse modelo foi usado para simulações DES dos dados dos cenários de 1 até 16 . A única diferença de um cenário para outro foi a alteração do parâmetro lead time no respectivo modelo em ARENA ${ }^{\circledR}$.

Os valores dos tempos apresentados nas Tabelas de 3 até 6 tiveram seus respectivos desvios-padrão inseridos nos modelos correspondentes em ARENA $^{\circledR}$. Para os modelos em ARENA ${ }^{\circledR}$ admitiu-se que os tempos em questão variam conforme distribuições normais.

Figura 7 - Modelo em ARENA® para os cenários de 1 até 16
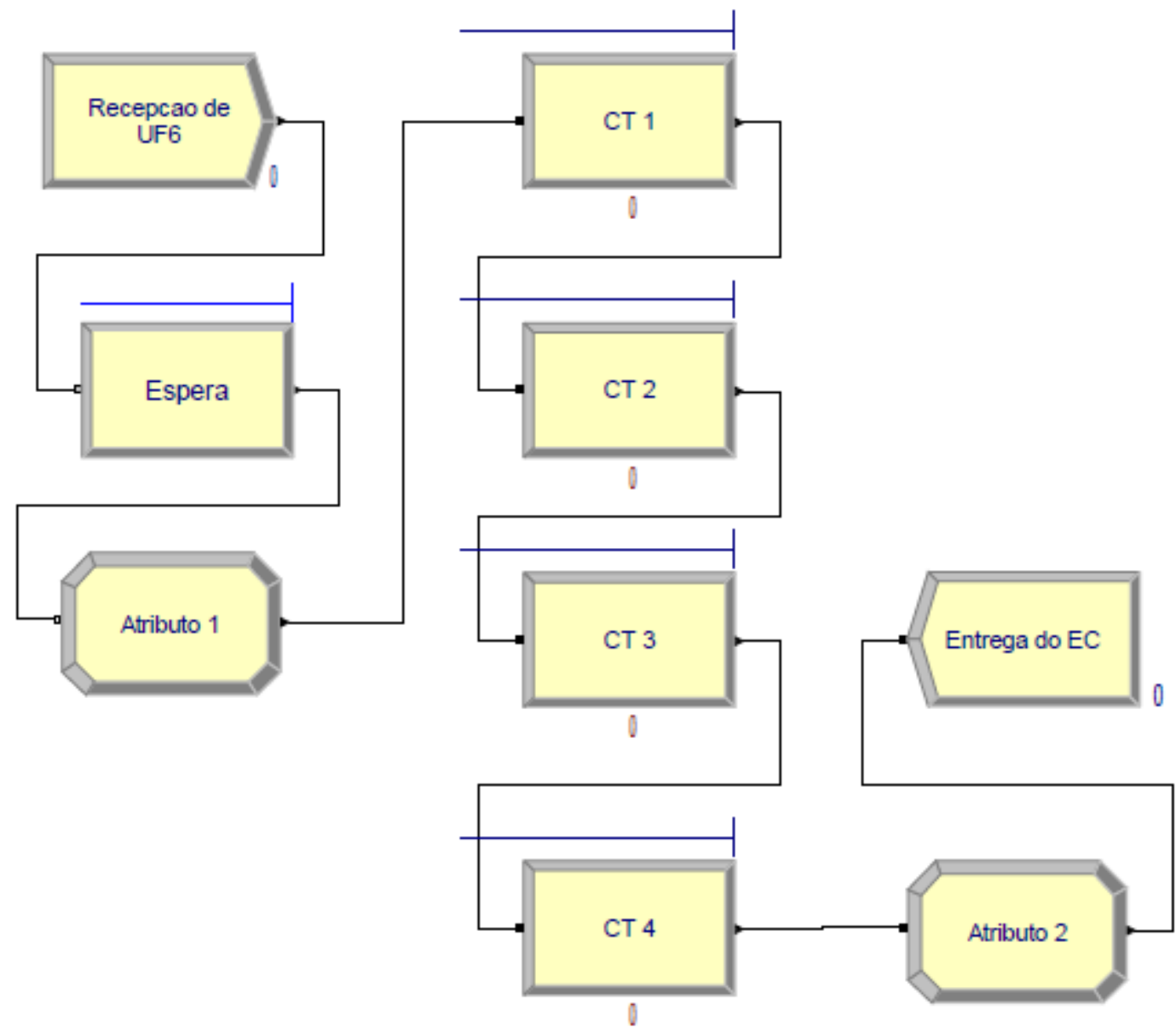


\section{RESULTADOS}

Nesta seção são apresentados os resultados do teste do modelo proposto para ampliação da capacidade produtiva. Primeiramente são expostos os resultados da aplicação do modelo, isto é, como se deu a expansão da capacidade por meio de ambas as estratégias propostas. Em seguida são mostrados os resultados fornecidos pela DES no software ARENA ${ }^{\circledR}$.

\subsection{RESULTADOS DA APLICAÇÃO DO MODELO}

\subsubsection{Estratégia tradicional}

Esta estratégia reduz pela metade o tempo de processamento do gargalo. Essa redução acarreta diminuição do lead time do CT onde está localizado o gargalo e também no lead time total da fábrica. Essa contração foi incorporada no cenário subsequente e constituiu sua caracterização. A cada nova redução de lead time, obteve-se um cenário novo. Os valores resultantes da aplicação desse procedimento estão apresentados na Tabela 8.

$\mathrm{Na}$ Tabela 8 fica clara uma característica marcante da estratégia tradicional, que é a manutenção de todos os quatro CT em número igual ao que havia na situação original, ou seja, quatro CT. Sabe-se que, nesta estratégia, apenas o processo individual do gargalo é alterado. Dado que todos os processos ocorrem dentro de algum CT, então o aumento de capacidade de um dado processo não altera o $\mathrm{CT}$, onde esse processo é executado. Por isso, na estratégia tradicional a quantidade de $\mathrm{CT}$ não muda e as diferenças de um cenário para o próximo são a redução do lead time do CT-gargalo e do lead time total da fábrica. 
Tabela 8 - Lead times segundo a estratégia tradicional

\begin{tabular}{crrrrr}
\hline Cenário & CT 1 & CT 2 & \multicolumn{1}{c}{ CT 3 } & CT 4 & $\begin{array}{c}\text { Toda a } \\
\text { fábrica }\end{array}$ \\
\hline 1 & 5,63 & 2,59 & 2,13 & 7,06 & 17,41 \\
2 & 5,63 & 2,59 & 2,13 & 6,51 & 16,86 \\
3 & 5,63 & 2,59 & 2,13 & 5,99 & 16,34 \\
4 & 5,63 & 2,59 & 2,13 & 5,56 & 15,91 \\
5 & 4,53 & 2,59 & 2,13 & 5,56 & 14,81 \\
6 & 4,53 & 2,59 & 2,13 & 5,17 & 14,42 \\
7 & 4,53 & 2,59 & 2,13 & 4,89 & 14,14 \\
8 & 4,53 & 2,59 & 2,13 & 4,62 & 13,87 \\
9 & 4,53 & 2,59 & 2,13 & 4,38 & 13,63 \\
10 & 3,98 & 2,59 & 2,13 & 4,38 & 13,08 \\
11 & 3,98 & 2,59 & 2,13 & 4,17 & 12,87 \\
12 & 3,98 & 2,59 & 2,13 & 3,95 & 12,65 \\
13 & 3,58 & 2,59 & 2,13 & 3,95 & 12,25 \\
14 & 3,58 & 2,59 & 2,13 & 3,74 & 12,04 \\
15 & 3,58 & 2,59 & 2,13 & 3,54 & 11,84 \\
16 & 3,30 & 2,59 & 2,13 & 3,54 & 11,56 \\
\hline
\end{tabular}

Valores dos lead times em dias úties

Fonte: autor da tese

Desse modo, bastou um fluxograma e um modelo em ARENA ${ }^{\circledR}$ para simular os cenários de 1 até 16 . O fluxograma em questão está apresentado na Figura 6. O modelo em ARENA ${ }^{\circledR}$ contem os 4 CT e os diferentes valores dos lead times dos CT são atribuídos como variação de parâmetro nesse modelo. Detalhes dos fluxogramas de todos os cenários e seus respectivos modelos em ARENA ${ }^{\circledR}$ estão expostos no Apêndice $A$. 


\subsubsection{Estratégia da divisão}

A estratégia da divisão aumenta a capacidade do CT gargalo por meio de seu desmembramento, de forma que passam a existir dois CT, onde antes existia apenas um. Dessa maneira, a diferença principal de um cenário para o próximo é o acréscimo de um CT. Uma característica importante da estratégia da divisão é que todos os cenários têm o mesmo lead time, pois não há alterações em processos individuais. Por conseguinte, a soma dos lead time de todos os CT é a mesma em todos os cenários desta estratégia e resulta em 17,41 dias úteis. Esses fatos geraram os dados que estão apresentados na Tabela 9.

A construção dos fluxogramas e dos respectivos modelos de simulação para os cenários desta estratégia deve refletir o aumento do número de $\mathrm{CT}$. Esse aumento está exposto no Apêndice A, onde consta o detalhamento dos fluxogramas de todos os cenários e seus respectivos modelos em ARENA ${ }^{\circledR}$. 
Tabela 9 - Dados dos cenários pela estratégia da divisão

\begin{tabular}{|c|c|c|c|c|c|c|c|c|c|c|c|c|c|}
\hline Cenário & $\begin{array}{l}\text { Número } \\
\text { de CT }\end{array}$ & & & & & & & & CT 3 & & & 4 & \\
\hline \multirow{2}{*}{1} & \multirow{2}{*}{4} & CT & 1 & & & & 2 & & 3 & 4 & & & \\
\hline & & $\mathrm{L}$ & 5,63 & & & & 2,59 & & 2,13 & 7,06 & & & \\
\hline \multirow{2}{*}{17} & \multirow{2}{*}{5} & CT & 1 & & & & 2 & & 3 & 4.1 & 4.2 & & \\
\hline & & L & 5,63 & & & & 2,59 & & 2,13 & 3,47 & 3,60 & & \\
\hline \multirow{2}{*}{18} & \multirow{2}{*}{6} & CT & 1.1 & 1.2 & & & 2 & & 3 & 4.1 & 4.2 & & \\
\hline & & L & 2,63 & 3,00 & & & 2,59 & & 2,13 & 3,47 & 3,60 & & \\
\hline \multirow{2}{*}{19} & \multirow{2}{*}{7} & CT & 1.1 & 1.2 & & & 2 & & 3 & 4.1 & 4.2 & 4.3 & \\
\hline & & L & 2,63 & 3,00 & & & 2,59 & & 2,13 & 2,06 & 2,38 & 2,63 & \\
\hline \multirow{2}{*}{20} & \multirow{2}{*}{8} & CT & 1.1 & 1.2 & 1.3 & & 2 & & 3 & 4.1 & 4.2 & 4.3 & \\
\hline & & L & 2,4 & 2,42 & 0,81 & & 2,59 & & 2,13 & 2,06 & 2,38 & 2,63 & \\
\hline \multirow{2}{*}{21} & \multirow{2}{*}{9} & CT & 1.1 & 1.2 & 1.3 & & 2 & & 3 & 4.1 & 4.2 & 4.3 & 4.4 \\
\hline & & L & 2.4 & 2,42 & 0,81 & & 2,59 & & 2,13 & 1,63 & 1,83 & 1,76 & 1,83 \\
\hline \multirow{2}{*}{22} & \multirow{2}{*}{10} & CT & 1.1 & 1.2 & 1.3 & & 2.1 & 2.2 & 3 & 4.1 & 4.2 & 4.3 & 4.4 \\
\hline & & L & 2.4 & 2,42 & 0,81 & & 1,30 & 1,29 & 2,13 & 1,63 & 1,83 & 1,76 & 1,83 \\
\hline \multirow{2}{*}{23} & \multirow{2}{*}{11} & CT & 1.1 & 1.2 & 1.3 & 1.4 & 2.1 & 2.2 & 3 & 4.1 & 4.2 & 4.3 & 4.4 \\
\hline & & L & 1,86 & 0,76 & 2,19 & 0,81 & 1,30 & 1,29 & 2,13 & 1,63 & 1,83 & 1,76 & 1,83 \\
\hline
\end{tabular}

Fonte: autor da tese

CT: Centros de trabalho;

Cor vermelha: CT 1 e suas divisões; Cor azul: CT 3; 


\subsubsection{Passos 4, 5 e 6 do guia para modelagem de simulação}

O passo 4 do guia para modelagem de simulação trata da verificação e validação do modelo. Os únicos dados disponíveis para validação do modelo eram aqueles provenientes da coleta de dados feita na situação inicial, expostos nas seções anteriores. A execução do modelo de simulação do cenário 1 em ARENA ${ }^{\circledR}$ retorna produção de $28 \mathrm{EC}$ ao ano e esse é o mesmo valor calculado por meio do gráfico de Gantt da Figura 3. Essa coincidência de valores valida o modelo proposto para a simulação do cenário 1 .

Quanto aos modelos para os demais cenários, tem-se que as Tabelas 8 e 9 foram levantadas anteriormente à construção desses modelos. Tem-se também que a simulação desses modelos mostrou gargalos nos mesmos pontos previstos nas Tabela 8 e 9. Esse fato valida os modelos construidos para os cenários de $2 \mathrm{a}$ 23. Dessa forma, cumpriu-se o passo 4 do guia para modelagem de simulação.

$\mathrm{O}$ passo 5 do guia para modelagem de simulação pede o projeto $\mathrm{e}$ execução de experimentos de simulação, isto é, a implementação prática do modelo ou de parte dele. Este passo está fora do escopo deste trabalho, conforme explicado na seção 4.1 .

O passo 6 do guia para modelagem de simulação prevê a análise dos resultados e corresponde ao conteúdo deste Capítulo 5.

\subsection{RESULTADOS DA SIMULAÇÃO EM COMPUTADOR}

\section{Cenário 1}

Conforme mencionado anteriormente, a configuração inicial da fábrica de combustível nuclear do IPEN é chamada de cenário 1, está representada nas Tabelas 3 a 6 e a simulação desse cenário em ARENA ${ }^{\circledR}$ resultou em produção de $28 \mathrm{EC}$ ao ano. $\mathrm{O}$ gargalo identificado nesse cenário é laminação a quente e recozimento, que é o processo 28 do CT 4 . Uma vez conhecidas a produção anual e o gargalo do cenário 1, avançou-se para o próximo cenário tanto por meio da estratégia tradicional, como por meio da estratégia da divisão, como exposto a seguir. 


\subsubsection{Estratégia tradicional}

\section{Cenário 2}

Foi dobrada a capacidade do gargalo do cenário 1, de modo que seu novo tempo de processamento passou a ser 4,415 horas. Este novo dado configurou o cenário 2. Neste ponto executou-se DES para o cenário 2, cujo resultado foi a produção de $30 \mathrm{EC}$ por ano. O gargalo do cenário 2 foi identificado como os quatro processos em PC, que é o de número 32, executado no CT 4.

\section{Cenários 3 a 16}

Para o estudo dos cenários 3 a 16 executaram-se os mesmos procedimentos descritos para o cenário 2 e ilustrados na FIG. 4. Dessa forma foram encontrados novos tempos de ciclo, novas produções anuais e novos gargalos, cujos resultados e comparações estão apresentados na Tabela 10.

O aumento de produção médio entre os cenários da Tabela 10 é de 1,7\%. Esse valor foi considerado pequeno e muda pouco independentemente do número de cenários gerados. Além disso, frequentemente é necessário comprar equipamentos novos para os aumentos de capacidade promovidos pela estratégia tradicional.

\subsubsection{Estratégia da divisão}

\section{Cenário 17}

Conforme citado, foi mantida a numeração ascendente dos cenários, de forma que o primeiro cenário da estratégia da divisão é o de número 17. O gargalo do cenário 1 pela estratégia da divisão era o CT 4 inteiro, ou seja, pela visão macro. Conforme previsto por esta estratégia, dividiu-se o CT 4, gerando dois CT, os quais caracterizaram o cenário 17. Executou-se DES para esse cenário e obtiveram-se 35 EC por ano. O gargalo do cenário 17 foi identificado como o CT 1.

\section{Cenários 18 a 23}

Os cenários de 18 a 23 foram gerados mediante a aplicação dos mesmos procedimentos citados para o cenário 17 e ilustrados na Figura 5. Dessa 
forma foram encontrados novos tempos de ciclo, novas produções anuais e novos gargalos, cujos resultados e comparações estão apresentados na Tabela 11.

Tabela 10 - Resultados pela estratágia tradicional

\begin{tabular}{|c|c|c|c|c|c|c|}
\hline \multirow{2}{*}{$\begin{array}{l}\text { Ce- } \\
\text { ná- } \\
\text { rio }\end{array}$} & \multicolumn{2}{|l|}{ Gargalo } & \multirow{2}{*}{$\begin{array}{c}\text { Tempo } \\
\text { de } \\
\text { ciclo } \\
\text { total } \\
\text { (dias) }\end{array}$} & \multirow{2}{*}{$\begin{array}{l}\text { Produ- } \\
\text { ção } \\
\text { (EC ao } \\
\text { ano) }\end{array}$} & \multicolumn{2}{|c|}{$\begin{array}{l}\text { Aumento } \\
\text { porcentual em } \\
\text { relação a }\end{array}$} \\
\hline & Processo & Nr. & & & $\begin{array}{l}\text { Cenário } \\
\text { anterior }\end{array}$ & $\begin{array}{c}\text { Cenário } \\
1 \\
\end{array}$ \\
\hline 1 & Laminação a quente & 28 & 7,5 & 28 & - & - \\
\hline 2 & Quatro processos & 32 & 7,0 & 30 & 7 & 7 \\
\hline 3 & Montagem do EC & 38 & 6,4 & 33 & 10 & 18 \\
\hline 4 & Secagem do UF 4 & 9 & 6,2 & 34 & 3 & 21 \\
\hline 5 & Decapagem & 37 & 5,8 & 36 & 6 & 29 \\
\hline 6 & Laminação a quente & 28 & 5,5 & 38 & 6 & 36 \\
\hline 7 & Quatro processos & 32 & 5,3 & 40 & 5 & 43 \\
\hline 8 & Controle dimensional & 35 & 5,0 & 42 & 5 & 50 \\
\hline 9 & Secagem do UF 4 & 9 & 5,0 & 42 & 0 & 50 \\
\hline 10 & Pré-corte & 31 & 4,7 & 45 & 7 & 61 \\
\hline 11 & Montagem do EC & 38 & 4,5 & 47 & 4 & 68 \\
\hline 12 & Desidratação do UF 4 & 10 & 4,4 & 48 & 2 & 71 \\
\hline 13 & $\begin{array}{l}\text { Controle de } \\
\text { qualidade }\end{array}$ & 39 & 4,2 & 50 & 4 & 79 \\
\hline 14 & Decapagem & 37 & 4,0 & 52 & 4 & 86 \\
\hline 15 & Secagem do UF 4 & 9 & 4,0 & 53 & 2 & 89 \\
\hline 16 & Corte final & 33 & 3,8 & 55 & 4 & 96 \\
\hline
\end{tabular}

Fonte: autor da tese 
Tabela 11 - Resultados pela estratégia da divisão

\begin{tabular}{lcrrrrr}
\hline Cenário & Gargalo & \multicolumn{2}{c}{$\begin{array}{l}\text { Tempo de } \\
\text { ciclo } \\
\text { (dias) }\end{array}$} & total & $\begin{array}{l}\text { Produção } \\
\text { (EC ao ano) }\end{array}$ & \multicolumn{2}{c}{$\begin{array}{l}\text { Aumento porcentual } \\
\text { em relação a }\end{array}$} \\
\hline 1 & Cenário & Cenário 1 \\
anterior & Cenar 4 & 7,5 & 28 & - & - \\
17 & CT 1 & 6,0 & 35 & 25 & 25 \\
18 & CT 4 & 4,0 & 53 & 51 & 89 \\
19 & CT 1 & 3,3 & 64 & 21 & 129 \\
20 & CT 4 & 3,0 & 71 & 11 & 154 \\
21 & CT 2 & 2,8 & 75 & 6 & 168 \\
22 & CT 1 & 2,7 & 78 & 4 & 179 \\
23 & Não se aplica & 2,4 & 86 & 10 & 207 \\
\hline
\end{tabular}

Fonte: autor da tese 


\section{OUTROS ASPECTOS DO GERENCIAMENTO DA CAPACIDADE PRODUTIVA}

FABRIL

Nos capítulos anteriores foram considerados os principais elementos que compõem um modelo para planjemanto da capacidade no escopo deste trabalho. Com o objetivo de gerar apoio ao processo de tomada de decisão por parte dos gestores de fábricas de combustível nuclear para reatores de pesquisa, apresentam-se, neste capítulo, outros elementos de interesse.

\subsection{CONSIDERAÇÕES SOBRE A DEMANDA}

O início do projeto de uma fábrica qualquer geralmente se dá pelo conhecimento da demanda [22,77]. Isto é, projeta-se uma fábrica para atender a uma certa demanda. As ampliações de capacidade produtiva também ocorrem pelo mesmo motivo [64,78]. Por outro lado, o desequilíbrio entre a capacidade e a demanda pode ter consequências econômicas negativas para a organização. Por isso é necessário harmonizar a capacidade produtiva com a demanda a ser atendida com o menor custo possível [46,53].

A demanda por combustível nuclear para reatores de pesquisa vem crescendo nas últimas décadas. Quanto à tendência futura dessa demanda, ela deve continuar em elevação [7-9]. Entretanto, os patamares de demanda por combustível nuclear para reatores de pesquisa não se alteram significativamente no período de um ano, que é o horizonte de planejamento mais comum para a indústria em geral $[52,56,111]$. Outra característica da demanda por combustível nuclear para reatores de pesquisa é a pouca sazonalidade. Essas características da demanda permitem dimensionar a capacidade pelo pico da demanda. Esse tipo de dimensionamento da capacidade toma como referência o maior valor da senóide representada na Figura 8. 
Figura 8 - Dimensionamento da capacidade pelo pico da demanda

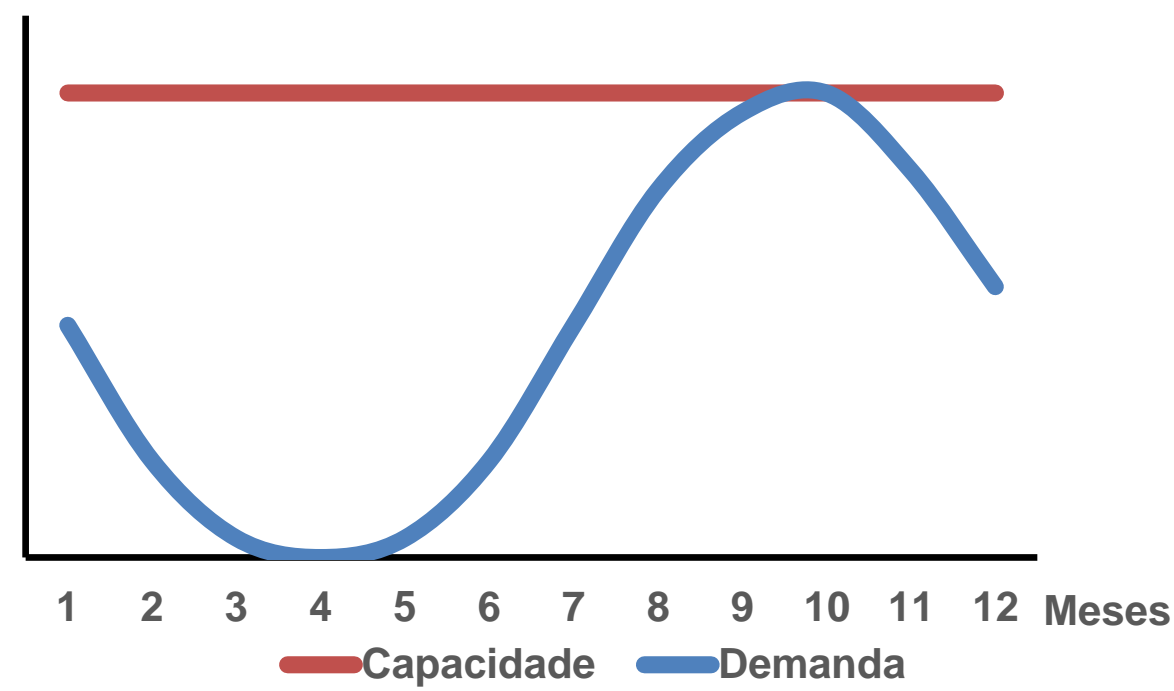

Fonte: autor da tese

Pelo gráfico da Figura 8 percebe-se que a demanda sempre está abaixo da capacidade produtiva. Esse tipo de dimensionamento da capacidade produtiva proporciona os seguintes benefícios:

- Garante-se que toda a demanda será atendida;

- Obtém-se reserva de capacidade, que pode ser usada no caso de uma eventual elevação inesperada da demanda;

- Reduz-se o nível de estoque.

Na Figura 9 reflete-se o comportamento estável da demanda por combustível nuclear, considerando-se que o tipo de dimensionamento de capacidade seja pelo pico da demanda.

Entretanto, o gráfico da Figura 9 corresponde parcialmente à realidade, pois a produção da maioria das fábricas de combustível nuclear tem paradas para manutenção. Essas paradas de produção foram mencionadas nas seções anteriores e influem diretamente no atendimento à demanda. Para que a demanda seja atendidada durante os períodos de parada da produção é necessária a implementação de estoques de segurança, ou de reserva de capacidade ou ambos. Esses conceitos estão aprofundados na seção a seguir. 
Figura 9 - Dimensionamento pelo pico com demanda constante

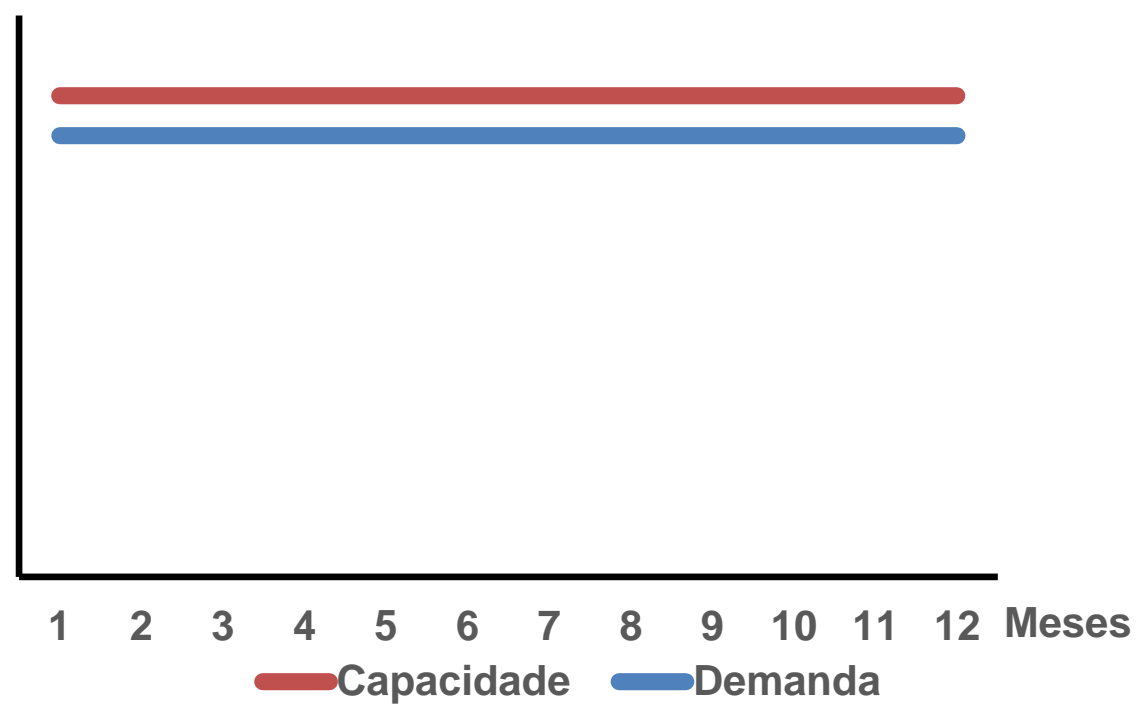

Fonte: autor da tese

\subsection{CONSIDERAÇÕES SOBRE CUSTOS}

O tipo de dimensionamento da capacidade produtiva a ser determinado pelos gestores depende de vários fatores. Dentre esses, destaca-se o custo. Ou seja, é necessário levantar detalhadamente os custos de implementação de capacidade produtiva e de estocagem. A comparação entre esses custos permitirá decidir o nível de capacidade a ser instalado, visando minizar estoques e mantendo o atendimento da demanda $[54,62,66]$. O levantamento de tais custos está fora do escopo do presente trabalho, porém, foi feita uma estimativa de custo do EC tipo placa típico, conforme exposto mais adiante.

Essa estimativa de custo permitiu o uso da lógica de uma parte específica da maioria dos sistemas de planejamento e controle da produção (PCP). A parte em questão é o planejamento agregado da produção, descrito na literatura [49,51,112]. Uma das ferramentas do planejamento agregado da produção são os modelos de apoio à decisão. Esse apoio à tomada de decisão baseia-se em modelos matemáticos de otimização linear, que são amplamente utilizados para maximizar lucros, minimizar custos e planejar a produção em atividades tão diversas quanto agricultura, telecomunicações, finanças, transportes e hospitais $[105,109,113,114]$. Tais modelos matemáticos foram encontrados na literatura 
sobre Pesquisa Operacional [113-120]. Alguns desses modelos foram adaptados para o contexto deste trabalho. Desse modo, foi elaborado um modelo de programação linear para a minimização do custo de produção de uma fábrica de EC tipo placa típicos para reatores nucleares de pesquisa.

\subsubsection{Modelo de otimização linear}

A seguir estão apresentados as hipóteses adotadas, as restrições, os dados de entrada e os resultados do modelo de otimização linear elaborado neste trabalho.

- A fábrica produz apenas um produto;

- Deseja-se planejar a produção para o horizonte de tempo $T$;

- O período usado é de um mês;

- O modelo refere-se a um ano de planejamento, ou seja, $T=12$ meses;

- A demanda é de 120 EC ao ano;

- A demanda é estável a cada mês;

- A fábrica tem 210 dias úteis ao ano;

- Não há restrição de matérias primas;

- É possível manter-se estoque de um mês para outro.

Na Tabela 12 constam as variáveis de entrada do modelo, seus símbolos e os valores adotados.

O custo de produção de um EC (W) indicado na Tabela 12 foi calculado por meio do procedimento apresentado no Apêndice B e publicado em 2016 [121].

As variáveis desconhecidas são os valores mensais da produção de EC. Essas variáveis desconhecidas geralmente recebem o nome de variáveis de decisão $[47,61,87,93]$. Desse modo, as variáveis de decisão são os níveis mensais de produção $x_{t}$, ou seja:

$\mathrm{Xt}_{\mathrm{t}}=$ quantidade de $\mathrm{EC}$ a ser produzida no mês $t$

Esse valor nunca será negativo, isto é:

$$
x_{t} \geq 0 \quad t=1,2, \ldots, T
$$

A produção é interrompida por dois meses ao ano para manutenção. Para tanto considera-se $x_{1}=x_{7}=0$. 
Tabela 12 - Variáveis de entrada

\begin{tabular}{llr}
\hline Símbolo & \multicolumn{1}{c}{ Definição } & \multicolumn{1}{c}{ Valor } \\
\hline $\mathrm{dt}_{\mathrm{t}}$ & Demanda no mês $t$ & $10 \mathrm{EC}$ \\
$\mathrm{D}$ & Demanda anual & $120 \mathrm{EC}$ \\
$\mathrm{CP}_{\mathrm{t}}$ & Capacidade produtiva no mês $t$ & $12 \mathrm{EC}$ \\
$\mathrm{IB}_{1}$ & Estoque ao princípio do primeiro mês & $10 \mathrm{EC}$ \\
$\mathrm{Imax}_{\mathrm{t}}$ & Estoque máximo no mês $t$ & $10 \mathrm{EC}$ \\
$\mathrm{Imin}_{\mathrm{t}}$ & Estoque mínimo no mês $t$ & $0 \mathrm{EC}$ \\
$\mathrm{R}$ & Taxa de juros ao mês & $1,5 \%$ \\
$\mathrm{~W}$ & Custo de produção de um EC & $\mathrm{US} \$ 30.716,59$ \\
$\mathrm{IB}_{\mathrm{t}}$ & Estoque ao princípio do mês $t$ & Tabela 13 \\
$\mathrm{IE}_{\mathrm{t}}$ & Estoque ao final do mês $t$ & Tabela 13 \\
\hline
\end{tabular}

Fonte: autor da tese

Esse tipo de modelo de otimização linear está sujeito a restrições também lineares. As restrições são descrições matemáticas de hipóteses aplicadas ao modelo. Abaixo está a descrição das restrições e das hipóteses que as geraram.

Restrição de capacidade - A produção não pode ser maior que a capacidade produtiva (CP), ou seja:

$$
x_{t} \leq C P_{t} \quad t=1,2, \ldots, T
$$

Restrições de estoque - Assume-se que o estoque ao final de um dado mês $\left(\mathrm{IE}_{\mathrm{t}}\right)$ seja a soma do estoque ao princípio do mês $\left(\mathrm{IB}_{\mathrm{t}}\right)$ com a produção $\left(\mathrm{X}_{\mathrm{t}}\right)$ e subtraído da demanda $\left(d_{t}\right)$, ou seja:

$$
I E_{t}=I B_{t}+x_{t}-d_{t} \quad t=1,2, \ldots, T
$$

Assume-se que o estoque do início de cada mês $\left(\mathrm{IB}_{\mathrm{t}}\right)$ seja igual àquele do final do mês anterior ( $\left(\mathrm{E}_{\mathrm{t}-1}\right)$. Isto é:

$$
I B_{t}=I E_{t-1} \quad t=1,2, \ldots, T \text {; }
$$

Conforme a TAB. 12:

$$
\begin{array}{ll}
I \min _{t} \leq I E_{t} \leq I \max _{t} & t=1,2, \ldots, T \text { e também } \\
I \operatorname{Imin}_{t} \leq I B_{t} \leq I \max _{t} & t=1,2, \ldots, T
\end{array}
$$


Susbtituindo os valores da TAB. 12:

$$
\begin{aligned}
& 0 \leq I B_{t} \leq 10 \\
& 0 \leq I E_{t} \leq 10
\end{aligned}
$$$$
t=1, \ldots, 12 \text {; }
$$$$
t=1, \ldots, 12
$$

Restrição de demanda - Não se pode fornecer mais que a demanda. Assim a soma do estoque inicial com a produção deve ser menor que a demanda, ou seja:

$I B_{t}+x_{t} \geq d_{t} \quad$ ou $\quad I B_{t}+x_{t}-d_{t} \geq 0$.

Mas sabe-se que $I B_{t}+x_{t}-d_{t}=I E_{t}$.

Assim para garantir que a demanda será atendida, basta impor:

$I \min _{t} \leq I E_{t} \leq \operatorname{Imax}_{t}$

$$
t=1,2, \ldots, T
$$

Susbtituindo os valores da TAB. 12:

$$
0 \leq I E_{t} \leq 10
$$

$$
t=1, \ldots, 12
$$

Custo de estoque - Foi adotado que a quantidade de EC mantida em estoque em cada mês seja a média aritmética entre o número de $\mathrm{EC}$ em estoque ao princípio e ao fim de cada mês $[61,120]$. Também se adotou que o custo para manutenção de estoque (IC) seja equivale aos juros decorrentes da quantidade de EC em estoque naquele mês. Ou seja:

$$
I C_{t}=W \cdot R \cdot\left(I E_{t}+I B_{t}\right) / 2 \quad t=1,2, \ldots, T
$$

A Função Objetivo, $f(x)$, é a equação que depende das variáveis de decisão e que define o que se pretende delas $[57,61,120]$. Nesse trabalho, a Função Objetivo, $f(x)$, é minimizar o custo total de produção, que é dado pela soma do custo da produção com o custo do estoque. A união da Função Objetivo com as restrições constitui o modelo matemático de otimização linear, o qual está apresentado a seguir: 
Minimizar

$$
f(x)=\sum_{t=1}^{12}\left(x_{t} \cdot W+I C_{t}\right)
$$

Sujeito a:

$$
\begin{array}{ll}
I E_{t}=I E_{t-1}+x_{t}-d_{t} & t=1,2, \ldots, 12 \\
I B_{t}=I E_{t-1} & t=1,2, \ldots, 12 \\
0 \leq I E_{t} \leq 10 & t=1,2, \ldots, 12 ; \\
I C_{t}=W \cdot R \cdot\left(I E_{t}+I B_{t}\right) / 2 & t=1,2, \ldots, T \\
x_{t} \leq 12 & t=1,2, \ldots, 12 ; \\
x_{t} \geq 0 & t=1,2, \ldots, 12 \\
x_{1}=x_{7}=0 &
\end{array}
$$

O modelo tem mais equações que incógnitas, circunstância que the confere mais que uma solução. Um modo frequente para encontrar a solução ótima neste tipo de situação é o Método Simplex, que está bem apresentado na literatura [30, 32, 34, 37, 38, 41, 58-61]. A solução ótima para o modelo de otimização linear foi encontrada por meio do Método Simplex.

As respostas do modelo são os valores mensais de produção, de estoque, de custo e também o custo minimizado de produção anual. Na Tabela 13 estão expostos os resultados da execução deste modelo, tanto em número de EC como em milhares de dólares americanos, respectivamente.

Pela Tabela 13 percebe-se a necessidade de estoque de $10 \mathrm{EC}$ ao final do mês 6 . Essa resposta do modelo corresponde ao atendimento da demanda do mês 7 , no qual há uma parada de produção. Também pela Tabela 13 vê-se que foi necessário admitir-se estoque inicial de $10 \mathrm{EC}$ no mês 1 , pelas mesmas razões. Ou seja, a parada de produção implica na manutenção de estoque em seu nível máximo no período anterior à parada. Ou ainda, é necessária a implementação de infra-estrutura de armazenagem de até $10 \mathrm{EC}$ para atender a demanda durante as paradas de produção. 
Tabela 13 - Resultados do modelo para minimização do custo de produção

\begin{tabular}{lrrrr}
\hline $\begin{array}{l}\text { Mês } \\
\text { do ano }\end{array}$ & \multicolumn{1}{c}{$\begin{array}{c}\mathrm{IB}_{\mathrm{t}} \\
(\mathrm{EC})\end{array}$} & \multicolumn{1}{c}{$\begin{array}{c}\mathrm{X} \mathrm{t} \\
(\mathrm{EC})\end{array}$} & \multicolumn{1}{c}{$\begin{array}{c}\mathrm{IE}_{\mathrm{t}} \\
(\mathrm{EC})\end{array}$} & $\begin{array}{c}\text { Custo } \\
(1.000 \times \mathrm{XS} \$)\end{array}$ \\
\hline 1 & 10,0 & 0,0 & 0,0 & 2,3 \\
2 & 0,0 & 12,0 & 2,0 & 369,1 \\
3 & 2,0 & 12,0 & 4,0 & 370,0 \\
4 & 4,0 & 12,0 & 6,0 & 370,9 \\
5 & 6,0 & 12,0 & 8,0 & 371,8 \\
6 & 8,0 & 12,0 & 10,0 & 372,7 \\
7 & 10,0 & 0,0 & 0,0 & 2,3 \\
8 & 0,0 & 10,0 & 0,0 & 307,2 \\
9 & 0,0 & 10,0 & 0,0 & 307,2 \\
10 & 0,0 & 10,0 & 0,0 & 307,2 \\
11 & 0,0 & 10,0 & 0,0 & 307,2 \\
12 & 0,0 & 10,0 & 0,0 & 307,2 \\
Total & 40,0 & 110,0 & 30,0 & $3.395,0$ \\
Média & 3,3 & 9,2 & 2,5 & 282,9 \\
\hline
\end{tabular}

Fonte: autor da tese

\subsubsection{Análise de sensibilidade}

O objetivo da análise de sensibilidade do modelo de otimização linear é oferecer outros parâmetros para a tomada de decisão por parte da gerência de fábricas de combustível nuclear para reatores de pesquisa. Essa análise aborda a capacidade do modelo em prever custos em situações diferentes e está exposta na Tabela 14. No levantamento dessa tabela foram consideradas as seguintes hipóteses:

Linha 1 - valores obtidos da Tabela 13

Linha 2 - produção no mês 1 e alteração de $I B_{1}$ de 10 para zero e

Linha 3 - produção nos meses 1 e 7 e alteração de $I B_{1}$ e $I B_{7}$ de 10 para zero. 
Todos os demais parâmetros usados para a execução do modelo foram mantidos iguais àqueles usados para a Tabela 13.

Tabela 14 - Análise de sensibilidade

\begin{tabular}{ccccc}
\hline & Paradas & $\mathrm{I} \mathrm{B}_{\mathrm{t}}$ médio $(\mathrm{EC})$ & $\mathrm{IE}_{\mathrm{t}}$ médio $(\mathrm{EC})$ & $\mathrm{CP}_{\mathrm{t}}(\mathrm{EC})$ \\
\hline 1 & 2 meses & 3,3 & 2,5 & 12 \\
2 & 1 mês & 2,5 & 2,5 & 12 \\
3 & 15 dias & 1,0 & 1,0 & 11 \\
\hline
\end{tabular}

Fonte: autor da tese

Pela Tabela 14 percebe-se que quanto menor o tempo de parada de produção, menores as necessidades de estoque e de capacidade produtiva. Por isso é necessário estudar em detalhes os custos para poder fazer a comparação entre eles. Essa comparação apoiará a decisão dos gestores sobre qual elemento alterar, isto é, capacidade produtiva, capacidade de estoque, parada de produção e eventual não atendimento da demanda. 


\section{CONCLUSÕES}

O objetivo deste trabalho - proposição e teste de um modelo conceitual para expansão da capacidade produtiva de fábricas de EC tipo placa típico para reatores nucleares de pesquisa, que usem $\mathrm{U}_{3} \mathrm{Si}_{2}$ e cuja rota de produção inclua a hidrólise de $\mathrm{UF}_{6}$ - foi atingido plenamente, conforme apresentado na seção 4.1. O teste do modelo proposto foi executado por meio do estudo de caso da fábrica de combustível nuclear do IPEN.

Ambas as estratégias para o aumento da capacidade produtiva do gargalo mostraram-se eficazes no aumento da capacidade total da fábrica. A estratégia tradicional, cenários 1-16, gerou até $96 \%$ de aumento e a da divisão, cenários $17-23$, até $207 \%$. Portanto, a estratégia da divisão produziu maiores aumentos da capacidade produtiva que a estratégia tradicional. Pela comparação da produção anual entre os cenários 1 e 23, último cenário da estratégia da divisão, concluiu-se que é possível produzir três vezes mais que na situação inicial pela simples realocação de processos, sem necessidade de compra de novos equipamentos.

Esse aumento da capacidade produtiva acarreta um aumento da produção e uma diminuição do tempo de ciclo total da fábrica. Considerando o estudo de caso abordado, passa-se de um tempo de ciclo total da fábrica de 7 para 2,44 dias úteis.

A estimativa de custo de um EC tipo placa típico indica que este é um produto com alto valor agregado. $\mathrm{O}$ estudo preliminar desse custo comprova a necessidade da comparação entre outros custos para apoiar as decisões dos getores da fábrica.

As mudanças indicadas são relevantes, pois algumas instalações de fabricação de combustível nuclear para reatores de pesquisa operam da mesma forma há décadas. Esse fato torna estas conclusões significativas para os administradores dessas instalações, configurando uma grande contribuição do presente trabalho.

Para trabalhos futuros cabe assinalar que o presente modelo fornece a base para a agregação de estudos de várias áreas que tem impactos sobre a 
ampliação da capacidade produtiva. Entre essas áreas, destacam-se criticalidade, mão de obra, segurança, qualidade e custos. A associação dos estudos de cada uma dessas áreas com o modelo desenvolvido neste trabalho permitirá a elaboração de outros modelos de simulação em trabalhos futuros. 


\section{APÊNDICE A - FLUXOGRAMAS E MODELOS DE SIMULAÇÃO}

a) Fluxogramas

Conforme mencionado anteriormente, o fluxograma da Figura 6 serviu de base para a simulação de todos os cenários da estratégia tradicional, pois todos eles mantem o mesmo número de CT. Esse fluxograma está repetido na Figura 10 para maior clareza.

Com relação à estratégia da divisão, conforme mencionado anteriormente, a construção dos fluxogramas e dos respectivos modelos de simulação para os cenários desta estratégia deve refletir o aumento do número de CT. Os fluxogramas correspondentes aos cenários de números 17 a 23 estão expostos nas Figuras de 11 a 17. Pela sequência dessas figuras configura-se 0 aumento do número de CT de um cenário para outro, como deve ocorrer na estratégia da divisão. 
Figura 10 - Fluxograma para os cenários de 1 até 16

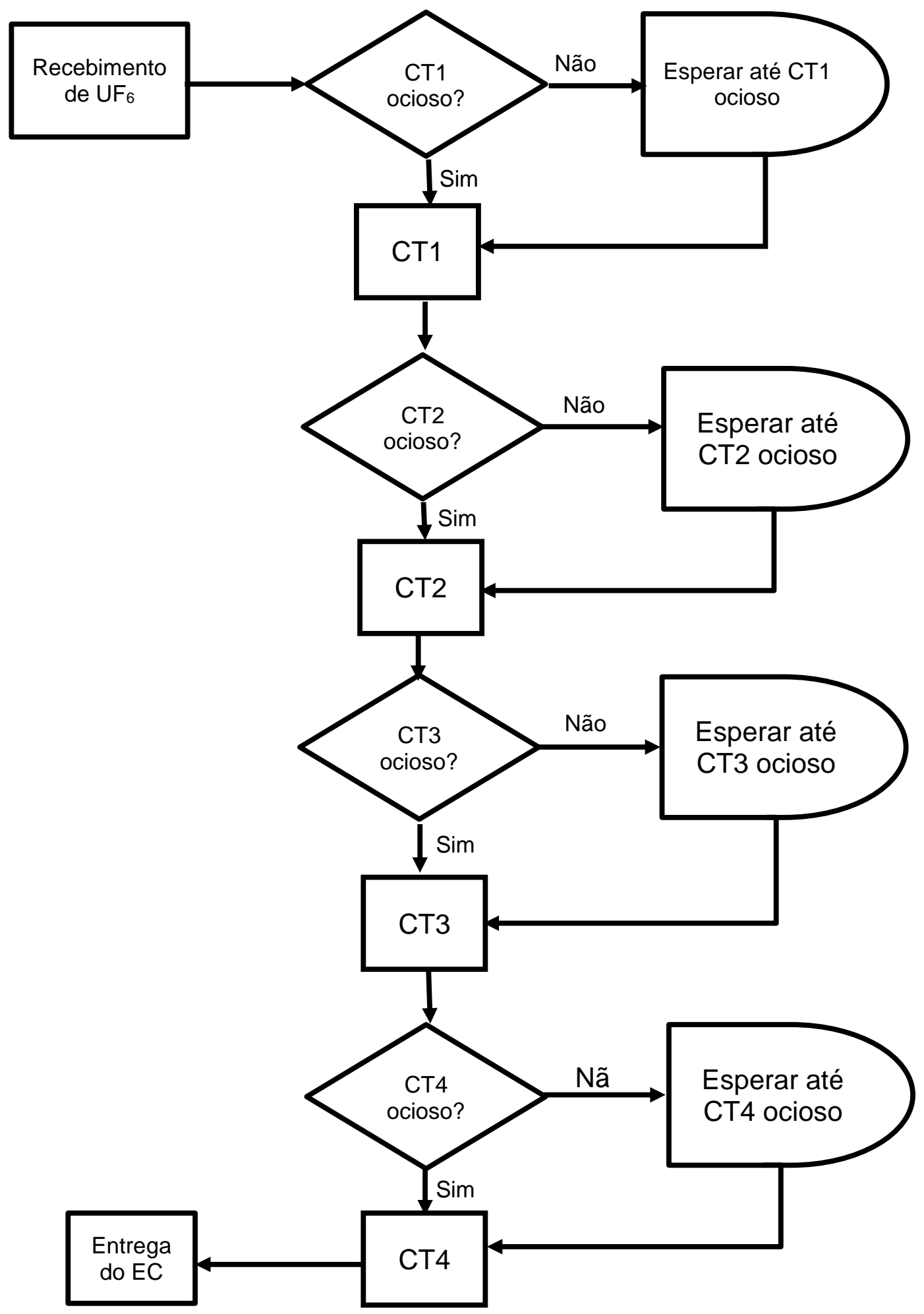

Fonte: autor da tese 
Figura 11 - Fluxograma para o cenário 17

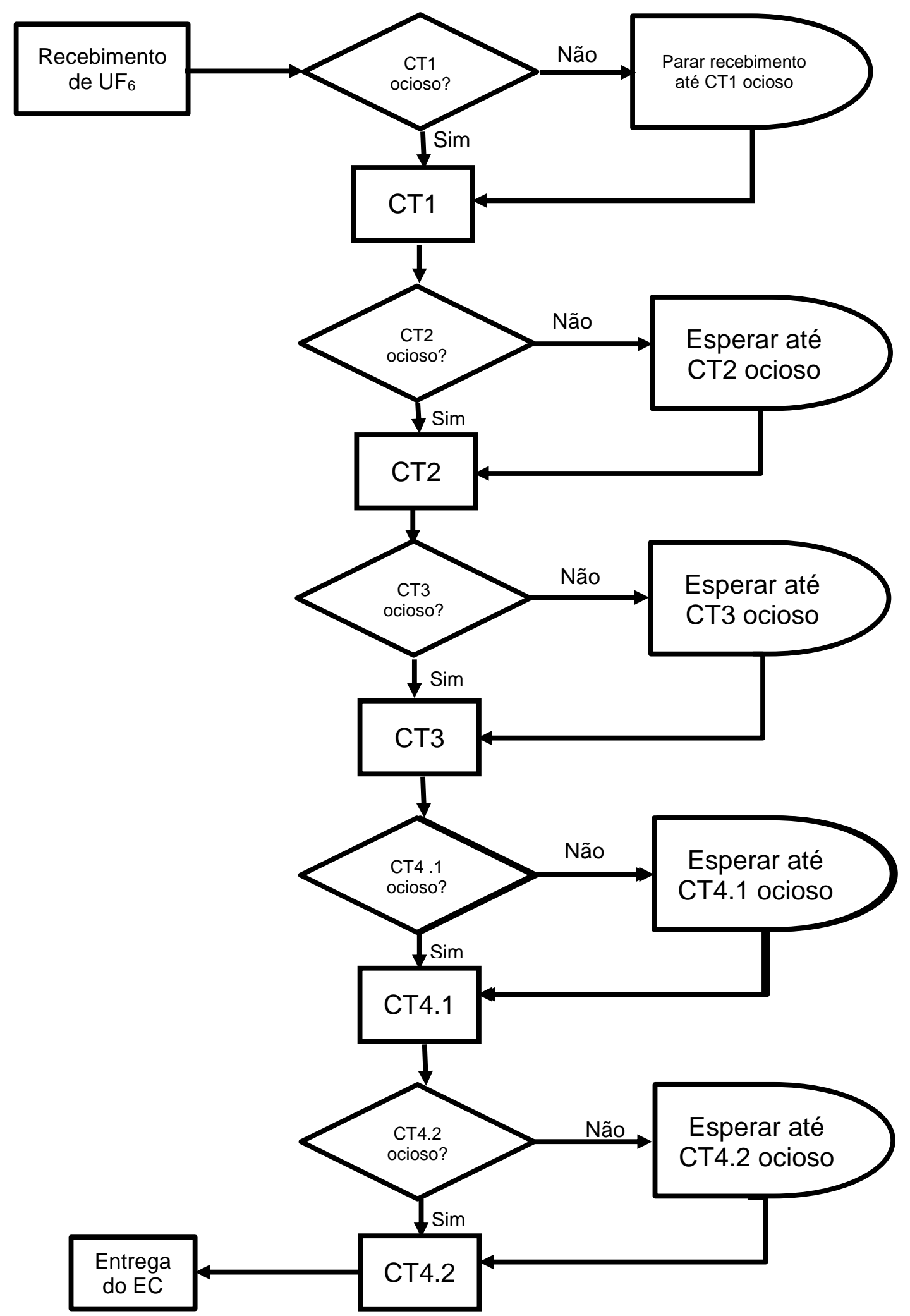

Fonte: autor da tese 
Figura 12 - Fluxograma para o cenário 18

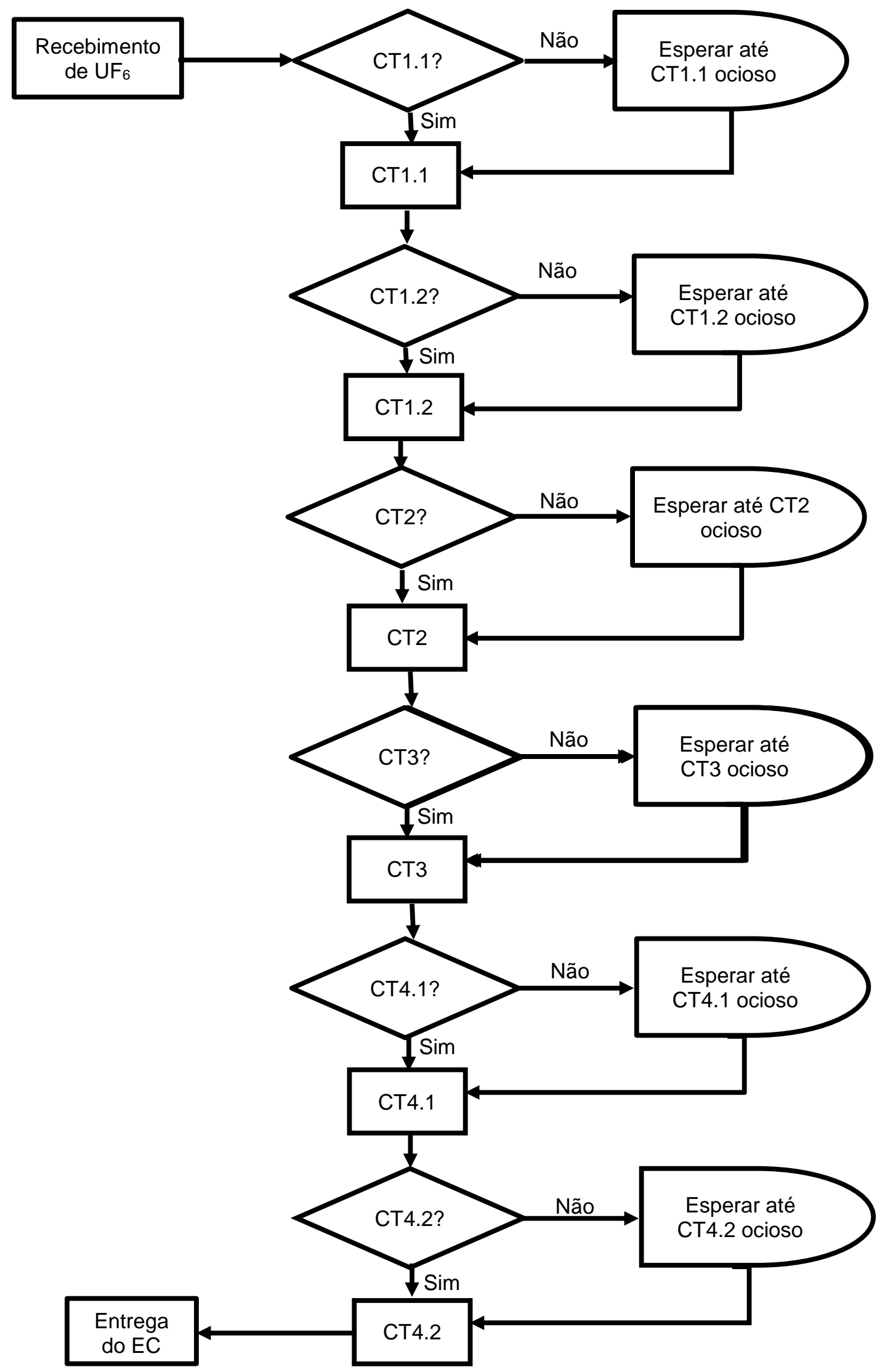

Fonte: autor da tese 
Figura 13 - Fluxograma para o cenário 19

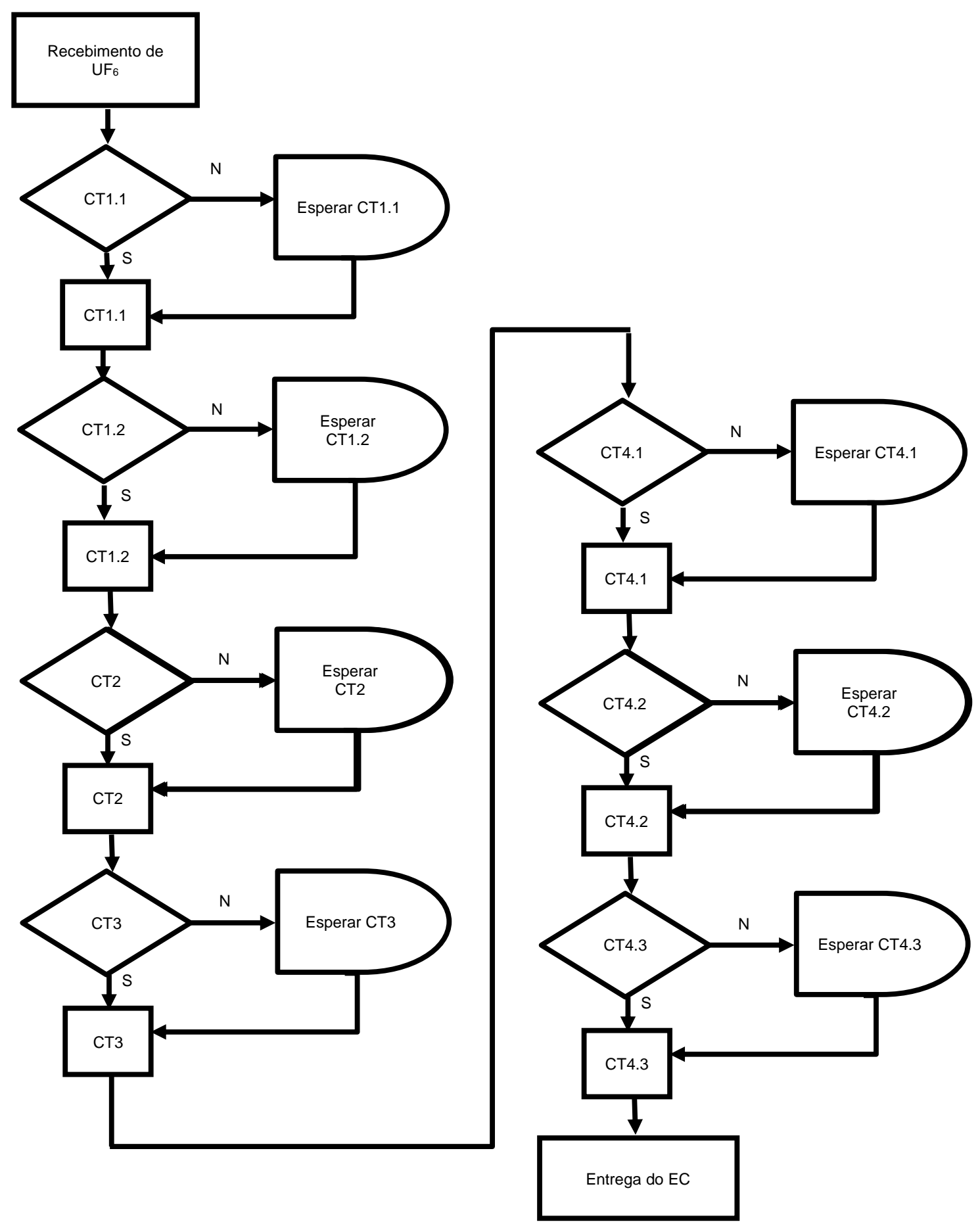

Fonte: autor da tese 
Figura 14 - Fluxograma para o cenário 20
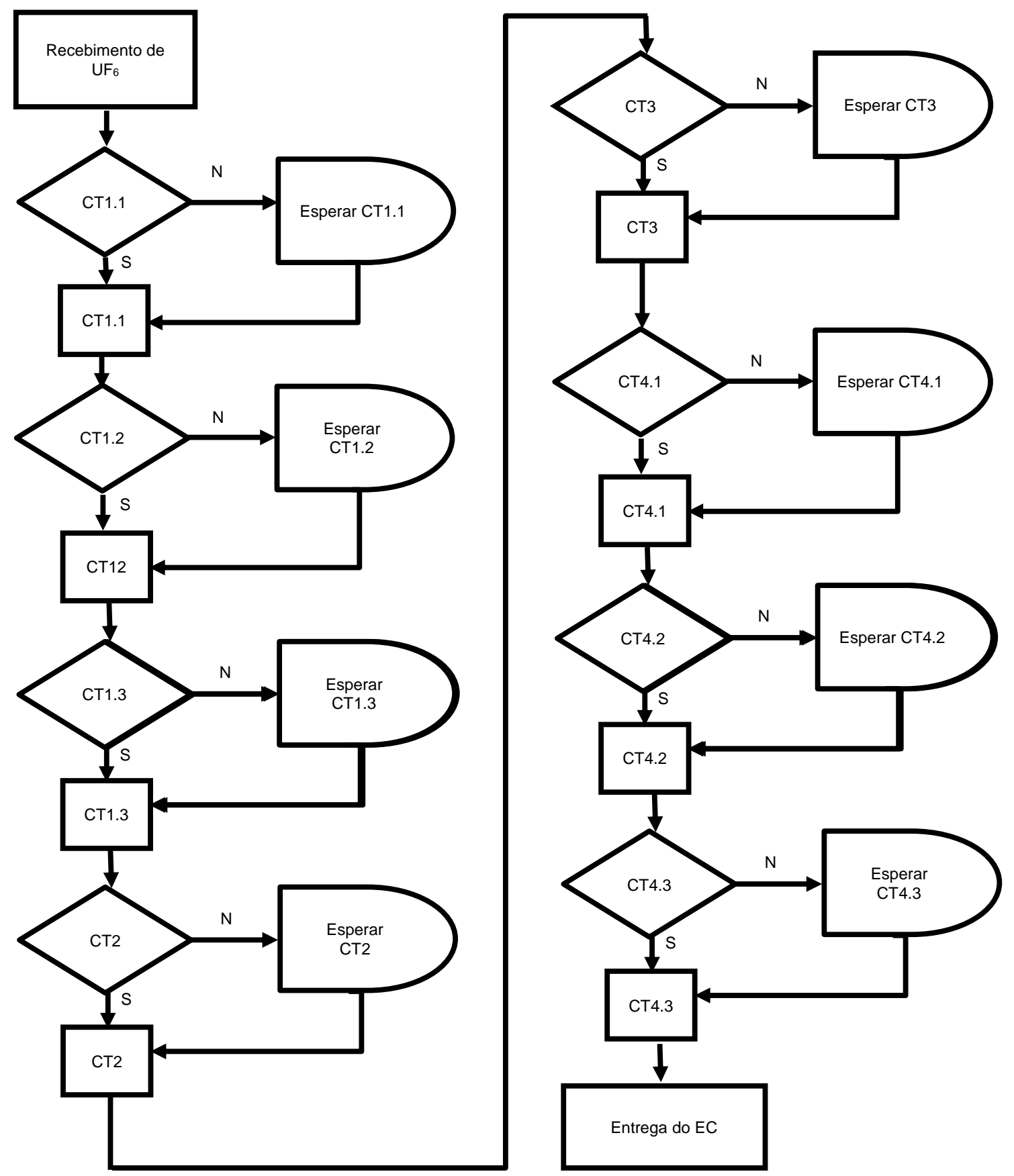

Fonte: autor da tese 
Figura 15 - Fluxograma para o cenário 21
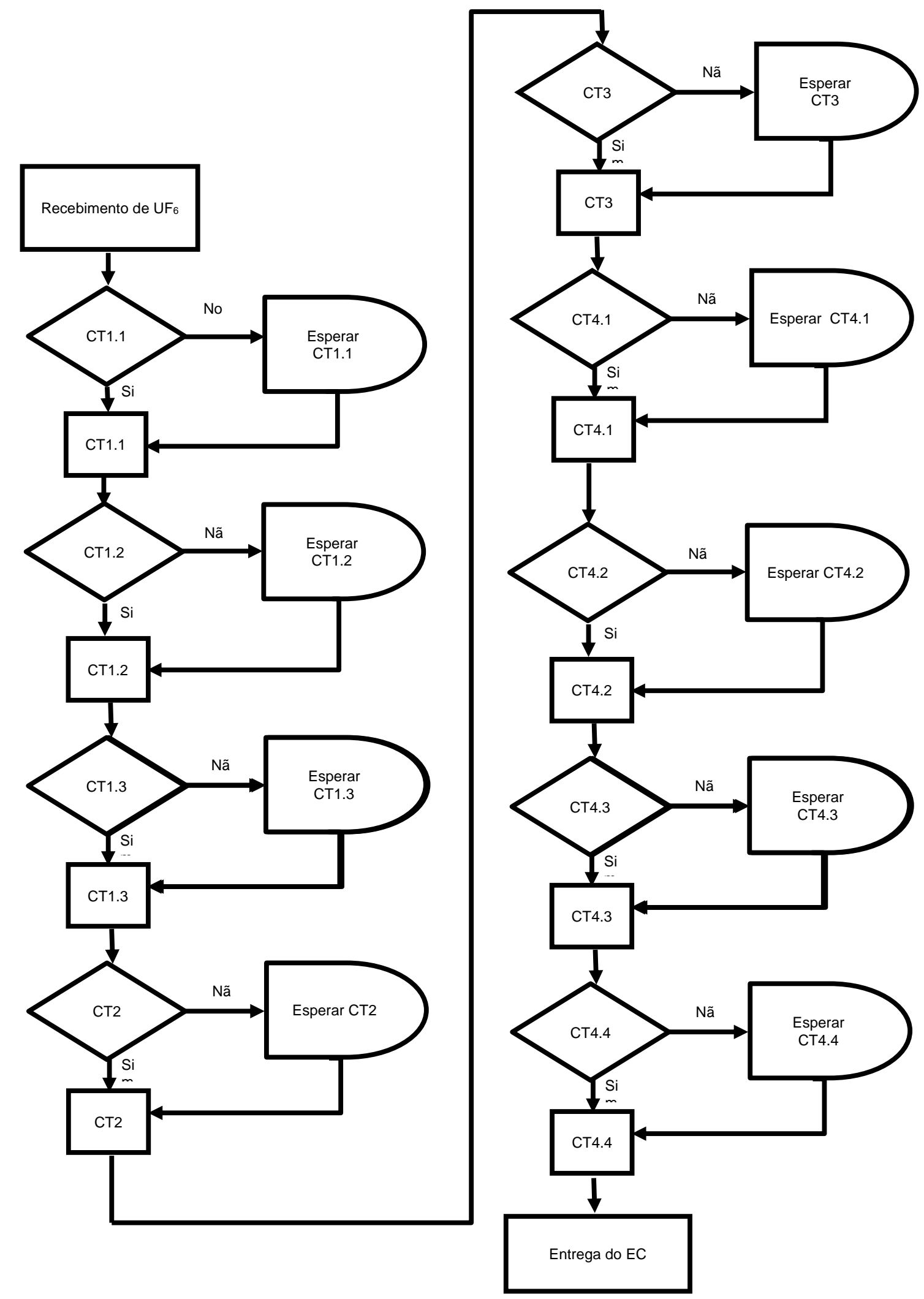

Fonte: autor da tese 
Figura 16 - Fluxograma para o cenário 22
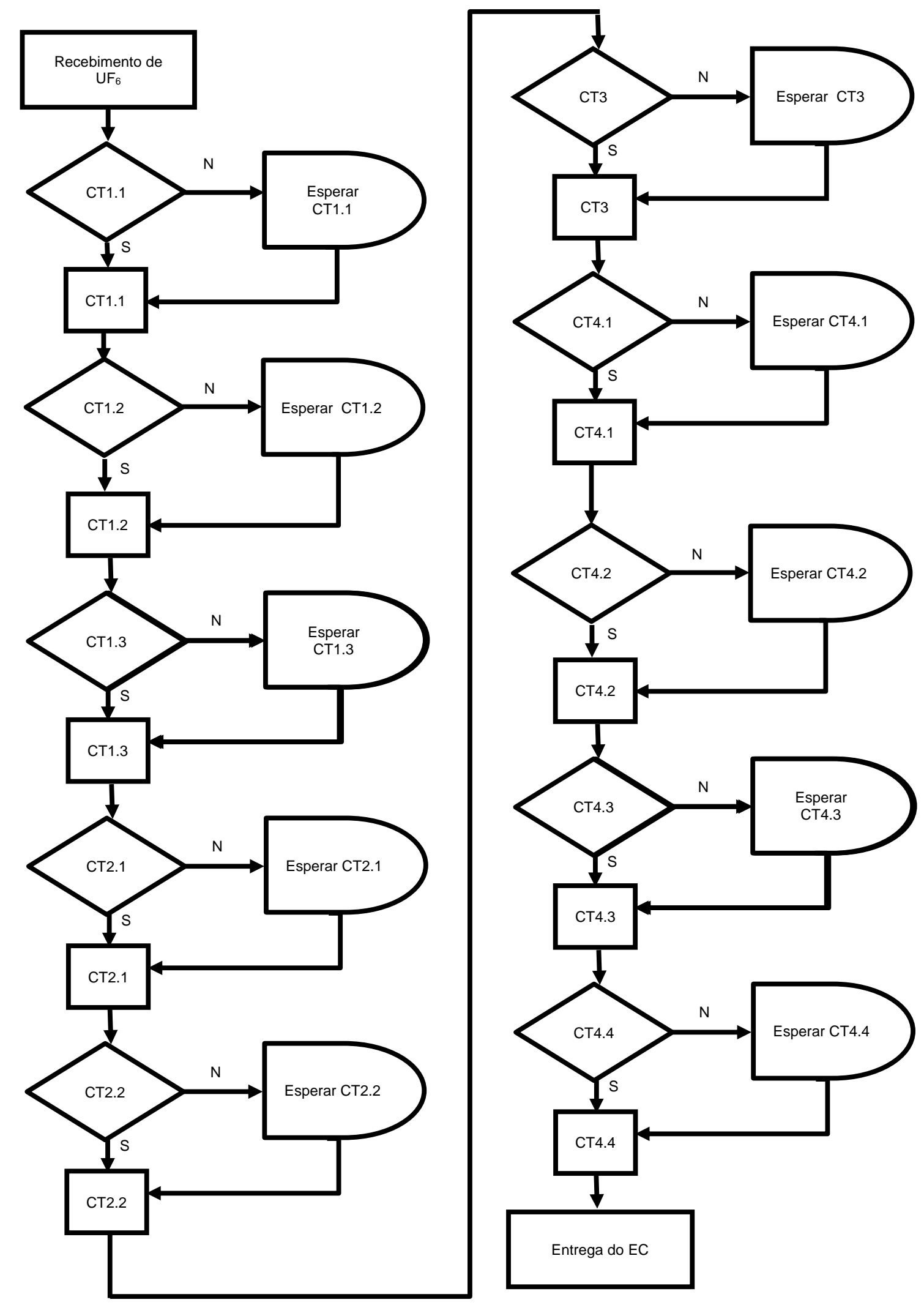

Fonte: autor da tese 
Figura 17 - Fluxograma para o cenário 23
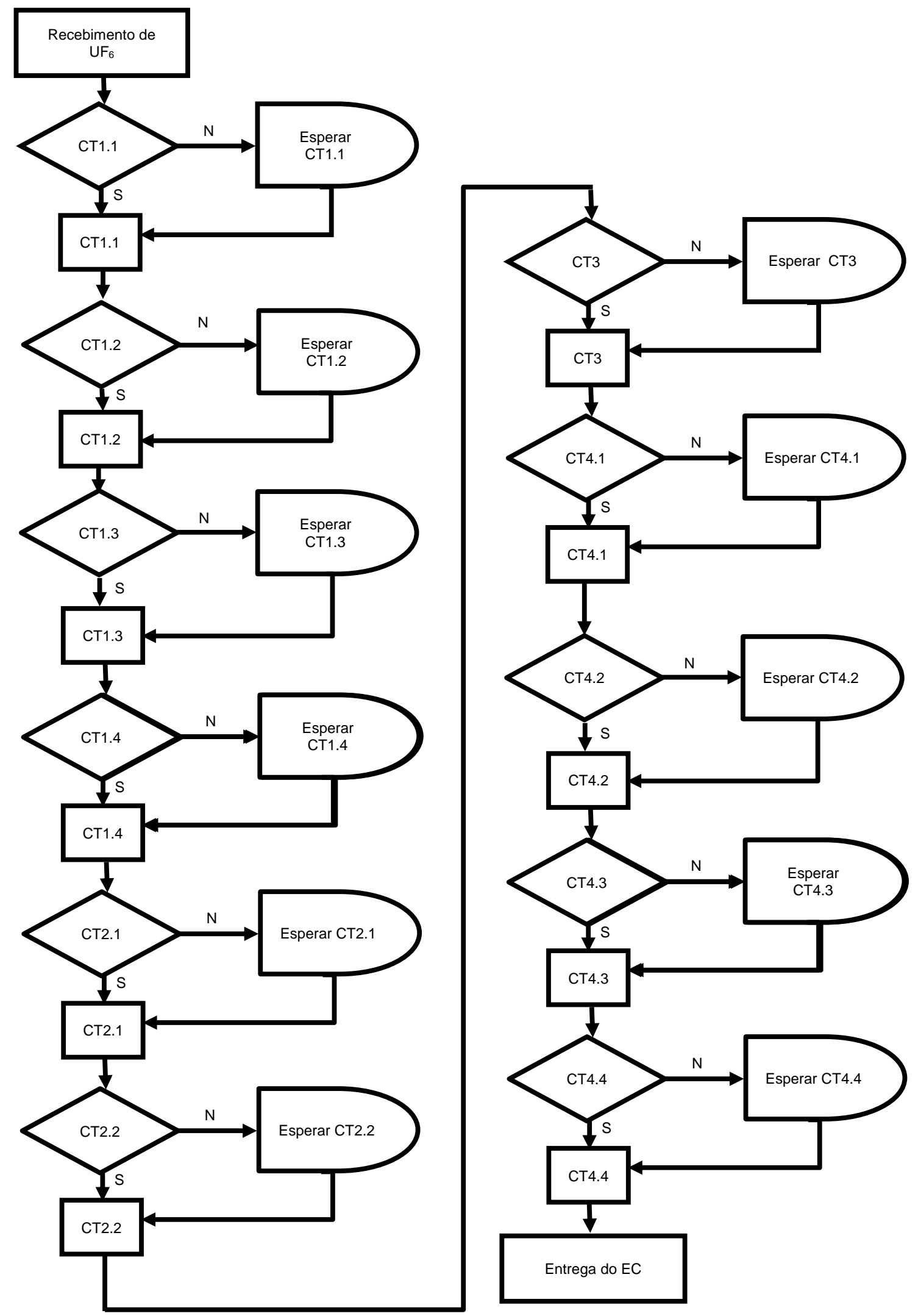

Fonte: autor da tese 
b) Modelos de simulação em ARENA ${ }^{\circledast}$

Os fluxogramas apresentados anteriormente serviram de base para a programação de algoritmos de simulação em computador. Também conforme mencionado, foi selecionado o software ARENA ${ }^{\circledR}$ para essa programação. Foram construídos 8 modelos de simulação em ARENA ${ }^{\circledR}$, que foram distribuídos como se segue:

- um mesmo modelo foi usado para todos os cenários da estratégia tradicional e

- foram criados mais 7 modelos, um para cada cenário da estratégia da divisão.

O software ARENA ${ }^{\circledR}$ dispõe de vários tipos de "blocos de programação", que representam processos produtivos, entregas de matéria primas, entregas de produtos acabados, atribuição de propriedades e divisão de tarefas [82,95]. Os modelos de simulação construídos neste trabalho usaram 5 tipos de "blocos" do ARENA ${ }^{\circledR}$. Esses blocos foram create, hold, assign, process e dispose. A seguir são expostos alguns detalhes sobre os blocos usados neste trabalho.

O bloco hold foi usado em conjunto com o bloco assign, com o propósito de limitar o número de lotes de produção em processamento dentro da fábrica. Esse limite correspondeu ao número de CT em cada cenário, pois não pode haver mais que um lote em cada CT. Se houver mais que um lote em um dado CT, surge a possibilidade de um acidente de criticalidade.

Os blocos process foram usados para caracterizar os CT da fábrica de combustível nuclear do IPEN. Segue-se uma lista de características comuns a todos os blocos process usados nos modelos de simulação de cenários criados no ARENA ${ }^{\circledR}$.

$\begin{array}{ll}\text { Type } & \text { Standard } \\ \text { Action } & \text { Seize Delay Release } \\ \text { Priority } & \text { Medium (2) } \\ \text { Resources } & 1 \text { row } \\ \text { Delay Type } & \text { Normal } \\ \text { Units } & \text { Days } \\ \text { Allocation Value } & \text { Added } \\ \text { Report Statistics } & \text { Yes }\end{array}$


Detalhes sobre o significado de cada um dos parâmetros acima foram omitidos neste relatório, pois tem pouca relevância na consecução dos objetivos deste trabalho e porque podem ser encontrados na literatura [82,99].

Os blocos process usados não consideram os processos individuais que ocorrem dentro de cada $\mathrm{CT}$, devido ao não processamento de mais de um lote por um mesmo CT ao mesmo tempo. Por esse motivo foi possível considerar cada CT como uma única máquina, conforme a visão macro.

O bloco create simula as entregas de matéria prima. $\mathrm{O}$ bloco create construído neste trabalho foi usado em todos os 8 modelos de simulação e gera a entrega de um lote de 3,0 $\mathrm{kg}$ de $\mathrm{UF}_{6}$ a cada dois dias úteis. Esse ritmo de entrega de matéria prima foi definido para assegurar que não faltaria matéria prima e para simular o acúmulo de $\mathrm{UF}_{6}$ no $\mathrm{CT} 1$, ou seja, no primeiro $\mathrm{CT}$ da fábrica. Esse acúmulo se dá na realidade, pois essa matéria prima é fornecida em cilindros com $25 \mathrm{~kg}$. Desse cilindro são retirados $3,0 \mathrm{Kg}$ de UF 6 para compor um lote de produção e o restante fica armazenado no próprio cilindro. Nos modelos em ARENA ${ }^{\circledR}$, os lotes de UF6 ficam armazenados no bloco hold, após deixarem o bloco create.

Por último foi alocado um bloco dispose para simular as entregas de produtos acabados, ou seja, EC tipo placa típicos carregados com LEU U $3 \mathrm{Si}_{2}-\mathrm{Al}$. Esse mesmo bloco dispose foi usado para simular as entregas de EC em todos os 8 modelos construídos em ARENA ${ }^{\circledR}$.

Em todos os modelos de simulação deste trabalho foi atribuído o tempo de simulação de um ano para considerar as diferentes situações que ocorrem em um ano, como, por exemplo, manutenção, variações da demanda e férias. Conforme mencionado anteriormente, adotaram-se 210 dias de produção ao ano, que é o resultado da média de 21 dias úteis por mês multiplicada por 10 meses de produção em um ano.

A simulação foi replicada dez vezes para cada cenário, de forma a simular dez anos de produção. Deste modo, aumentou-se a confiabilidade dos resultados por meio da obtenção de valores médios baseados nos dez anos de replicação. ARENA ${ }^{\circledR}$ retorna valores médios de vários parâmetros como resposta. Neste trabalho foi considerado apenas o valor referente à média da produção anual de cada cenário em número de EC. 
O primeiro modelo construído em ARENA ${ }^{\circledR}$ foi o do cenário 1. A base para esse modelo foi o fluxograma das Figuras 6 e 10. Foram inseridos 4 blocos process em ARENA ${ }^{\circledR}$ e a cada bloco process foi alocado o lead time total de cada CT apresentado na Tabela 2. Além disso foram usados um bloco create, um bloco hold, dois blocos assign e um bloco dispose, todos idênticos aos mencionados anteriormente.

Por outro lado, sabe-se que todos os cenários da estratégia tradicional têm o mesmo número de $\mathrm{CT}$, ou seja, quatro. Por isso o modelo em ARENA ${ }^{\circledR}$ para o cenário 1 serviu também para a simulação dos cenários de 2 até 16 . Esse modelo em ARENA ${ }^{\circledR}$ contém os 4 CT e os diferentes valores dos lead times dos CT são atribuídos como variação do parâmetro lead time nesse modelo. $\mathrm{O}$ modelo em questão está repetido na Figura 18.

Figura 18 - Modelo em ARENA® para os cenários de 1 até 16
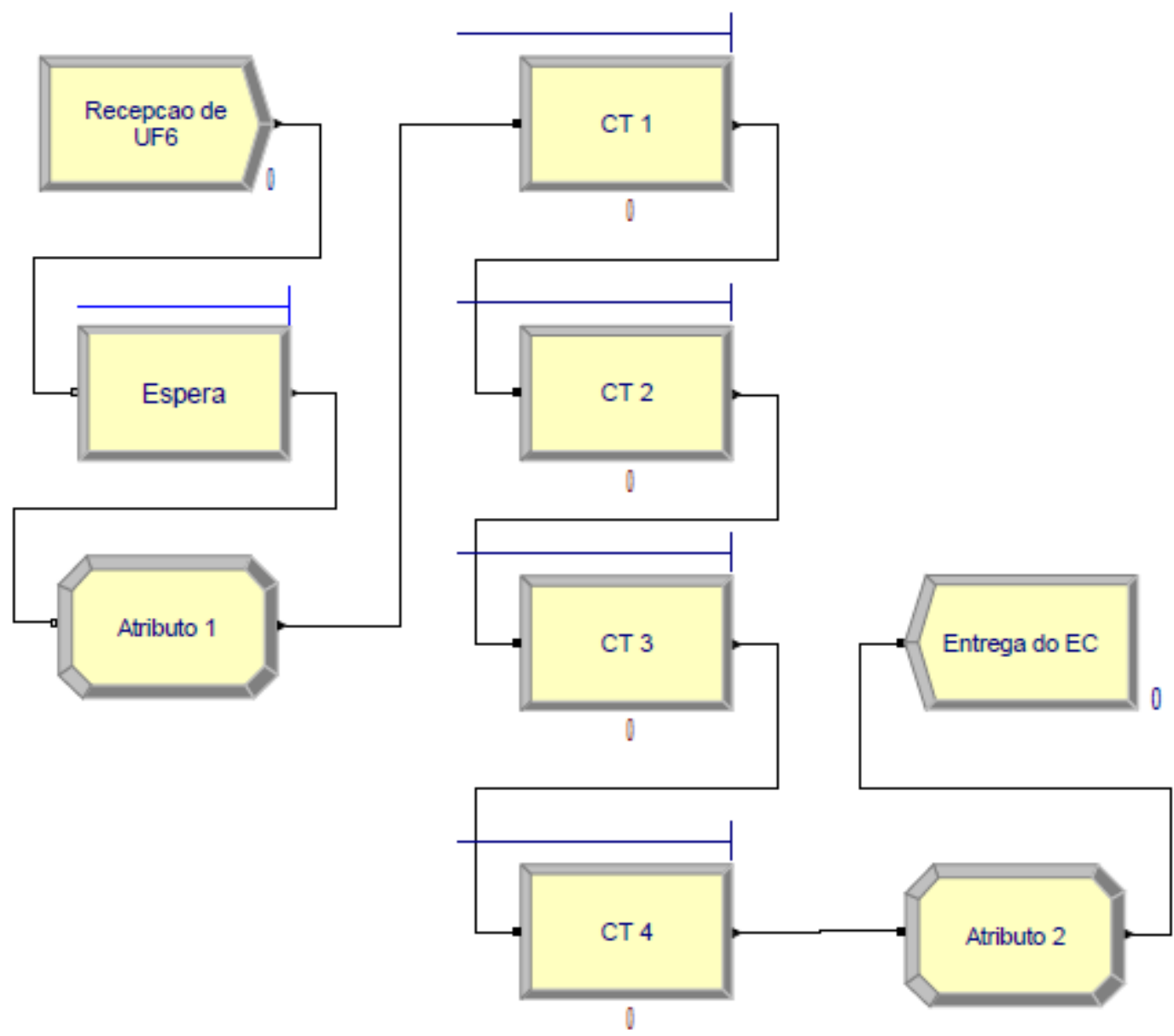

Fonte: autor da tese 
Quanto à estratégia da divisão, a construção dos modelos de simulação deve refletir o aumento do número de $\mathrm{CT}$, conforme mencionado. Esse fato demanda que um novo modelo em ARENA ${ }^{\circledR}$ seja construído para cada cenário. Por isso foram construídos 7 novos modelos, cada um deles baseado nos fluxogramas das Figuras de 11 a 17. Cada novo modelo em ARENA ${ }^{\circledR}$ foi acrescido de um bloco process. Foram mantidos os mesmos blocos create, hold, assign e dispose usados no modelo da estratégia tradicional. Nas Figuras de 19 a 25 estão expostos os modelos em ARENA ${ }^{\circledR}$ criados para simular a estratégia da divisão.

Figura 19 - Modelo em ARENA® para o cenário 17
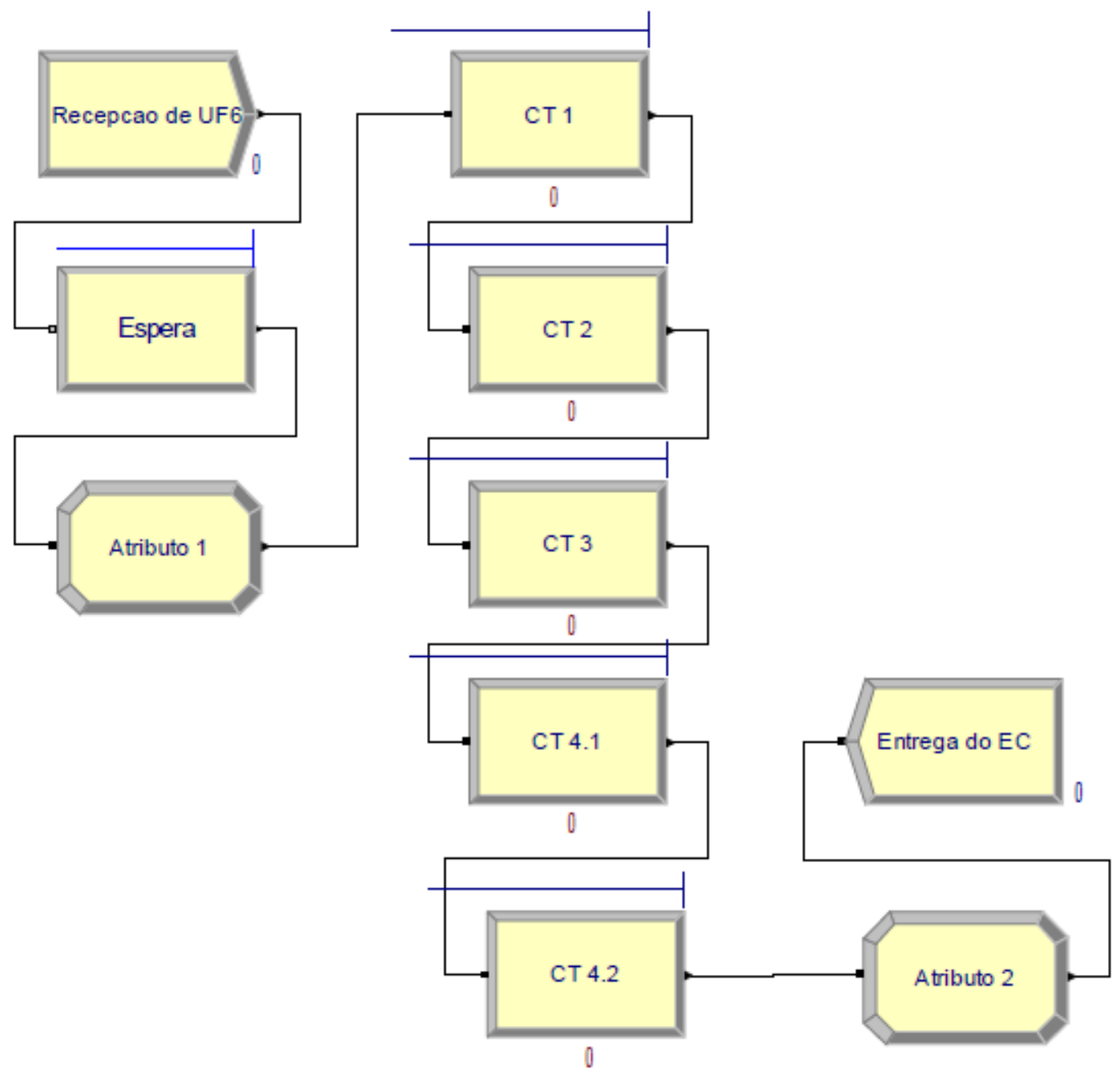

Fonte: autor da tese 
Figura 20 - Modelo em ARENA® para o cenário 18
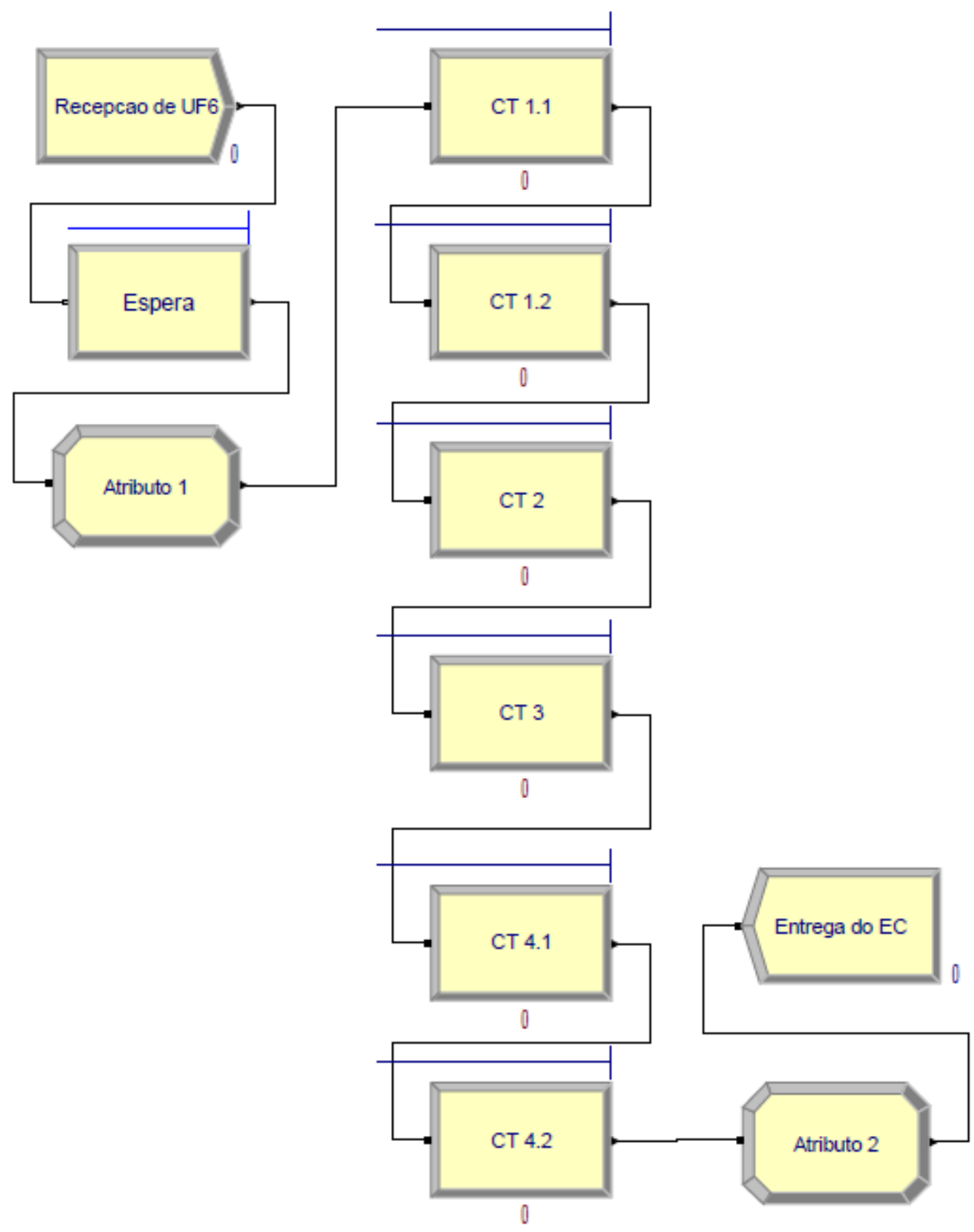

Fonte: autor da tese 
Figura 21 - Modelo em ARENA ${ }^{\circledR}$ para o cenário 19

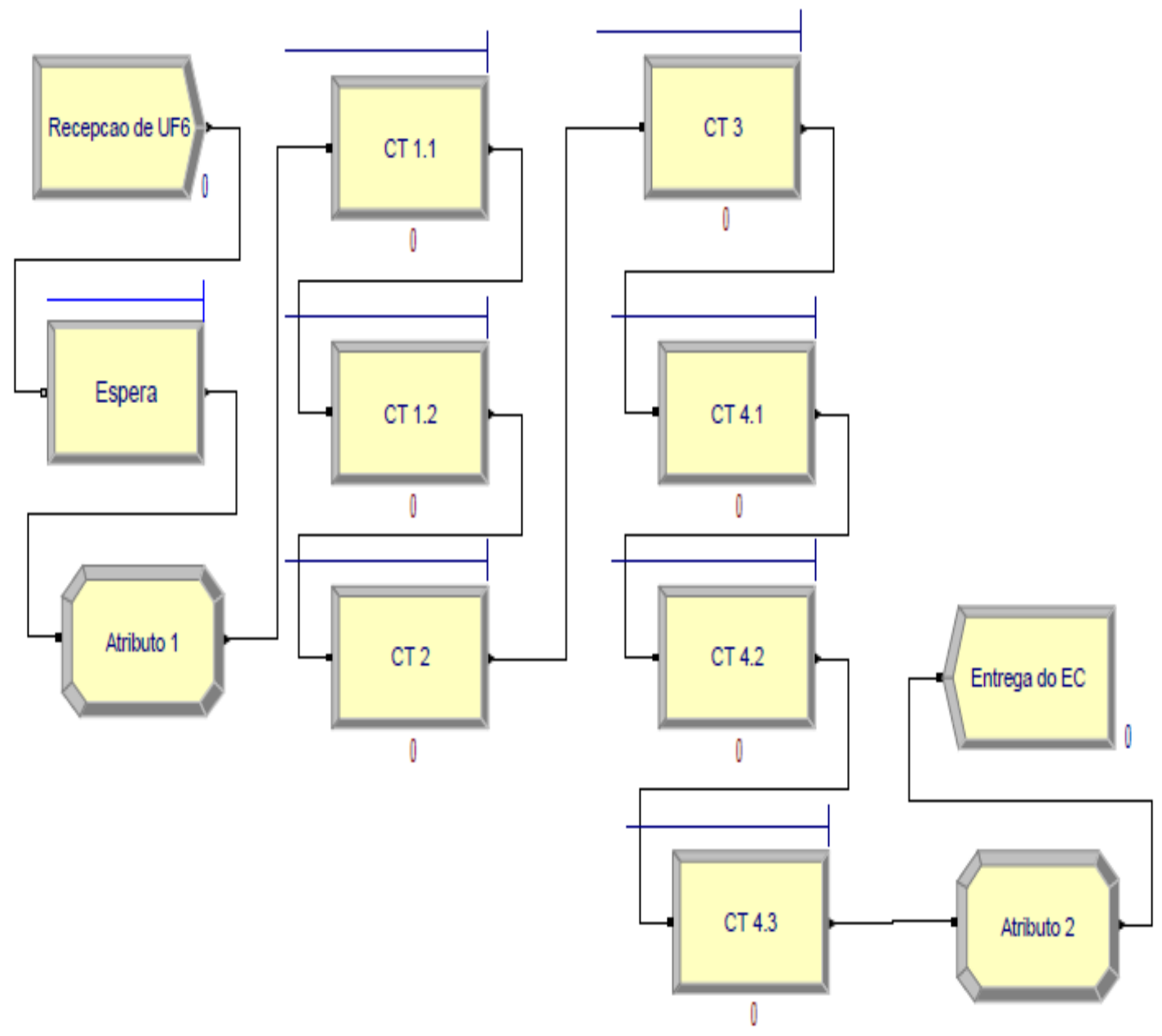

Fonte: autor da tese 
Figura 22 - Modelo em ARENA® para o cenário 20

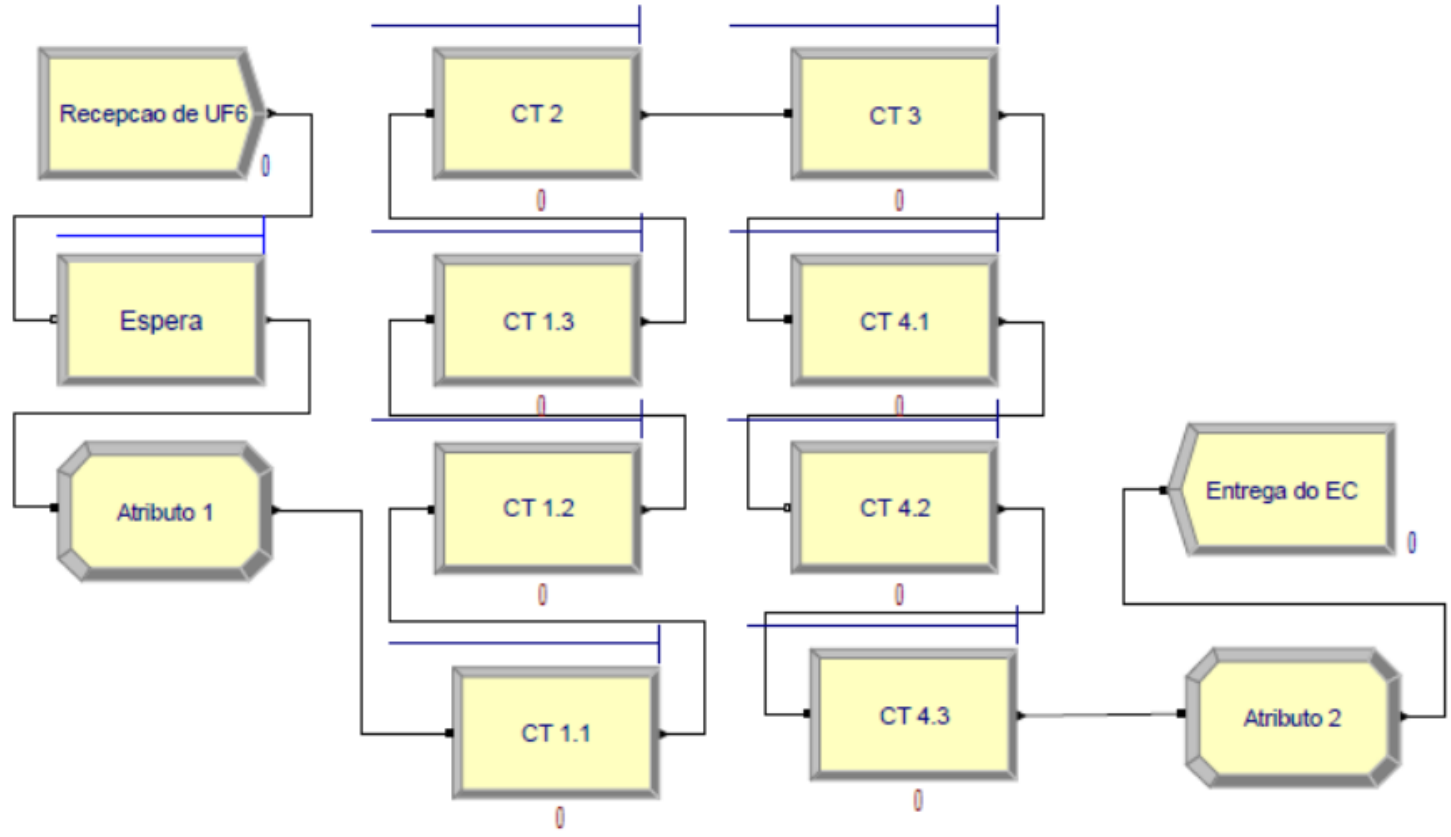

Fonte: autor da tese 
Figura 23 - Modelo em ARENA® para o cenário 21

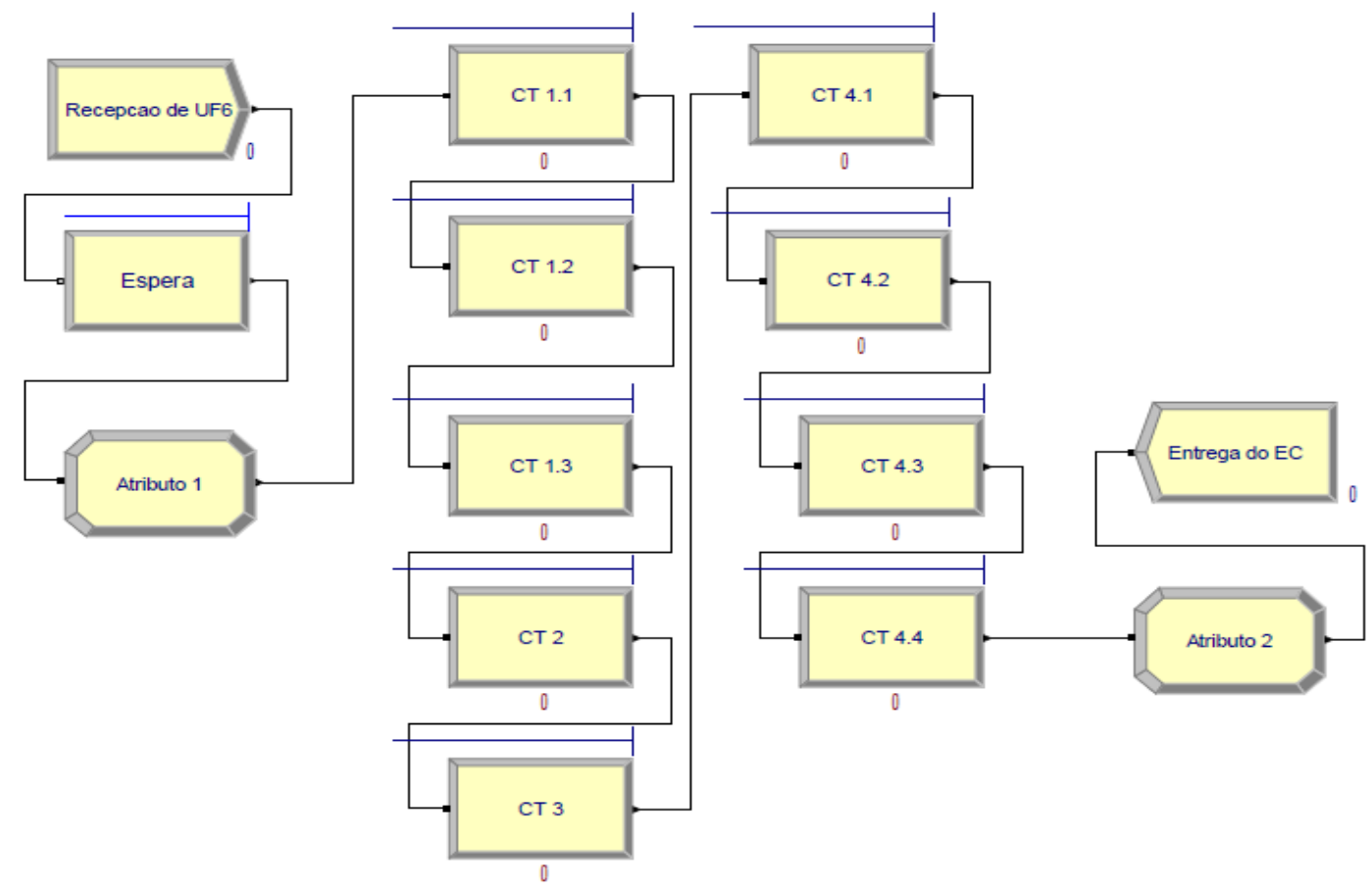

Fonte: autor da tese

Figura 24 - Modelo em ARENA® para o cenário 22
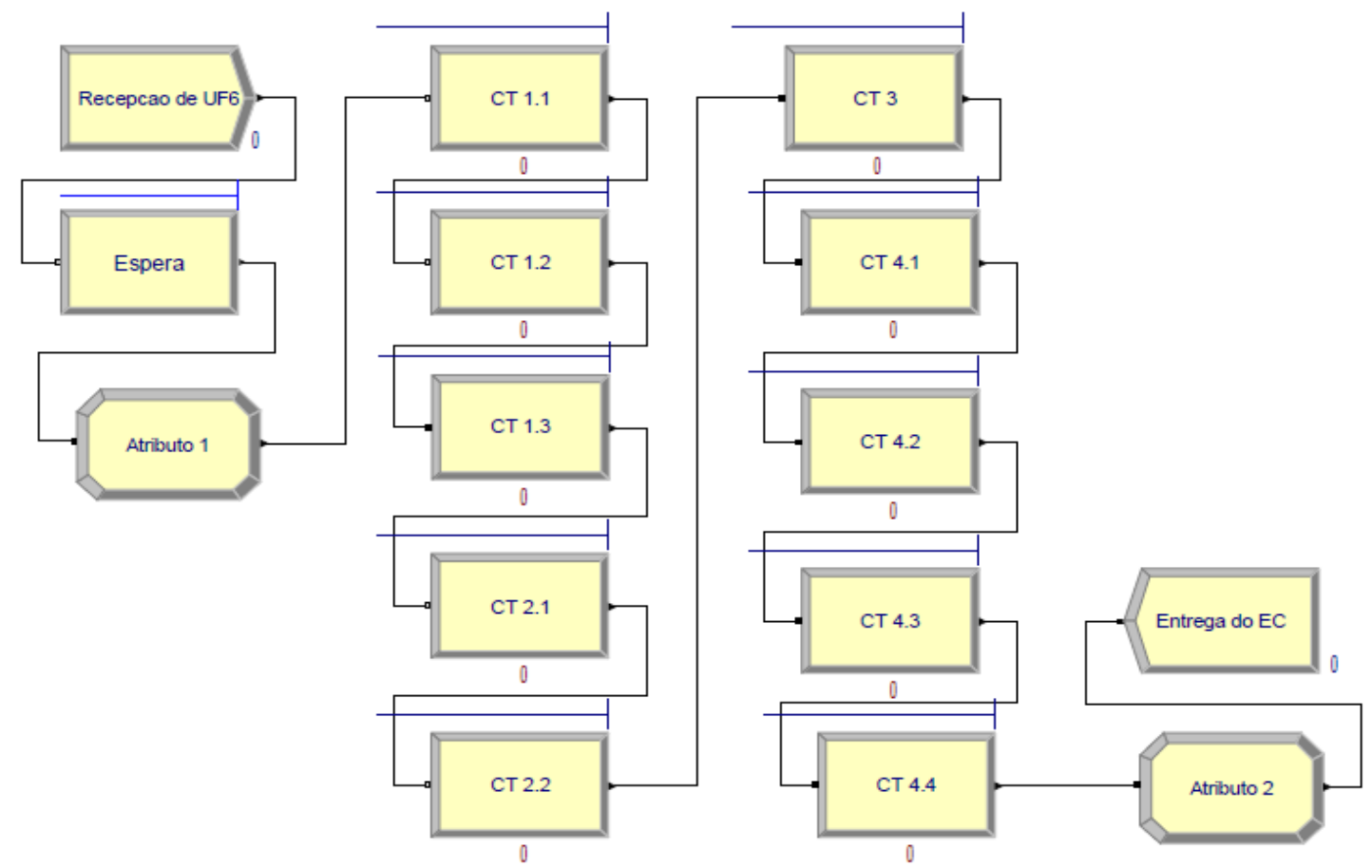

Fonte: autor da tese 
Figura 25 - Modelo em ARENA® para o cenário 23

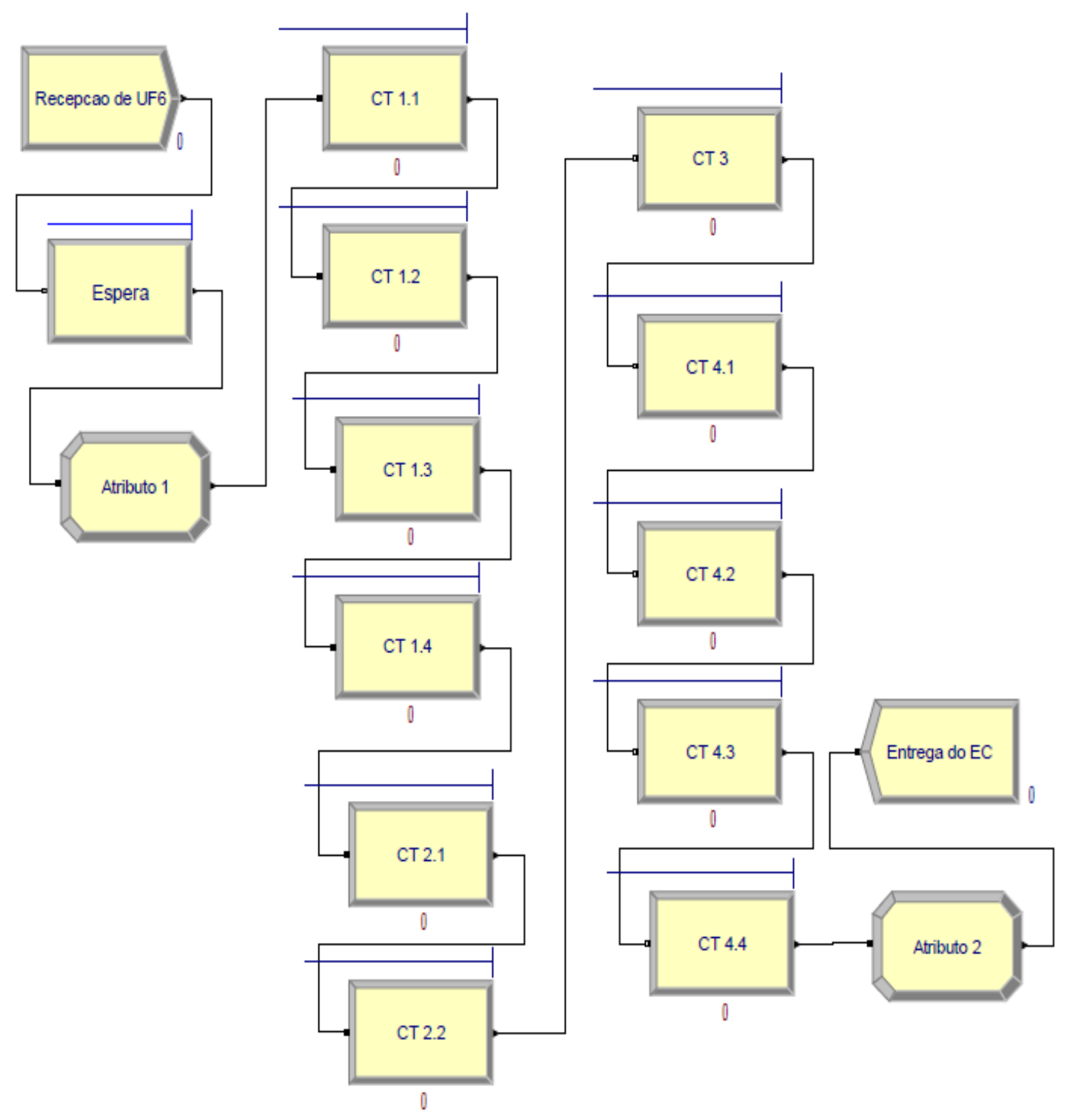

Fonte: autor da tese 


\section{APÊNDICE B - ESTIMATIVA DE CUSTO DE UM EC}

Apresenta-se a seguir o memorial de cálculo para estimativa de custo de um EC tipo placa típico, carregado com LEU U $\mathrm{U}_{3} \mathrm{Si}_{2}-\mathrm{Al}$ para uso em reatores nucleares de pesquisa. Foi feita apenas uma estimativa de custo, pois o levantamento exato desse valor é uma tarefa extensa, que excede o escopo deste trabalho. Por outro lado, tal estimativa mostrou-se útil para atingir os objetivos de parte da tese.

A referência adotada para esta estimativa de custo foi a fábrica de combustível nuclear do IPEN. Os motivos para a definição dessa referência foram:

- Necessidade de um referencial para preços de matéria prima, mão de obra e energia;

- A definição de um referencial aproxima a estimativa de custos da realidade desse referencial;

- A estimativa de custos baseada em um referencial serve de exemplo para a tese e

- Disponibilidade de dados.

A estimativa de custo foi feita com base na análise dos principais componentes de custo de um EC tipo placa típico. Para tanto foram consultadas referências bibliográficas específicas, que foram indicadas ao longo do presente memorial de cálculo. Nas seções a seguir está exposta a citada análise dos componentes de custo, iniciando-se pela estimativa de custos das matérias primas.

a) Alumínio

O material mais empregado na fabricação desse EC é o alumínio e na Tabela 15 estão apresentados os componentes feitos de alumínio, as dimensões médias desses componentes e o volume bruto de cada um [21,23,24,27,29,36-38].

$\mathrm{Na}$ Tabela 16 estão apresentados os passos seguintes da estimativa de custo de alumínio. Segue-se a explanação dos procedimentos usados para a elaboração da Tabela 16. 
Tabela 15 - Componentes do EC

\begin{tabular}{llll}
\hline $\begin{array}{l}\text { Nú- } \\
\text { mero }\end{array}$ & Componentes retangulares & $\begin{array}{c}\text { Comprimento, } \\
\text { Largura e altura }(\mathrm{mm})\end{array}$ & $\begin{array}{c}\text { Volume } \\
\left(\mathrm{m}^{3}\right)\end{array}$ \\
\hline 1 & Bocal & $265 \times 70 \times 70$ & 0,0013 \\
2 & Placa combustível interna & $660 \times 1,35 \times 74$ & $6,6 \times 10^{-5}$ \\
3 & Placa combustível externa & $670 \times 1,5 \times 74$ & $7,4 \times 10^{-5}$ \\
4 & Placa lateral & $875 \times 5 \times 81$ & 0,00035 \\
5 & Espaçador de placas & $75 \times 10 \times 30$ & $2,3 \times 10^{-5}$ \\
& combustíveis & Comprimento e & \\
& Componentes redondos & diâmetro (mm) & $1,5 \times 10^{-6}$ \\
6 & Pivô do espaçador & $5 \times 78$ & $1,1 \times 10^{-5}$ \\
7 & Pino de manuseio & $13 \times 81$ & $1,0 \times 10^{-6}$ \\
8 & Parafuso & $10 \times 13$ & \\
\hline
\end{tabular}

Fonte: autor da tese

Tabela 16 - Sequência de cálculo de custo de alumínio

\begin{tabular}{llcccc}
\hline $\begin{array}{l}\text { Nú- } \\
\text { mero }\end{array}$ & $\begin{array}{c}\text { Número de } \\
\text { peças em } \\
\text { um EC }\end{array}$ & $\begin{array}{c}\text { Peso } \\
\text { unitário } \\
(\mathrm{kg})\end{array}$ & $\begin{array}{c}\text { Peso em } \\
\text { um EC } \\
(\mathrm{kg})\end{array}$ & $\begin{array}{c}\text { Fator de } \\
\text { correção }\end{array}$ & $\begin{array}{c}\text { Peso final } \\
\text { em um EC } \\
(\mathrm{kg})\end{array}$ \\
\hline 1 & 1 & 3,50 & 3,50 & 1,0 & 4,51 \\
2 & 16 & 0,18 & 2,84 & 1,2 & 4,48 \\
3 & 2 & 0,20 & 0,40 & 1,2 & 0,83 \\
4 & 2 & 0,96 & 1,91 & 1,2 & 3,06 \\
5 & 2 & 0,06 & 0,12 & 1,2 & 0,19 \\
6 & 2 & 0,01 & 0,02 & 2,0 & 0,06 \\
7 & 1 & 0,03 & 0,03 & 2,0 & 0,08 \\
8 & 8 & 0,01 & 0,08 & 2,0 & 0,19 \\
\hline
\end{tabular}

Fonte: autor da tese 
- Na segunda coluna da Tabela 16 mostra-se o número de peças de cada componente necessário para fabricar um EC [21,23,24,27,29,36-38];

- Foi usada a densidade média do alumínio de $2.700 \mathrm{~kg} / \mathrm{m}^{3}$ [122]. Este valor foi multiplicado pelos volumes obtidos na Tabela 15 e os resultados estão expostos na terceira coluna da Tabela 16;

- A quarta coluna é o resultado da multiplicação entre as colunas 2 e 3;

- Na quinta coluna estão mostrados os fatores de engenharia aplicados para considerar o excesso de material necessário para a produção de cada componente [123,124] e

- A última coluna resulta do acréscimo de $30 \%$ aos valores da quinta, pois esse é o percentual médio da perda de alumínio em todos os processos necessários à fabricação de um EC [125].

A soma de todos os valores da última coluna da Tabela 16 resulta no peso médio de $13,4 \mathrm{~kg}$ de alumínio para fabricar um EC. O preço do alumínio é de cerca de US $\$ 5,22$ por $\mathrm{kg}$ [122] para compra de grandes quantidades desse material com referencial FOB portos norte-americanos. Foi acrescentado o fator de $100 \%$ sobre esse preço para considerar pequenas quantidades e impostos, de forma que o preço de alumínio usado neste trabalho foi US\$10,44 por $\mathrm{kg}$. Multiplicando-se esse preço pelo peso médio de $13,4 \mathrm{~kg}$, chega-se ao custo total de alumínio para a produção de um EC, que é de US\$139,90 e que foi chamado de Custo 1.

b) Outras matérias primas

As demais matérias primas consideradas neste trabalho foram hexafluoreto de urânio $\left(\mathrm{UF}_{6}\right)$, silício $(\mathrm{Si})$, magnésio $(\mathrm{Mg})$, nitogênio $(\mathrm{N})$, ácido nítrico $\left(\mathrm{HNO}_{3}\right)$ e cloreto estanoso $(\mathrm{SnCl})$. Na Tabela 17 estão apresentadas essas matérias primas, suas respectivas quantidades médias usadas na produção de um EC tipo placa típico $[21,24,36,37]$, seus custos, as referências de fontes de informação para os custos e o custo total de cada uma para a produção de um EC. 
Tabela 17 - Custo de outras matérias primas

\begin{tabular}{llrcrr}
\hline $\begin{array}{l}\text { Nú- } \\
\text { mero }\end{array}$ & Fórmula & $\begin{array}{r}\text { Preço } \\
\text { (US } \$ \text { lunidade) }\end{array}$ & Referência & $\begin{array}{r}\text { Quantidade } \\
\text { em um EC }\end{array}$ & $\begin{array}{c}\text { Custo em um } \\
\text { EC (US } \$)\end{array}$ \\
\hline 1 & $\mathrm{UF}_{6}$ & $110,20 / \mathrm{kg}$ & {$[126]$} & $2,25 \mathrm{~kg}$ & 247,95 \\
2 & $\mathrm{Si}$ & $6,00 / \mathrm{kg}$ & {$[127]$} & $3,00 \mathrm{~kg}$ & 18,88 \\
3 & $\mathrm{Mg}$ & $4,00 / \mathrm{kg}$ & {$[128]$} & $3,00 \mathrm{~kg}$ & 12,00 \\
4 & $\mathrm{~N}$ & $4,00 /$ litro & {$[129]$} & 50 litros & 200,00 \\
5 & $\mathrm{HNO}_{3}$ & $0,80 /$ litro & {$[130]$} & 5 litros & 4,00 \\
6 & $\mathrm{SnCl}$ & $88,00 / \mathrm{kg}$ & {$[131]$} & $10,00 \mathrm{~kg}$ & 880,00 \\
\hline
\end{tabular}

Fonte: autor da tese

Os valores obtidos das referências expostas na Tabela 17 são preços para grandes quantidades FOB portos dos EUA. Os preços apresentados na Tabela 17 incluem um acréscimo de 100\% sobre aqueles das referências para considerar pequenas quantidades e impostos. A soma de todos os valores da última coluna dessa tabela resulta em US\$1.361,95, chamado de Custo 2 .

\section{c) Peças compradas}

Algumas peças de um EC tipo placa típico não são produzidas na mesma fábrica que faz o combustível e monta o EC, ou seja, elas são compradas de fornecedores externos. Tais peças são geralmente feitas com o mesmo tipo de alumínio usado na fabricação das demais partes do EC. Para estimar o custo extra dessas peças, foram aplicados fatores de produção sobre o conteúdo de alumínio de cada peça comprada. Os resultados estão expostos na Tabela 18 [123-125].

Os custos expostos na Tabela 18 são uma estimativa dos custos de produção das peças constantes da mesma tabela. Esses custos não incluem o custo da matéria prima, já considerado nas Tabelas 16 e 17. O fator de produção constante da quarta coluna da Tabela 18 foi obtido da literatura [123-125]. A última coluna dessa tabela foi obtida pela multiplicação de sua terceira coluna por sua quarta coluna por US\$10,44, preço do alumínio citado anteriormente. A soma dos valores da última coluna da Tabela 18 resulta US\$214,23, chamado de Custo 3 . 
Tabela 18 - Custo de peças compradas

\begin{tabular}{llrrr}
\hline $\begin{array}{l}\text { Nú- } \\
\text { mero }\end{array}$ & Componente & $\begin{array}{r}\text { Peso de } \\
\text { Al (kg) }\end{array}$ & $\begin{array}{r}\text { Fator de } \\
\text { produção }\end{array}$ & $\begin{array}{r}\text { Custo em um } \\
\text { EC (US\$) }\end{array}$ \\
\hline 1 & Bocal & 4,51 & 4 & 188,34 \\
7 & Pino de & 0,19 & 8 & 15,87 \\
8 & manuseio & 0,08 & 12 & 10,02 \\
\hline
\end{tabular}

Fonte: autor da tese

d) Energia

O principal tipo de energia usado na fabricação do EC tipo placa típico é a elétrica, motivo pelo qual esse foi o único tipo de energia considerado neste trabalho. Na Tabela 19 estão apresentados os principais equipamentos usados pela fábrica de combustível nuclear do IPEN, suas respectivas potências registradas durante a coleta de dados, o tempo de operação de cada equipamento para a produção de um EC $[21,24]$ e o custo.

Tabela 19 - Custo de energia elétrica

\begin{tabular}{llrrr}
\hline Item & Equipamento & $\begin{array}{c}\text { Potência } \\
(\mathrm{kW})\end{array}$ & $\begin{array}{c}\text { Operação } \\
\text { média (horas) }\end{array}$ & $\begin{array}{c}\text { Custo em um } \\
\text { EC (US\$) }\end{array}$ \\
\hline 1 & Estufa & 5,6 & 36 & 348,77 \\
2 & Forno elétrico & 32,5 & 4 & 224,90 \\
3 & Forno de indução & 43,8 & 3 & 227,32 \\
4 & Forno de recozimento & 22,3 & 8 & 308,63 \\
\hline
\end{tabular}

Fonte: autor da tese

A última coluna da Tabela 19 foi obtida pela multiplicação de sua terceira coluna por sua quarta coluna e por US\$1,73, que é o preço por kWh de energia elétrica [132]. A soma dos valores da última coluna da Tabela 19 resulta no valor de US\$1.109,62, que é a estimativa de custo de energia elétrica consumida pelos 
equipamentos citados nessa tabela para a produção de um EC. Porém, foi necessário aumentar esse valor em $20 \%$ para considerar o chamado consumobase da fábrica [124,125]. Chama-se consumo-base à energia elétrica necessária para manutenção e para contabilizar as perdas. A aplicação do aumento de $20 \%$ resultou em US\$1.331,55 como custo total de energia para a produção de um EC, nomeado como Custo 4.

\section{e) Mão de obra}

Tomou-se como referência para custo de mão de obra o salário mensal de um técnico no topo da Carreira de Desenvolvimento Tecnológico do IPEN. Esse salário era de $R \$ 7.902,14$ [133] em julho de 2015, representando US\$2.507,94 de acordo com a taxa de câmbio de US\$1,00 = R \$ 3,15 [134]. O gasto da organização com esse empregado é de aproximadamente $80 \%$ de um salário, além do próprio salário, devido a impostos e leis laborais [135,136]. Dessa forma, o custo aproximado de um técnico resultou em US\$ 5.414,29 por mês ou US\$ 28,21 por hora, assumindo 160 horas de trabalho por mês.

Na Tabela 20 está exposto o número de trabalhadores alocados em cada um dos quatro CT existentes na fábrica de combustível nuclear do IPEN na situação inicial. A terceira coluna da Tabela 20 foi obtida pela multiplicação do número de trabalhadores de cada centro de trabalho pelo custo de um trabalhador por hora. A quarta coluna da Tabela 22 apresenta o tempo necessário em cada CT para produzir um EC $[21,24,29]$ no cenário 1. Na quinta coluna dessa tabela estão apresentados os resultados da multiplicação de suas respectivas colunas três e quatro.

A soma da última coluna da Tabela 20 resultou em US\$20.321,37, valor que corresponde à estimativa de custo de mão de obra para a produção de um EC. Nesse valor não estão incluídos os custos de mão de obra que ocorrem durante os dois meses reservados para manutenção.

Admitiu-se que a produção ocorresse durante dez meses por ano. Mas os custos laborais incidem todos os doze meses do ano. Por isso deve haver um acréscimo de (12/10) - $1=20 \%$ sobre o custo de mão de obra. Assim, somou-se $20 \%$ ao valor obtido para a produção de um EC e obteve-se US $\$ 24.385,64$ como o custo total de mão de obra por EC, chamado de Custo 5. 
Tabela 20 - Custo de mão de obra

\begin{tabular}{lcrrr}
\hline CT & $\begin{array}{c}\text { Número de } \\
\text { trabalhadores }\end{array}$ & $\begin{array}{c}\text { Custo } \\
\text { (US\$/hora) }\end{array}$ & $\begin{array}{r}\text { Tempo } \\
\text { (horas) }\end{array}$ & \multicolumn{1}{c}{$\begin{array}{c}\text { Custo em um } \\
\text { EC (US } \$)\end{array}$} \\
\hline 1 & 4 & 112,86 & 45,0 & $5.078,58$ \\
2 & 3 & 84,64 & 20,8 & $1.756,34$ \\
3 & 5 & 141,07 & 17,0 & $2.398,22$ \\
4 & 6 & 169,29 & 65,5 & $11.088,23$ \\
\hline
\end{tabular}

Fonte: autor da tese

f) Custo ambiental e custo total

A taxa ambiental crítica é um coeficiente usado para levar em conta os custos ambientais de diferentes atividades humanas e pode variar substancialmente [137]. Assim, foi considerado o valor da taxa ambiental crítica como 10\% para a produção de um EC. Na Tabela 21 estão apresentados os custos de 1 até 5 calculados anteriormente, sua soma, intitulada subtotal, o acréscimo de $10 \%$ para o custo ambiental e o custo total estimado para a produção de um EC.

Tabela 21 - Estimativa de custo de um EC tipo placa típico

\begin{tabular}{clr}
\hline Custo & \multicolumn{1}{c}{ Descrição } & \multicolumn{1}{c}{ US\$ } \\
\hline 1 & Alumínio & 139,90 \\
2 & Outras matérias primas & $1.361,95$ \\
3 & Peças compradas & 214,23 \\
4 & Energia & $1.331,55$ \\
5 & Mão de obra & $24.385,64$ \\
6 & Subtotal & $27.433,27$ \\
7 & Ambiental & $2.743,33$ \\
8 & Total geral & $30.716,59$ \\
\hline
\end{tabular}

Fonte: autor da tese 
O total geral de US\$30.716,59 é a estimativa final de custos para a produção de um EC tipo placa típico carregado com LEU U $\mathrm{U}_{3} \mathrm{Si}_{2}-\mathrm{Al}$. Esse valor corresponde ao custo de produção de um EC (W), usado como dado de entrada no modelo linear de minimização de custo no Capítulo 6. 


\section{0 ÍNDICE}

A

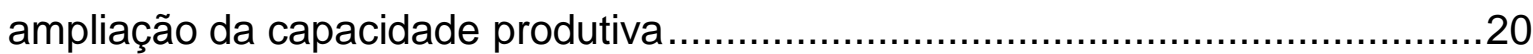

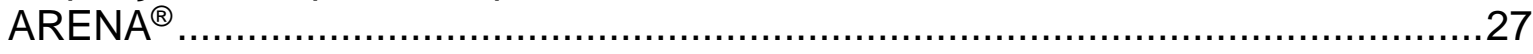

C

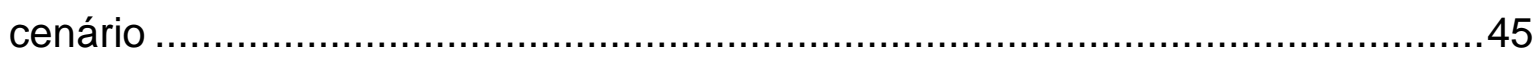

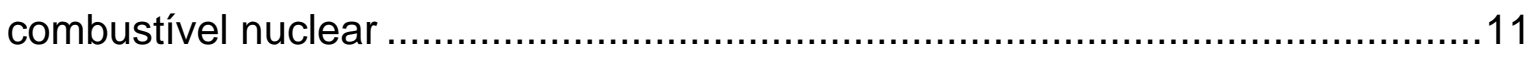

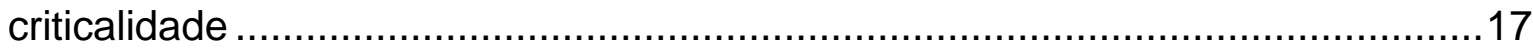

E

elemento combustível (EC) tipo placa típico ....................................................11

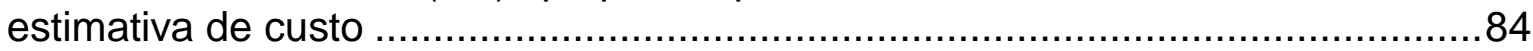

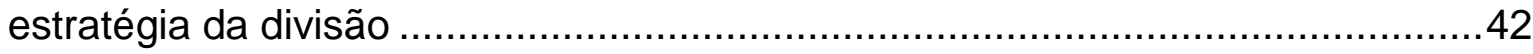

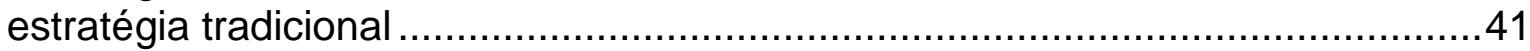

$\boldsymbol{F}$

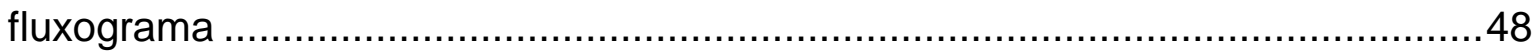

G

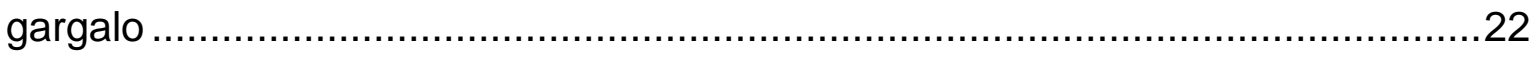

$\boldsymbol{H}$

HEU ……

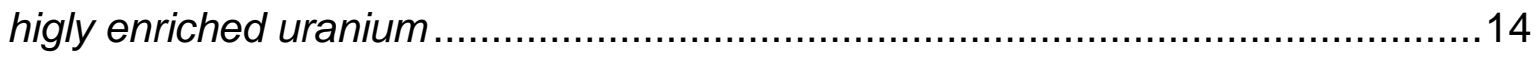

$\boldsymbol{L}$

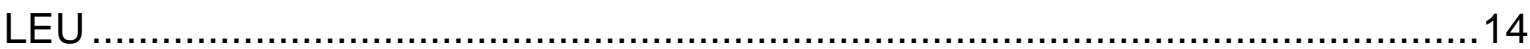

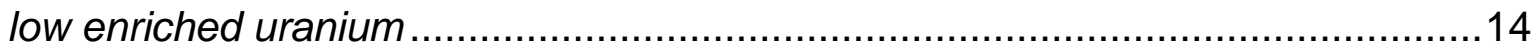

M

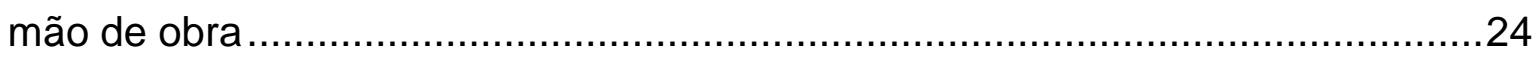

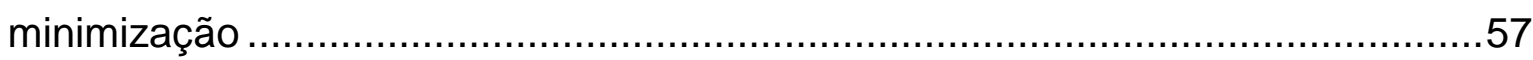

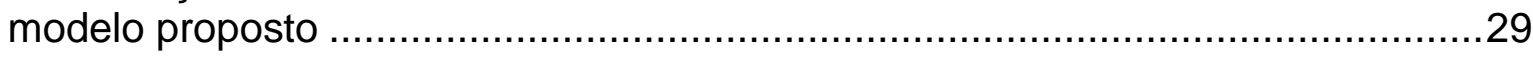

$\boldsymbol{P}$

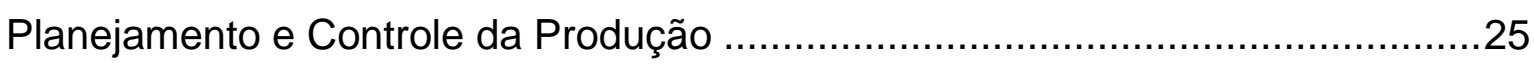

$\boldsymbol{R}$

reatores nucleares de pesquisa.

$S$

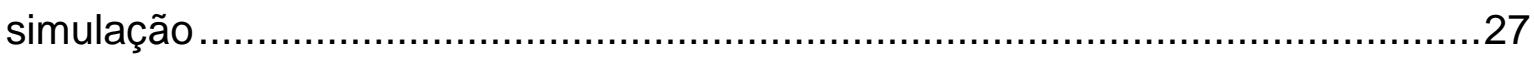

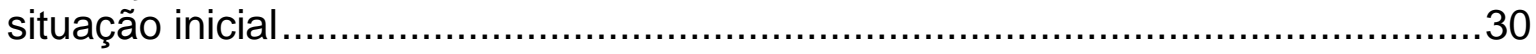


visão macro

22

visão micro

..22 


\section{REFERÊNCIAS BIBLIOGRÁFICAS}

[1] AMALDI, E. From the discovery of the neutron to the discovery of nuclear fission. Physics Reports, v. 111, n. 1-4, p. 1-331, 1984.

[2] SEKIMOTO, H. Nuclear reactor theory. 1. ed. Tokyo, Japan: Tokyo Institute of Technology, 2007. v. 1

[3] GIRALDO, J. S. et al. Fundamentals of Nuclear Power. n. December, p. 1-67, 2012.

[4] BLANCO, D. E. Atlas Energia Nuclear Aneel. Atlas Energia Nuclear Aneel, v. III, p. 117-128, 1999.

[5] REACTOR, A. N. IPEN / MB-01 Um reator nuclear projetado e construído no Brasil. 1988.

[6] RAYLMAN, R. R.; STOLIN, A. V. Immersion cooling of silicon photomultipliers (SiPM) for nuclear medicine imaging applications. Radiation Measurements, $v$. 85, p. 111-115, 2016.

[7] WRIGHT, C. L. et al. Advancing Precision Nuclear Medicine and Molecular Imaging for Lymphoma. PET Clinics, v. 12, n. 1, p. 63-82, 2016.

[8] CHEN, T. et al. Recent developments in the application of nuclear technology on agro-food quality and safety control in China. Food Control, p. 1-7, 2015. [9] CHENG, X. et al. European activities on crosscutting thermal-hydraulic phenomena for innovative nuclear systems. Nuclear Engineering and Design, $v$. 290, p. 2-12, 2015.

[10] IPEN. Órbita IPENSão Paulo, SP, Brasil, 2012.

[11] ALMAZ, E. et al. The effects of neutron irradiation and low temperature annealing on the electrical properties of highly doped $4 \mathrm{H}$ silicon carbide. Nuclear Instruments and Methods in Physics Research, Section A: Accelerators, Spectrometers, Detectors and Associated Equipment, v. 622, n. 1, p. $200-$ 206, 2010.

[12] HUSEYNOV, E. M. Investigation of the agglomeration and amorphous transformation effects of neutron irradiation on the nanocrystalline silicon carbide (3C-SiC) using TEM and SEM methods. Physica B: Condensed Matter, v. 510, n. December 2016, p. 99-103, 2017. 
[13] VIERERBL, L. et al. Radiation measurements after irradiation of silicon for neutron transmutation doping. Radiation Physics and Chemistry, v. 95, p. 389391, 2014.

[14] ZHANG, H. et al. Thirty meters small angle neutron scattering instrument at China advanced research reactor. Nuclear Instruments and Methods in Physics Research, Section A: Accelerators, Spectrometers, Detectors and Associated Equipment, v. 735, p. 490-495, 2014.

[15] FERRARO, D.; VILLARINO, E. Full 3-D core calculations with refueling for the OPAL Research Reactor using Monte Carlo Code Serpent 2. Annals of Nuclear Energy, v. 92, p. 369-377, 2016.

[16] HONG, S.; BRADSHAW, C. J. A.; BROOK, B. W. Nuclear power can reduce emissions and maintain a strong economy: Rating Australia's optimal future electricity-generation mix by technologies and policies. Applied Energy, v. 136, p. 712-725, 2014.

[17] KHAJVAND, N.; MIRVAKILI, S. M.; FAGHIHI, F. Cold neutron source conceptual designing for Tehran Research Reactor. Annals of Nuclear Energy, v. 92, p. 407-412, 2016.

[18] TURCANU, C. et al. Like a bridge over troubled water - Opening pathways for integrating social sciences and humanities into nuclear research. Journal of Environmental Radioactivity, v. 153, p. 88-96, 2016.

[19] PEGONEN, R. et al. Hot fuel element thermal-hydraulics in the Jules Horowitz Reactor. Nuclear Engineering and Design, v. 300, p. 149-160, 2016.

[20] CHOO, K. N. et al. Contribution of Hanaro irradiation technologies to national nuclear R\&D. Nuclear Engineering and Technology, v. 46, n. 4, p. 501-512, 2014.

[21] DURAZZO, M.; RIELLA, H. G. Procedures for Manufacturing Nuclear

Research Reactor Fuel Elements. 1st. ed. Saarbrücken, Germany:

OmniScriptum GmbH \& Co. KG, 2015.

[22] NEUMANN, C.; SCALICE, R. K. Projeto de Fábrica e layout. 1st. ed. Rio de Janeiro, RJ, Brasil: Editora Elsevier, 2015.

[23] SNELGROVE, J. L. et al. THE USE OF U3Si2 DISPERSED IN ALUMINUM IN PLATE-TYPE FUEL ELEMENTS FOR RESEARCH AND TEST

REACTORSANL / RERTR / TM-11. Argonne, IL: [s.n.]. 
[24] SALIBA-SILVA, A. M. et al. Research Reactor Fuel Fabrication to Produce Radioisotopes. Radioisotopes-Applications in Physical Sciences: InTech, 2011.

[25] COMISSÃO NACIONAL DE ENERGIA NUCLEAR. Descomissionamento de usinas nucleoelétricas. . 2012, p. 8.

[26] FERRUfINO, F. B. J. Metrologia e Controle de Processo do Elemento Combustível. São Paulo, SP, Brasil: [s.n.].

[27] GAN, J. et al. Microstructure of the irradiated $U$ $3 \mathrm{Si}$

2/Al silicide dispersion fuel. Journal of Nuclear Materials, v. 419, n. 1-3, p. 97104, 2011.

[28] HEDAYAT, A. Developing a practical optimization of the refueling program for ordinary research reactors using a modified simulated annealing method.

Progress in Nuclear Energy, v. 76, p. 191-205, 2014.

[29] IAEA. Nuclear Reactor Fuel ManufactureAtomic Energy, 2000.

[30] U.S. DEPARTMENT OF ENERGY. GTRI's Convert Program: Minimizing the Use of Highly Enriched Uranium. Disponível em:

<http://www.nnsa.energy.gov/mediaroom/factsheets/gtri-convert>. Acesso em: 10 set. 2015.

[31] U.S. DEPARTMENT OF ENERGY. RERTR - Reduced Enrichment for Research and Test Reactors. Disponível em:

$<$ http://www.rertr.anl.gov/index.html>.

[32] DIVISION, N. E.; LANDERS, C. Research and test reactor conversion to low enriched uranium fuel: technical and programmatic progress. p. 1-9, [s.d.].

[33] FINLAY, M. R.; HOFMAN, G. L.; SNELGROVE, J. L. Irradiation behaviour of uranium silicide compounds. Journal of Nuclear Materials, v. 325, n. 2-3, p. 118-128, 2004.

[34] KIM, Y. S. et al. Temperature and dose dependence of fission-gas-bubble swelling in U3Si2. Journal of Nuclear Materials, v. 389, n. 3, p. 443-449, 2009. [35] IAEA. Good Practices for Qualification of High Density Low Enriched Uranium Research Reactor FuelsEnergy SeriesAustria, 2009. [36] SIMNAD, M. T. PERSPECTIVE ON RESEARCH REACTORS AND THEIR FUEL ELEMENTS. Journal of Nuclear Materials, v. 100, p. 78-92, 1981. [37] OLIVARES, L. Manufacture of Nuclear Fuel Elements in ChileChilean 
Nuclear Energy Commission, , 2013.

[38] ORGANISATION FOR ECONOMIC CO-OPERATION AND DEVELOPMENT; NUCLEAR ENERGY AGENCY. Nuclear Energy in a Sustainable Development Perspective. 2000.

[39] KIM, H. et al. Drop Impact Analysis of Plate-Type Fuel Assembly in Research Reactor. Nuclear Engineering and Technology, v. 46, n. 4, p. 529-540, 2014. [40] HODGES, M. S.; SANDERS, C. E. Nuclear criticality accident safety, near misses and classificationProgress in Nuclear Energy. [s.I.] Elsevier Ltd, 2014. Disponível em: <http://dx.doi.org/10.1016/j.pnucene.2014.05.018>.

[41] AYRES, D.; EATON, M. D. Uncertainty quantification in nuclear criticality modelling using a high dimensional model representation. Annals of Nuclear Energy, v. 80, p. 379-402, 2015.

[42] PRUVOST, N. L.; PAXTON, H. C. Nuclear Criticality Safety Guide. Los Alamos, CA: [s.n.].

[43] WANG, T. R. et al. An empirical classification-based framework for the safety criticality assessment of energy production systems, in presence of inconsistent data. Reliability Engineering and System Safety, v. 157, p. 139-151, 2017. [44] COMISSÃO NACIONAL DE ENERGIA NUCLEAR. Norma CNEN 1. 09 Segurança de fábricas de elementos combustíveis. . 1980, p. 1-68. [45] IAEA SAFETY STANDARDS SERIES NO. GS-R-3. The Management System for Facilities and ActivitiesInternational Atomic Energy Agency - IAEA, , 2006.

[46] KRAJEWSKI, L. J.; MALHOTRA, M. K.; RITZMAN, L. Operations Management: Processes and Supply Chains Plus. 11ht. ed. Upper Saddle River, New Jersey, USA: Prentice Hall, 2015.

[47] CHASE, R.; JACOBS, R. Operations and Supply Chain Management. 14th. ed. New York, NY, USA: McGraw-Hill Higher Education, 2013.

[48] SLACK, N. et al. Operations and Process Management. 2nd. ed. Upper Saddle River, New Jersey, USA: Prentice Hall, 2008.

[49] STEVENSON, W. J. Operations Management. 12th. ed. New York, NY, USA: McGraw-Hill Education, 2014.

[50] MIGUEL, P. C. Metodologia de Pesquisa em Engenharia de Produção e Gestão de Operações. 2. ed. ed. São Paulo, SP, Brasil: Elsevier Editora Ltda., 
2012.

[51] HOPP, W. J.; SPEARMAN, M. L. FACTORY PHYSICS: FOUNDATIONS OF

MANUFACTURING MANAGEMENT. 2nd. ed. New York, NY: Irwin/McGraw-Hill, 2001.

[52] BALAMAN, Ş. Y. Investment planning and strategic management of sustainable systems for clean power generation: An $\varepsilon$-constraint based multi objective modelling approach. Journal of Cleaner Production, v. 137, p. 1179_ 1190, 2016.

[53] BROCKE, J. VOM; ZELT, S.; SCHMIEDEL, T. On the role of context in business process management. International Journal of Information Management, v. 36, n. 3, p. 486-495, 2016.

[54] CERCHIONE, R.; ESPOSITO, E. A systematic review of supply chain knowledge management research: State of the art and research opportunities. International Journal of Production Economics, v. 182, p. 276-292, 2016. [55] CHOI, S.; MESSINGER, P. R. The role of fairness in competitive supply chain relationships: An experimental study. European Journal of Operational Research, v. 251, n. 3, p. 798-813, 2014.

[56] TSENG, M.-L. et al. A framework for evaluating the performance of sustainable service supply chain management under uncertainty. International Journal of Production Economics, n. 2012, 2016.

[57] ZHAO, R. et al. An Optimization Model for Green Supply Chain Management by Using a Big Data Analytic Approach. Journal of Cleaner Production, 2016. [58] ZHU, Q.; FENG, Y.; CHOI, S.-B. The role of customer relational governance in environmental and economic performance improvement through green supply chain management. Journal of Cleaner Production, p. 27, 2016.

[59] GOLDRATT, E. M. Não é sorte : a aplicação dos processos de raciocínio da teoria das restrições. 1st. ed. São Paulo, SP, Brasil: Editora Nobel, 2004. [60] JACOBS, F. R.; CHASE, R. B. Administração da Produção e de Operações. 1. ed. ed. São Paulo, SP, Brasil: Bookman Cia. Editora Ltda., 2009. [61] RAGSDALE, C. Spreadsheet Modeling \& Decision Analysis, Sixth Edition. Sixth ed. Mason, OH: South-Western Cengage Learning, 2012. [62] SLACK, N.; BRANDON-JONES, A.; JOHNSTON, R. Operations management. 7th. ed. Upper Saddle River, New Jersey, USA: Prentice Hall, 
2013.

[63] CERDAS, F. et al. ScienceDirect Defining Circulation Factories - A pathway towards Factories of the Future. Procedia CIRP, v. 29, p. 627-632, 2015.

[64] CALLE, M. et al. Integrated management of inventory and production systems based on floating decoupling point and real-time information: A simulation based analysis. International Journal of Production Economics, p. 1-10, 2014.

[65] QIN, F. et al. Supply-chain performance anomalies: Fairness concerns under private cost information. European Journal of Operational Research, v. 252, n. 1, p. 170-182, 2016.

[66] MUTHER, R. Planejamentyo do Lay-out: Sistema SLP. 1st. ed. São Paulo, SP, Brasil: Edgard Blücher, 1986.

[67] KOLBACHEV, E.; KOLBACHEVA, T.; SALNIKOVA, Y. Application of Natural Science and Engineering Methods as a Trend in the Development of Economic and Management Research and Education. Procedia - Social and Behavioral Sciences, v. 214, n. June, p. 1000-1007, 2015.

[68] ALMOMANI, M. A. et al. A proposed approach for setup time reduction through integrating conventional SMED method with multiple criteria decisionmaking techniques. Computers and Industrial Engineering, v. 66, n. 2, p. 461469, 2013.

[69] IZMAILOV, A.; KORNEVA, D.; KOZHEMIAKIN, A. Effective Project Management with Theory of Constraints. Procedia - Social and Behavioral Sciences, v. 229, n. March, p. 96-103, 2016.

[70] OLARTE, C.; PIMENTEL, E. On concurrent behaviors and focusing in linear logic. Theoretical Computer Science, n. August, 2016.

[71] UYGUN, Ö.; DEDE, A. Performance evaluation of green supply chain management using integrated fuzzy multi-criteria decision making techniques.

Computers \& Industrial Engineering, 2016.

[72] ZHANG, L. L.; LEE, C.; ZHANG, S. An integrated model for strategic supply chain design: Formulation and ABC-based solution approach. Expert Systems with Applications, v. 52, p. 39-49, 2016.

[73] ADHVARYU, A. R.; NYSHADHAM, A. Health, Enterprise, and Labor Complementarity in the Household. Journal of Development Economics, v. 126, n. November 2016, p. 91-111, 2013. 
[74] CALIENDO, M.; MAHLSTEDT, R. Unobservable , but Unimportant? The Relevance of Usually Unobserved Variables for the Evaluation of Labor Market Policies. Labour Economics, v. 46, n. February, p. 14-25, 2017.

[75] CHAUDHURI, S.; MARJIT, S. International trade and quality of labour. International Review of Economics \& Finance, v. 49, n. December 2016, p. 582-595, 2017.

[76] LIM, S.; MAHBUB MORSHED, A. K. M. Fiscal policy in a small open economy with cross-border labor mobility. Journal of Macroeconomics, v. 52, p. 147-174, 2017.

[77] DO VALLE, C. E. Implantação de Indústrias. 1. ed. ed. Rio de Janeiro, RJ, Brasil: Livros Técncos e Científicos Editora S.A., 1975.

[78] GURGEL, F. A. Administração dos Fluxos de Materiais e de Produtos. 1st. ed. São Paulo, SP, Brasil: Editora Atlas, 1996.

[79] COMISSÃO NACIONAL DE ENERGIA NUCLEAR. Norma CNEN 1.04 Licenciamento de Instalações Nucleares. . 2002, p. 1-25.

[80] BARIL, C. et al. Use of a discrete-event simulation in a Kaizen event: A case study in healthcare. European Journal of Operational Research, v. 249, n. 1, p. 327-339, 2016.

[81] STOCKER, E. et al. Use of mechanistic simulations as a quantitative riskranking tool within the quality by design framework. International Journal of Pharmaceutics, v. 475, n. 1, p. e245-e255, 2014.

[82] ALTIOK, T.; MELAMED, B. Simulation Modeling and Analysis with ARENA. 1st. ed. Burlington, MA, USA: Academic Press, 2007.

[83] CHUNG, C. A. Simulation Modeling Handbook. 1st. ed. Boca Raton, FL, USA: CRC Press, Inc., 2004.

[84] DIALLO, S.; MUSTAFEE, N. Towards an Encyclopedia of Modeling and Simulation Methodology. n. 2003, p. 2692-2703, 2015.

[85] HARRINGTON, H. J.; TUMAY, K. Simulation Modeling Methods. 1st. ed. New York, NY, USA: McGraw-Hill, 2000.

[86] KOUKI, M. et al. Input data management for energy related discrete event simulation modelling. Journal of Cleaner Production, v. 141, p. 194-207, 2017. [87] LAW, A. M. Simulation Modeling and Analysis. 4th. ed. Boston, MA, USA: McGraw-Hill, 2007. 
[88] SHINGO, S. Una revolución en la producción: el sistema SMED. 3. ed. ed. Madrid, Espanha: Productivity Press, Inc., 1993.

[89] SOMOHANO, A. et al. a Model-Driven Engineering Approach To Simulation Experiment Design and Execution. Proceedings of the $\mathbf{2 0 1 5}$ Winter Simulation Conference, v. 1, n. 1, p. 2632-2643, 2015.

[90] TIMM, I. J.; LORIG, F. A survey on methodological aspects of computer simulation as research technique. Proceedings - Winter Simulation Conference, v. 2016-Febru, p. 2704-2715, 2016.

[91] VASILECAS, O.; KALIBATIENE, D.; LAVBI, D. Rule- and context-based dynamic business process modelling and simulation. Journal of Systems and Software, v. 122, p. 1-15, 2016.

[92] KÁDÁR, B.; PFEIFFER, A.; MONOSTORI, L. Discrete event simulation for supporting production planning and scheduling decisions in digital factories. 37th CIRP international seminar, 2004.

[93] ARENALES, M. et al. Pesquisa Operacional. 1. ed. Rio de Janeiro: Campus Editora, 2007. v. 1

[94] JEON, S. M.; KIM, G. A survey of simulation modeling techniques in production planning and control (PPC). Production Planning \& Control, v. 27, n. 5, p. 360-377, 2016.

[95] DONHAUSER, T. et al. Valid Methodology for Using Discrete Event Simulation to Improve the Resource Consumption for the Manufacturing of Masonry Units. Procedia CIRP, v. 41, p. 57-62, 2016.

[96] LIRAVIASL, K. K. et al. A Framework for Modelling Reconfigurable Manufacturing Systems Using Hybridized Discrete-Event and Agent-based Simulation. IFAC-PapersOnLine, v. 48, n. 3, p. 1535-1540, 2015.

[97] DIAS, L. M. S. et al. Discrete Simulation Tools RankingBraga, Portugal, 2011. Disponível em:

<https://repositorium.sdum.uminho.pt/bitstream/1822/15634/1/ISC_2011_Veneza_ 5_10.pdf>

[98] ROCKWELL AUTOMATION. Arena Simulation SoftwareWexford, PA, USA, 2015. Disponível em: <https://www.arenasimulation.com/> [99] JAHANGIRIAN, M. et al. Simulation in manufacturing and business: A review. European Journal of Operational Research, v. 203, n. 1, p. 1-13, 2010. 
[100] CERVO, A. L.; BERVIAN, P. A.; DA SILVA, R. Metodologia Científica. 6. ed. ed. São Paulo, SP, Brasil: Pearson Prentice Hall, 2009.

[101] VERGARA, S. C. Métodos de Pesquisa em Administração. 5. ed. ed. São Paulo, SP, Brasil: Editora Atlas S.A., 2012.

[102] BRYMAN, A. Social Research Methods. 3. ed. ed. New York, NY, USA:

Oxford University Press, 2008.

[103] GIBBS, G. Análise de Dados Qualitativos. 1. ed. ed. São Paulo, SP, Brasil: Bookman Cia. Editora Ltda., 2009.

[104] WACHS, D. M.; CLARK, C. R.; DUNAVANT, R. J. Conceptual Process

Description for the Manufacture of Low-Enriched Uranium-Molybdenum

Fuel. Idaho Falls, Idaho: [s.n.].

[105] PINEDO, M. L. Scheduling. New York, NY: Springer Science+Business Media, LLC, 2008.

[106] BRASIL, I. N. DO. Ciclo do Combustível Nuclear. Disponível em:

<http://www.inb.gov.br/pt-br/Acessolnfo/FAQ>. Acesso em: 30 out. 2013.

[107] CHASE, R. B.; AQUILANO, N. J. Fundamentals of operations

management. 2. ed. ed. Chicago: Irwin, 1995.

[108] YAMAGUSHI, M. Análise de Criticalidade do Cofre de Salvaguarda do

Centro de Combustível Nuclear (CCN). São Paulo, SP, Brasil: [s.n.].

[109] BRANDIMARTE, P.; VILLA, A. Advanced Models for Manufacturing

Systems Management. First ed. Boca Raton, FL: CRC Press, Inc., 1995.

[110] NEGAHBAN, A.; SMITH, J. S. Simulation for manufacturing system design and operation: Literature review and analysis. Journal of Manufacturing Systems, v. 33, n. 2, p. 241-261, 2014.

[111] CHASE, R. B.; JACOBS, F. R.; AQUILANO, N. J. Administração da

Produção para a Vantagem Competitiva. 10. ed. ed. São Paulo, SP, Brasil:

Artmed Editora S.A., 2006.

[112] LUSTOSA, L. J. et al. Planejamento e Controle da Produção. 1st. ed. São Paulo, SP, Brasil: Elsevier Editora Ltda., 2008.

[113] PINEDO, M. L. Planning and Scheduling in Manufacture and Services. 1. ed. New York, NY: Springer, 2005.

[114] PATERSON, C. et al. Inventory models with lateral transshipments: A review. European Journal of Operational Research, v. 210, n. 2, p. 125-136, 
2011.

[115] AZIZ, R. F. RPERT: Repetitive-projects evaluation and review technique.

Alexandria Engineering Journal, v. 53, n. 1, p. 81-93, 2014.

[116] GASS, S. I.; ASSAD, A. A. AN ANNOTATED TIMELINE OF OPERATIONS

RESEARCH, 2005. Disponível em: <http://ebooks.kluweronline.com>

[117] KUNSCH, P. L.; TEGHEM JR., J. Nuclear fuel cycle optimization using multiobjective stochastic linear programming. European Journal of Operational Research, v. 31, p. 240-249, 1987.

[118] SHRADER, C. R. History of Operations Research in the United States Army. 1. ed. ed. Washington, DC, USA: US Army, 2009. v. III 1973-1 [119] TATTERSON, J. PERT, CPM and the export process. Omega, v. 2, n. 3, p. 421-426, 1974.

[120] WINSTON, W. L.; GOLDBERG, J. B. Operations Research: Applications and Algorithms. Fourth ed. Belmont, CA: Cengage Learning, 2004.

[121] NEGRO, M. L. M. et al. Studies on Production Planning of Dispersion Type U3Si2-Al Fuel in Plate-Type Fuel Elements for Nuclear Research Reactors. World Journal of Nuclear Science and Technology, v. 6, n. 4, p. 217-231, 2016. [122] MIDWEST STEEL AND ALUMINUM. Aluminum pricesNew Hope, Minnesota, 2016. Disponível em:

<https://www.midweststeelsupply.com/store/6061aluminumplate>. Acesso em: 17 abr. 2016

[123] MARTINS, J. A. P.; ELIAS, M. A. DE. Fabricação a Partir Da Colagem De Pastilhas De Aço Sinterizado Com Tecido De Aramida. 2012.

[124] MELOROSE, J.; PERROY, R.; CAREAS, S. IMPLEMENTATION OF THE GLOBAL EFFICIENCY EQUIPMENT IN THE MACHINING SECTOR. Statewide Agricultural Land Use Baseline 2015, v. 1, p. 163-172, 2015.

[125] SOARES, F.; COSTA, D. A. GANHOS DE PRODUTIVIDADE E SISTEMAS TOOLSETTER LASER. 2014.

[126] EIA. 2012 Uranium Marketing Annual Report. n. May, p. 1-40, 2013.

[127] STATISTA GMBH. US silicon price by typeHamburg, Germany, 2016.

Disponível em: <http://www.statista.com/statistics/301564/us-silicon-price-bytype/>

[128] INFOMINE INC. Metal prices - magnesiumVancouver, BC CANADA, 2016. 
Disponível em: <http://www.infomine.com/investment/metal-prices/magnesium/> [129] UNIVERSITY OF ILLINOIS AT URBANA-CHAMPAIGN. So-Called 'Cheap' Liquid NitrogenUrbana, IL, 2007. Disponível em:

<https://van.physics.illinois.edu/qa/listing.php?id=1685>

[130] ICIS - RELX GROUP. Chemical profile - nitric acidLondon, UK, 2016.

Disponível em:

$<$ http://www.icis.com/resources/news/2008/05/19/9124327/chemical-profile-nitric$\mathrm{acid} />$

[131] SYNTH. Reagentes analiticos/cloreto de estanhoDiadema, SP, Brazil, 2016. Disponível em: <http://www.lojasynth.com/reagentes-analiticosmateriasprimas/reagentes-analiticosmaterias-primas/cloreto-de-estanho-oso-2h2o-p-a-a-cS>

[132] AES ELETROPAULO. Tarifas energia elétrica - setor públicoSão Paulo, SP, Brasil, 2016. Disponível em: <https://www.aeseletropaulo.com.br/poderpublico/prazos-e-tarifas/conteudo/tarifa-de-energia-eletrica> [133] SILVA, M. C. R. DA; MARIA VILANI MAIA DE FREITAS. Tabela de Remuneração dos Servidores Públicos Federais Civis e dos ExTerritóriosTécnico da Carreira de Desenvolvimento Tecnológico. [s.l: s.n.].

Disponível em: <http://www.planejamento.gov.br/assuntos/gestaopublica/arquivos-e-publicacoes/tabela-de-remuneracao-1>. [134] BANCO CENTRAL DO BRASIL. Conversão de moedasBrasília, DF, Brazil, 2016. Disponível em:

$<$ http://www4.bcb.gov.br/pec/conversao/conversao.asp?id=convmoeda> [135] MANZANO, M. P. F. CUSTO DE DEMISSÃO E PROTEÇÃO DO EMPREGO NO BRASIL. In: Crise e trabalho no Brasil: modernidade ou volta ao passado. [s.l: s.n.]. p. 253-268.

[136] ROCHA, W. CUSTO DE MÃO-DE-OBRA E ENCARGOS SOCIAIS.

Caderno de Estudos n06, São Paulo, FIPECAFI, n. Outubro/1992, p. 1-26, 1992.

[137] ALMANSA, C.; MARTINEZ-PAZ, J. M. What weight should be assigned to future environmental impacts? A probabilistic cost benefit analysis using recent advances on discounting. Science of the Total Environment, v. 409, n. 7, p. 1305-1314, 2011. 